Award Number:

W81XWH-10-1-0925

TITLE :

Neural and Behavioral Correlates of PTSD and Alcohol Use.

PRINCIPAL INVESTIGATOR:

Gina Forster, Ph.D.

CONTRACTING ORGANIZATION:

The University of South Dakota

Vermillion, SD, 57069

REPORT DATE :

December 2014

TYPE OF REPORT:

Final

PREPARED FOR: U.S. Army Medical Research and Materiel Command Fort Detrick, Maryland 21702-5012

DISTRIBUTION STATEMENT:

$\mathbf{x}$ Approved for public release; distribution unlimited

The views, opinions and/or findings contained in this report are those of the author(s) and should not be construed as an official Department of the Army position, policy or decision unless so designated by other documentation. 


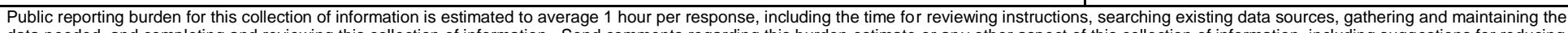

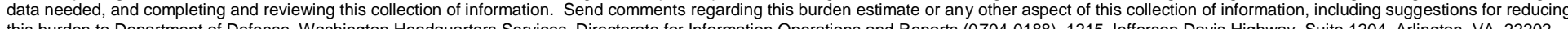

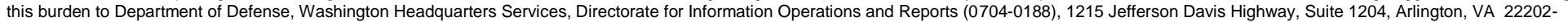

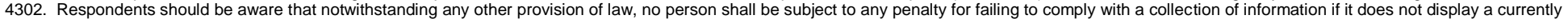
valid OMB control number. PLEASE DO NOT RETURN YOUR FORM TO THE ABOVE ADDRESS.

\begin{tabular}{l|l|l}
\hline 1. REPORT DATE (DD-MM-YYYY) & 2. REPORT TYPE & 3. DATES COVERED (FrOm - To)
\end{tabular}

December $2014 \quad$ Final

\section{TITLE AND SUBTITLE}

Neural and Behavioral Correlates of PTSD and Alcohol Use.

24 Sep $2010-23$ Sep 2014

5b. GRANT NUMBER

W81XWH-10-1-0925

5c. PROGRAM ELEMENT NUMBER

6. AUTHOR(S)

Gina Forster, Ph.D

email: gforster@usd.edu

7. PERFORMING ORGANIZATION NAME(S) AND ADDRESS(ES)

The University of South Dakota

5d. PROJECT NUMBER

5e. TASK NUMBER

5f. WORK UNIT NUMBER

8. PERFORMING ORGANIZATION REPORT NUMBER

Vermilion, SD, 57069-2037

9. SPONSORING / MONITORING AGENCY NAME(S) AND ADDRESS(ES)

10. SPONSOR/MONITOR'S ACRONYM(S)

U.S. Army Medical Research and

Materiel Command

Fort Detrick. Maryland

21702-5012

11. SPONSOR/MONITOR'S REPORT NUMBER(S)

12. DISTRIBUTION / AVAILABILITY STATEMENT

Approved for public release; distribution unlimited

\section{SUPPLEMENTARY NOTES}

\section{ABSTRACT}

Hazardous use of alcohol negatively impacts the treatment of PTSD. However, the mechanisms that underlie the association between PTSD and hazardous alcohol use in veterans are poorly understood. The current research takes a multi-level approach to study the psychological, behavioral, cognitive and neural relationships between PTSD and alcohol use in OEF/OIF veterans. Participants with PTSD showed greater difficulty in suppressing emotional content in favor of a cognitive output when presented with combat-associated stimuli, an effect mediated by the anterior cingulate cortex. PTSD was associated with heightened anterior cingulate activity during an emotional interference task, and comorbidity of PTSD with hazardous alcohol use resulted in more expansive recruitment of frontal regions involved in executive function when required to suppress emotional information. The findings from detailed analysis of contributing influences suggest that targeting the factors underlying the relationship between PTSD and hazardous alcohol use (affect liability, behavioral disinhibition, anterior cingulate activity) or recognizing factors that mediate effects on emotional expression and suppression and underlying brain regions (predeployment drinking, combat exposure intensity) may represent important treatment strategies for PTSD and hazardous alcohol use in recently returned combat veterans.

\section{SUBJECT TERMS}

Posttraumatic stress disorder; Alcohol; Neurobiology of anxiety disorders; Limbic System; Emotional Regulation.

\begin{tabular}{|l|l|l|l|l|l|}
\hline \multicolumn{2}{|l|}{ 16. SECURITY CLASSIFICATION OF: } & $\begin{array}{l}\text { 17. LIMITATION } \\
\text { OF ABSTRACT }\end{array}$ & $\begin{array}{l}\text { 18. NUMBER } \\
\text { OF PAGES }\end{array}$ & $\begin{array}{l}\text { 19a. NAME OF RESPONSIBLE PERSON } \\
\text { USAMRMC }\end{array}$ \\
\cline { 1 - 2 } $\begin{array}{l}\text { a. REPORT } \\
U\end{array}$ & $\begin{array}{l}\text { b. ABSTRACT } \\
\text { U }\end{array}$ & $\begin{array}{l}\text { c. THIS PAGE } \\
\text { U }\end{array}$ & & 68 & $\begin{array}{l}\text { 19b. TELEPHONE NUMBER (include area } \\
\text { code) }\end{array}$ \\
& & \\
\end{tabular}




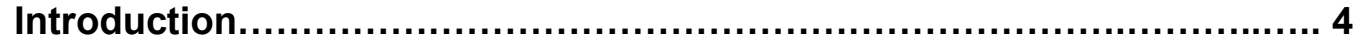

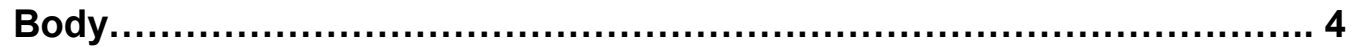

Key Research Accomplishments........................................23

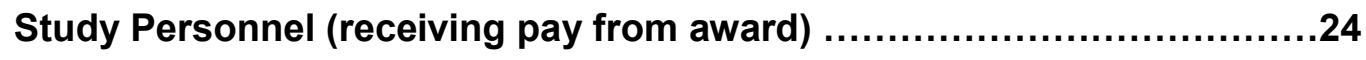

Reportable Outcomes.....................................................

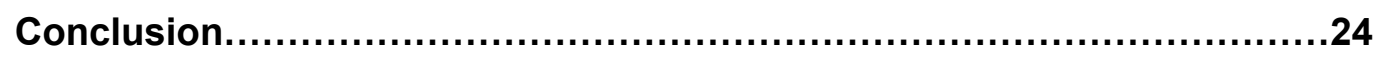

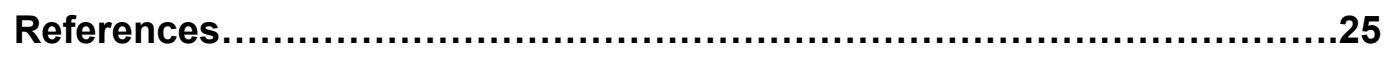

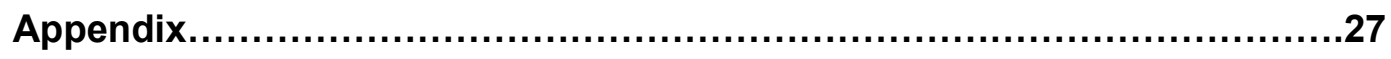




\section{Introduction:}

Posttraumatic stress disorder (PTSD) is a signature impairment of US soldiers arising from Operation Iraqi Freedom (OIF) and Operation Enduring Freedom (OEF) (Kennedy et al., 2007; Gaylord et al., 2008; Hoge et al., 2008). Furthermore, 25-35\% of returning OEF/OIF veterans report some alcohol misuse (i.e., using more than intended) (Hoge et al., 2004), and approximately 15\% of veterans screen positive for both PTSD and hazardous drinking (Jacobson et al., 2008; McDevitt-Murphy et al., 2010). The association between PTSD and alcohol use has clear therapeutic implications given that impairment associated with PTSD may be compounded by alcohol use (Dao-Castellana et al., 1998; Gilman and Homer, 2008). Furthermore, patients with PTSD and comorbid substance use disorder are least likely to benefit from treatment and more likely to relapse when compared to patients who have substance use disorder alone (Ouimette, et al., 2007; Schafer and Najavits, 2007). Therefore, it is important to study the behavioral and neural relationships between PTSD and alcohol use.

\section{Objective 1) To test a model linking PTSD symptoms and alcohol-related problems in a population of recently} returned soldiers.

Associations between PTSD symptoms and alcohol use disorder likely represent complex reciprocal relationships. However, longitudinal and experimental research indicates that PTSD symptomatology increases risk for alcohol use disorders. This objective will focus on enhancing understanding of the potential mechanisms by which PTSD may increase risk for alcohol use disorder. Recently returned veterans will be assessed for PTSD symptoms and other mental health issues, alcohol use and dependence issues, and factors related to stress coping and behavioral disinhibition. Specifically, we will test a model linking PTSD symptoms and alcohol use disorder via behavioral disinhibition and affective lability. Behavioral disinhibition is posited to link PTSD symptoms and alcohol-related negative consequences (e.g., interpersonal aggression), whereas affect lability is posited to link PTSD and symptoms of alcohol dependence. Secondary analyses will examine whether hyperarousal and reexperiencing symptoms represent core symptoms underlying the link between PTSD and alcohol use disorder.

Objective 2) To test a neural circuitry model linking trauma, alcohol consumption, and PTSD symptoms. This objective will focus on enhancing understanding of potential neural mechanisms by which traumatic experience and excessive alcohol use may contribute to PTSD symptoms in recently returned veterans. We will test a model linking trauma and alcohol consumption with PTSD symptoms via altered functioning in the anterior cingulate cortex and amygdala. The non-recursive model will incorporate bi-directional effects linking alcohol consumption, neural functioning, and PTSD symptoms. This will be achieved by conducting an fMRI study to examine activity of the amygdala during a masked emotional faces paradigm and to examine the activity of anterior cingulate cortex during the emotional counting Stroop task. The central hypothesis of this objective predicts that trauma and heavy alcohol use negatively impact the activity of and balance between ACC and amygdala function, thus increasing dysfunction associated with PTSD.

A further purpose of this funding was to enhance the capacity of USD to perform fMRI research at USD's health care partner, Avera Sacred Heart Hospital. Therefore, the technical objectives of this project are:

1) To substantially increase the ability of The University of South Dakota and its health care partners to research the neural bases of psychological health impairment, diagnosis and treatment by initiating fMRI research.

2) To conduct a short-term initial feasibility study to bring together the components of recruitment, screening, imaging, testing, and data analysis; all critical for subsequent fMRI longitudinal studies.

\section{Body:}

Objectives and Milestones:

The scientific objectives for this research project were:

1) To test a model linking PTSD symptoms and alcohol-related problems in a population of recently returned soldiers. 
2) To test a neural circuitry model linking trauma, alcohol consumption, and PTSD symptoms.

This project received a one-year no-cost extension (Sept $24^{\text {th }} 2012-$ Sept $23^{\text {rd }} 2013$ ), and during this no-cost extension year, a further no-cost extension (until Sept 23 ${ }^{\text {rd }}$ 2014) was requested in April 2013 and granted in October 2013. The reason for the further no-cost extension were given in detail in previous reports, but briefly, involved problems with recruitment and with tasks employed to activate the amygdala in the imaging component of the study. Having overcome these issues, we were able to complete the project by September 2014.

\section{Table 1: Modifications to the Project Timeline}

\begin{tabular}{|c|c|c|c|}
\hline Tasks/Milestones & Start Date & $\begin{array}{l}\text { Duration } \\
\text { (days) }\end{array}$ & End Date \\
\hline \multicolumn{4}{|c|}{ Objective 1: Testing a model linking PTSD symptoms and alcohol-use. } \\
\hline Task 1: Obtain IRB approval. & $9 / 24 / 2010$ & 447 & $12 / 15 / 2011$ \\
\hline Task 2: Hiring of personnel. & $10 / 1 / 2010$ & 304 & $8 / 1 / 2011$ \\
\hline Task 3: Advertising \& recruitment. & $12 / 15 / 2011$ & 803 & $2 / 28 / 2014$ \\
\hline Task 4: Interview participants. & $1 / 1 / 2012$ & 790 & $3 / 1 / 2014$ \\
\hline Task 5: Analysis/statistical modeling of assessment data. & $4 / 30 / 2012$ & 791 & $6 / 30 / 2014$ \\
\hline Task 6: Manuscript/s for assessment data prepared for publication. & $5 / 30 / 2014$ & 116 & $9 / 23 / 2014$ \\
\hline \multicolumn{4}{|c|}{ Objective 2: Testing a neurocircuitry model linking trauma, alcohol consumption and PTSD symptoms. } \\
\hline Task 7: Purchase, set-up \& test infrastructure for fMRI study. & $9 / 24 / 2010$ & 495 & $2 / 1 / 2012$ \\
\hline Task 8: Conduct fMRI study. & $2 / 1 / 2012$ & 805 & $4 / 15 / 2014$ \\
\hline Task 9: Analysis of images. & $4 / 30 / 2012$ & 791 & $6 / 30 / 2014$ \\
\hline Task 10: Statistical analysis/modeling of fMRI \& behavioral data. & $7 / 1 / 2014$ & 45 & $8 / 15 / 2014$ \\
\hline Task 11: Manuscript/s for fMRI study prepared for publication. & $5 / 30 / 2014$ & 116 & $9 / 23 / 2014$ \\
\hline
\end{tabular}

The major objectives of the project are listed in Table 1, and a description of the outcomes of each objective is given below.

\section{Objective 1 Task 1 - Obtain IRB approval from the University of South Dakota and approval from the DoD} HRPO to perform the research.

Early in Year 1 (September 2010), an IRB form detailing both phases of the study (Objectives 1 and 2) was completed, and supporting documents generated. The supporting documents included informed consent forms, the paper and online psychological assessment that subjects will complete, MRI screening forms and protocols (generated in collaboration with Avera Sacred Heart Hospital), and recruitment materials including letters, telephone scripts, newspaper advertisements and fliers. These materials were sent to Ms. Ciccarello (Regulatory Compliance Specialist, TATRC) for review, and revisions were made based on her advice. Following this, the IRB form and supporting documents were submitted to the University of South Dakota (USD) IRB for review. We received the review of our protocol by the USD IRB (in late January 2011), made the required revisions and resubmitted the revised protocol for approval in February of 2011. Our protocol was then classed as 'greater than minimal risk' and further requirements needed to be met. Therefore, significant revisions were made to the protocol and supporting documents, and two Medical Monitor was assigned to the project: Dr. Gregory Taylor (Radiologist, Medical Director of the Avera Sacred Heart Hospital Radiology Dept) and Dr. Tim Soundry (Psychiatrist, Avera) both agreed to serve as Medical Monitors and provided input to improve the protocol. The revised protocol and supporting documents were resubmitted to the USD IRB in May 2011, and the PI and co-investigators were in attendance at the IRB meeting in June to answer questions. Following minor revisions made to the supporting documents, the protocol was approved by the USD IRB in June. The PI forwarded the protocols and supporting documents to Ms. Ciccarello (Regulatory Compliance Specialist, TATRC) who then then put a package together for the DoD Human Research Protection Office (HRPO) for review. Upon minor modifications to consent forms and recruitment materials, the protocol was approved in December 2011. 
Objective 1 Task 2 - Hiring of Personnel.

After extensive advertising and searching for the needed personnel during the first half of Year 1, interviews were conducted to hire study personnel. Two study personnel were hired with a start date of August $1^{\text {st }} 2011$. One individual had a Master's degree in Clinical Psychology and 2 years of experience in psychological assessment and working with veterans with PTSD and alcohol problems. She is responsible for the assessment of subjects, screening for PTSD symptoms and alcohol use (Objective 1). The second individual has a Bachelor's of Science degree and 9 years of experience in neuroscience research. She was responsible for recruitment and the imaging components of the study (Objective 2).

\section{Objective 1 Task 3 -Advertising and Recruitment.}

We unfortunately were not able to recruit thorough out local VA medical clinic or have clinicians pass on information about the study to their patients as originally planned. This was because our study could not be approved by the VA IRB since it was not conducted at a VA facility (our scanning has to be conducted on our research scanner, located at Avera Sacred Heart Hospital). We had spent quite some time trying to find ways around this problem, with little success. The delay in recruitment due to attempts to work around the VA policy as outlined above, is one reason for no-cost extension requests. During the second to fourth year of the award, advertisement efforts were directed towards Iraq/Afghanistan veterans via the USD veterans association, email listservs, public notices, fliers in clinics, South Dakota National Guard, contacting veterans from previous studies, and newspaper advertisements in daily and weekly newspapers within the southeast corner of South Dakota and adjacent Nebraska towns. Once it became apparent that we would need to find other sources of recruitment, we also engaged local University and community groups. For example, we contacted researchers at South Dakota State University (2 hours north of our campus in Vermillion) who were working with veterans, and they were happy to advertise our study among their veteran populations. This was successful in increasing our enrollment rate. Local radio stations also posted (on air and on websites) announcements about the study recruitment efforts, which was effective in increasing enrollment rates. These efforts resulted in an overall increase in enrollment by $54 \%$ from year 2 to 3 of the study.

By the conclusion of the study, we recruited 165 veterans who met the selection criteria for phase I of the study (psychological and alcohol use assessment). Of these, 102 participants met the MRI screening criteria and agreed to participate in phase II of the study involving fMRI and emotional suppression tasks (Table 3). Thus, $62 \%$ of phase I subjects participated in phase II, which is better than the $25 \%$ we originally anticipated. We met the recruitment goal of 25-30 participants in each group (Table 3) with the exception of the hazardous alcohol use without PTSD group. Despite our best efforts and an extension in recruitment timeline, we were not able to recruit any more than 12 participants for this group. This may be reflective of few individuals meeting this criteria in the sample population, or those that would met this criteria being less motivated to volunteer for the study.

\section{Objective 1 Task 4: Interview Participants:}

The psychological interview represents phase I of the study. Participants were invited to an interview session with the one of the Clinical Psychology investigators in the location of the participant's choice (Sioux Falls, Yankton or Vermillion). The participants filled in on-line validated assessment tools probing combat exposure, social support, PTSD symptoms, other mental health and health symptoms, alcohol use and misuse, stress coping and personality traits. They then underwent a clinical interview to confirm mental health status and cognitive status. Finally, screening for MRI contraindications was performed to assist in determining eligibility for phase II of the study. Each interview session was 2-3 hours in length. One hundred and sixty five participants were interviewed for phase I in total.

\section{Objective 1 Task 5: Analysis/Statistical Modeling of Assessment Data:}

Individual subject information was analyzed on a weekly basis as it relates to MRI compatibility, PTSD symptoms and alcohol use, and is made available by a confidential online process (PsychData) to the Neuroscience investigators of this project, so that they could quickly determine whether the participant could be 
invited to participate in phase II of this study (Objective 2 Task 8). Participants that did not have contraindications to MRI and that fell into one of the following groups qualified for phase II of the study: 1) low/no alcohol use and low/no PTSD symptoms; 2) low/no alcohol use and PTSD symptoms; 3) high alcohol use and low/no PTSD symptoms; 4) high alcohol use and high PTSD symptoms (Table 2). Table 3 shows the number of participants in each group.

\section{Table 2: Criteria Used for Allocating Participants to PTSD and Alcohol Use Groups}

\begin{tabular}{|c|c|c|}
\hline & \multicolumn{2}{|c|}{ Low-Moderate Alcohol Use } \\
\hline No PTSD & \multicolumn{2}{|c|}{$\begin{array}{l}<\text { score of } 29 \text { on PCL } \\
<7 / 14 \text { drinks/week (women/men) } \\
<\text { score of } 8 \text { on AUDIT }\end{array}$} \\
\hline PTSD & \multicolumn{2}{|c|}{$\begin{array}{l}\geq \text { score of } 29 \text { on PCL } \\
<7 / 14 \text { drinks/week (women/men) } \\
<\text { score of } 8 \text { on AUDIT }\end{array}$} \\
\hline \multirow{2}{*}{\multicolumn{3}{|c|}{$\begin{array}{l}P C L=P T S D \text { checklist, is used clinically to diagnose PTSD, wi } \\
\text { The number of drinks (shown for both men and women) is base } \\
\text { guidelines for problem drinking within a week, over the last } 30 \\
\text { AUDIT = Alcohol Use Disorders Identification Test, a score of } \\
\text { to problems associated with alcohol use in the last year). } \\
\text { Table 3: Number of Participants in Each Group for }\end{array}$}} \\
\hline & & \\
\hline & $\begin{array}{l}\text { Low-Moderate } \\
\text { Alcohol Use }\end{array}$ & $\begin{array}{l}\text { Hazardous } \\
\text { Alcohol Use }\end{array}$ \\
\hline No PTSD & 27 & 12 \\
\hline PTSD & 30 & 33 \\
\hline
\end{tabular}

Phase II total $=102$ participants.

Analysis of some of the data collected in Phase 1 was conducted to determine the demographic profile and the PTSD, alcohol, depression and combat exposure scores of the participants tested. This data is summarized by Table 4. As expected, PCL scores of PTSD symptoms were higher in the PTSD groups vs. nonPTSD groups, AUDIT scores of alcohol use and dependence were higher in the Hazardous Alcohol Use groups, and number of drinks per week over the last 30 days were also significantly higher in the Hazardous Alcohol Use groups (Table 4). However, depression scores and combat exposure were also significantly higher in the PTSD groups (Table 4), suggesting that these may be important mediators of the effects of PTSD on the study outcomes. .

Table 4: Participant Demographics.

\begin{tabular}{lllll}
\hline & $\begin{array}{l}\text { No PTSD \& } \\
\text { Non-Hazardous } \\
\text { Alcohol Use }\end{array}$ & $\begin{array}{l}\text { PTSD \& Non- } \\
\text { Hazardous } \\
\text { Alcohol Use }\end{array}$ & $\begin{array}{l}\text { No PTSD \& } \\
\text { Hazardous } \\
\text { Alcohol Use }\end{array}$ & $\begin{array}{l}\text { PTSD \& } \\
\text { Hazardous } \\
\text { Alcohol Use }\end{array}$ \\
\hline $\begin{array}{l}\text { Demographics } \\
\text { Age }\end{array}$ & $32.71 \pm 1.52$ & $30.45 \pm 1.44$ & $31 \pm 1.70$ & $30.89 \pm 1.34$ \\
$\begin{array}{l}\text { Gender } \\
\text { Male }\end{array}$ & $23(92 \%)$ & $17(77 \%)$ & $10(100 \%)$ & $27(96 \%)$ \\
$\quad$ Female & $2(8 \%)$ & $5(23 \%)$ & 0 & $1(4 \%)$
\end{tabular}


Race

White

Native American

$19(76 \%)$
$1(4 \%)$
$3(12 \%)$
$2(8 \%)$
0

$21(95 \%)$

Hispanic

African American

Asian

$14.92 \pm 0.55$

0

0

$1(5 \%)$

$\begin{array}{ll}10(100 \%) & 25(89 \%) \\ 0 & 2(7 \%) \\ 0 & 0 \\ 0 & 1(3.5 \%) \\ 0 & 0\end{array}$

Years Education

$13.95 \pm 0.69$

$15.80 \pm 0.61$

$13.67 \pm 0.69$

\section{Military Characteristics}

Service

$\begin{array}{lllll}\text { Army } & 15(60 \%) & 17(77 \%) & 6(60 \%) & 23(82 \%) \\ \text { Navy } & 0 & 3(14 \%) & 0 & 0 \\ \text { Airforce } & 7(28 \%) & 2(9 \%) & 4(40 \%) & 3(11 \%) \\ \text { Marines } & 3(12 \%) & 0 & 0 & 2(7 \%) \\ \text { Coast Guard } & 0 & 0 & 0 & 0\end{array}$

Deployments

$2.76 \pm 0.73$

$1.55 \pm 0.15$

$1.50 \pm 0.22$

$1.64 \pm 0.22$

Mths. since last

$51.65 \pm 6.15$

$64.40 \pm 4.28$

$52.11 \pm 9.00$

$58.89 \pm 4.57$

deployment

Combat exposure

$4.04 \pm 0.71$

$6.00 \pm 0.61 *$

$3.70 \pm 1.02$

$6.82 \pm 0.66^{*}$

\section{Psychological and Alcohol Use Assessment}

PCL

AUDIT score

No. of drinks/week

No. of heavy drinking days/week

Depression score

$$
23.96+0.69
$$

$$
4.38 \pm 0.40
$$

$5.16 \pm 0.93$

$0.16 \pm 0.09$

$24.68 \pm 0.73$
$46.09 \pm 2.86^{*}$

$$
5.00 \pm 0.46
$$

$4.59 \pm 0.96$

$0.28 \pm 0.12$

$36.64 \pm 2.33^{*}$
$23.80 \pm 1.13$

$14.50 \pm 1.31^{\#}$

$20.20 \pm 3.75^{\#}$

$1.50 \pm 0.37^{\#}$

$27.20 \pm 2.15$
$49.82+2.39 *$

$14.96 \pm 1.35^{\#}$

$19.21 \pm 2.77^{\#}$

$1.56 \pm 0.31^{\#}$

$35.96 \pm 2.04 *$

$* p<0.05$ PTSD vs no PTSD groups

$\# p<0.05$ Hazardous Alcohol Use vs. Non Hazardous Alcohol Use groups

$P C L$ : PTSD Checklist (possible range $=17-84$ ); Depression scores provided by the $C E D-D E P$ : Center for Epidemiological Studies Depression Scale (possible range $=20-80$ ); AUDIT: Alcohol Use Disorder Inventory Test (possible range $=0-40$ ); Drinks per week and heavy drinking days provided by the $D D Q 30$ : Daily Drinking Questionnaire, last 30 days (weekly totals provided); Combat exposure provided by the DRRI-CE Deployment Risk and Resilience Inventory - Combat Experiences Scale (possible range $=0-15$ ).

Finally, the assessment data collected from Phase I was used to test a model linking PTSD symptoms and alcohol-related problems in OEF/OIF veterans, and this analysis was completed in the final weeks of the project period. We tested a path model in Mplus 7.1 with the maximum likelihood robust estimator (see Figure 1). The initial model included two correlated outcomes; alcohol dependence symptoms (from the Alcohol Dependence Scale) and negative consequences (the Impulse Control subscale of the Drinkers Inventory of Consequences). This model did not fit optimally, $\chi 2(5, \mathrm{~N}=165)=29.30, \mathrm{p}<.001 . \mathrm{CFI}=.94$, RMSEA $=.172$, $90 \% \mathrm{CI}(.115-.234), \mathrm{SRMR}=.078$. Inspection of the modification indices suggested adding a path from alcohol dependence symptoms to negative consequences. This change resulted in a good fitting model, $\chi 2(5, \mathrm{~N}$ $=165)=16.74, \mathrm{p}=.005 . \mathrm{CFI}=.97, \mathrm{RMSEA}=.119,90 \% \mathrm{CI}(.059-.185), \mathrm{SRMR}=.042$. Significance of the indirect effects was calculated by bias-corrected boot strapped confidence intervals. Consistent with hypotheses, PTSD symptoms (i.e., PCL scores) were indirectly associated with alcohol dependence via affect lability $(\beta=0.29,95 \% \mathrm{CI}(0.18-0.40))$ and with negative consequences via behavioral disinhibition $(\beta=0.09$, $95 \% \mathrm{CI}(0.02-0.17))$. In addition, lability also mediated the effect of PTSD symptoms on negative consequences via alcohol dependence $(\beta=0.16,95 \% \mathrm{CI}(0.07-0.25))$ and behavioral disinhibition mediated the effect of PTSD symptoms on alcohol dependence via alcohol consumption $(\beta=0.05,95 \% \mathrm{CI}(0.001-0.09))$. 


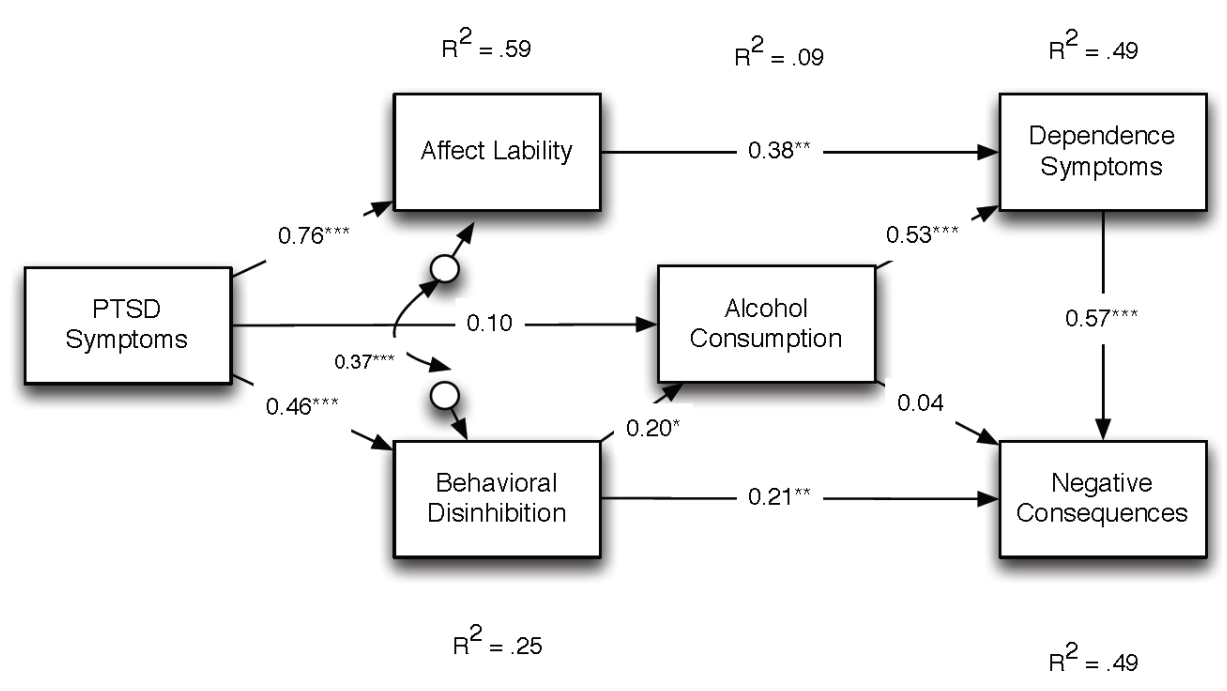

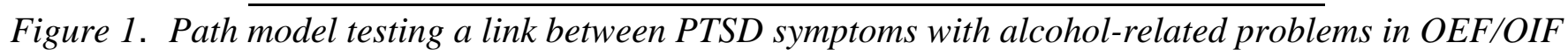
veterans $(N=165)$. All coefficients are standardized. Gender is included as a covariate with paths to all endogenous variables but is omitted for clarity.

Objective 1 Task 6: Manuscript/s for assessment data prepared for publication:

A manuscript describing and discussing the model linking PTSD symptoms with alcohol use in OEF/OIF veterans is in the very early stages of preparation. This data was made available at the end of the award period (later than originally anticipated due to extended recruitment timeline as described above) and the investigators are highly motivated to publish the work in a prompt fashion.

\section{Objective 2 Task 7: Infrastructure for fMRI:}

The 1.5 T MRI unit at Avera Sacred Heart Hospital was replaced with a $3 \mathrm{~T}$ scanner, and outfitted for research (e.g. presenting stimuli, recording subject responses) during the second half of Year 1. The new scanner (Siemens 3T Open Bore Magnetom Skyra) and the Esys fMRI system (stimulus presentation-response system with E-Prime stimulus generation software) required optimization by the investigators, prior to being used to image veteran populations. The PI and study personnel received training on the use of the fMRI equipment and software in September and October 2011, and obtained IRB approval to conduct test experiments with student subjects. During December 2011-Feberurary 2012, the PI and co-investigator Dr. Vince Magnotta (Director of MR Research Facility at the University of Iowa) conducted studies with test subjects recruited from USD student groups. We optimized the parameters for basic visual and motor tasks, and for the emotional tasks that were to be used in the scanner with the veteran populations. One problem did arise with the equipment when presenting the emotional tasks which involved the rate at which stimuli needed to be presented was not being supported by the Esys stimulus system. This was solved by the investigators and Esys technical staff with modifications to the stimulus design and mode of presentation. Also, a DICOM server with XNAT interface was set up between Avera Sacred Heart Hospital and USD, with password protected access being given to Dr. Magnotta so that he could download and process images in his laboratory at the University of Iowa. This system was tested with the data collected from the student participants in the fMRI optimization studies, and was a very successful means by which to transfer images to Dr. Magnotta at the University of Iowa. The fMRI infrastructure for this study was fully functional by March 2012, allowing the fMRI phase of the study with veteran subjects to begin at that time.

Objective 2 Task 8: Conduct fMRI Study:

Following psychological assessment as outlined in Objective 1 Task 4 above, qualifying veteran participants were invited to Avera Sacred Heart Hospital in Yankton for the fMRI component of the study. Participants 
were re-screened for MRI compatibility, tested for blood-alcohol levels, and then within the scanner, passively viewed masked emotional faces (to activate the amygdala) and performed an emotional stroop counting task (to activate the prefrontal cortex; Figure 2). After the tasks in the scanner were complete, participants then filled out a self-assessment manikin to rate their arousal levels upon viewing the stimuli that comprised the two tasks in the scanner (examples shown in Figures 3 and 4). The entire phase II study was approximately 2 hours long, with participants in the scanner for 45 minutes to 1 hour. One hundred and two veteran participants were scanned in phase II (see Table 3 for number of participants in each group).
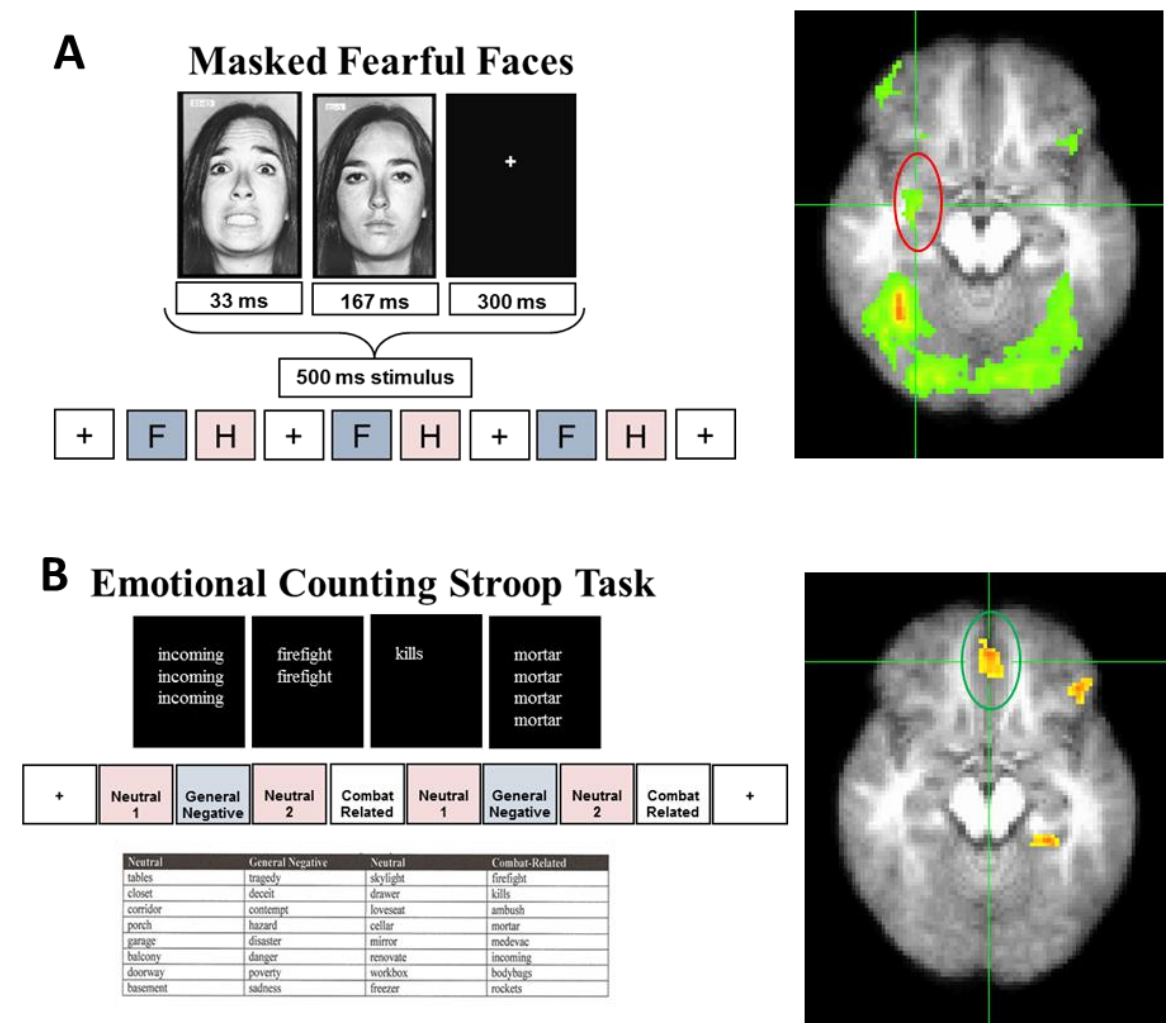

Figure 2: A) Masked Faces Paradigm: Used to elicit processing of fearful information in the brain. Each emotional face (happy or fearful) is backward masked by the neutral expression, as illustrated by the composite stimulus above (500 $\mathrm{ms}$ total). Stimuli are derived from the Ekman-Friesen stimulus set, and comprise 8 individuals (5 male, 3 female). Each fearful or happy block comprises 56 presentations of masked fearful or masked happy faces respectively. There are three blocks of each within the 10 block run. Two runs are conducted, with the presentation of fearful and happy blocks counterbalanced between runs. This task increases BOLD signal in the amygdala (circled in red) in control participants. B) Emotional Counting Stroop Task: Used to assess suppression of emotional information. Each word (in the table above) is presented 1-4 times on the screen as illustrated above, and the subjects are required to count the number of words and report

that number via button press. Words from neutral, negative and combat conditions are matched for length, number of syllables and frequency of use in American-English. Each word condition block comprises 20 word presentations (each 1450 msec duration with 50 msec between each), and each block is presented twice within the run. Two runs are conducted with the presentation of neutral, negative and combat blocks counterbalanced between runs. This task results in bilateral activation of the rostral anterior cingulate cortex (circled in green) in combat vs. negative word conditions.

Early in the third year of the study, we noticed that we failed to see BOLD increases of the amygdala in any group within the masked faces paradigm when fearful face condition was contrasted with happy face condition. This is in contrast to our previous preliminary analysis (see quarterly report 7, July 2012) and does not replicate the amygdala activation seen using this task in the past (e.g. Whalen et al., 1998; Rauch et al., 2000; Shin et al., 2005). A review of individual data suggested that the paradigm could activate amygdala 
activity in some but not all participants, irrespective of PTSD or alcohol status. Therefore, we decided to revisit the paradigm, and make changes to elicit more reliable activity.

The first issue we addressed was whether the faces used to make the paradigm did in fact elicit an emotional response in our participants. Following the tasks in the scanner, it is our standard procedure for participants to fill out a self-assessment manikin to rate their arousal levels upon viewing the images. As illustrated by Figure 3, participants provided higher arousal levels the fearful faces as compared to the happy faces. Therefore, we concluded that the stimuli used were sufficient for eliciting an emotional response.

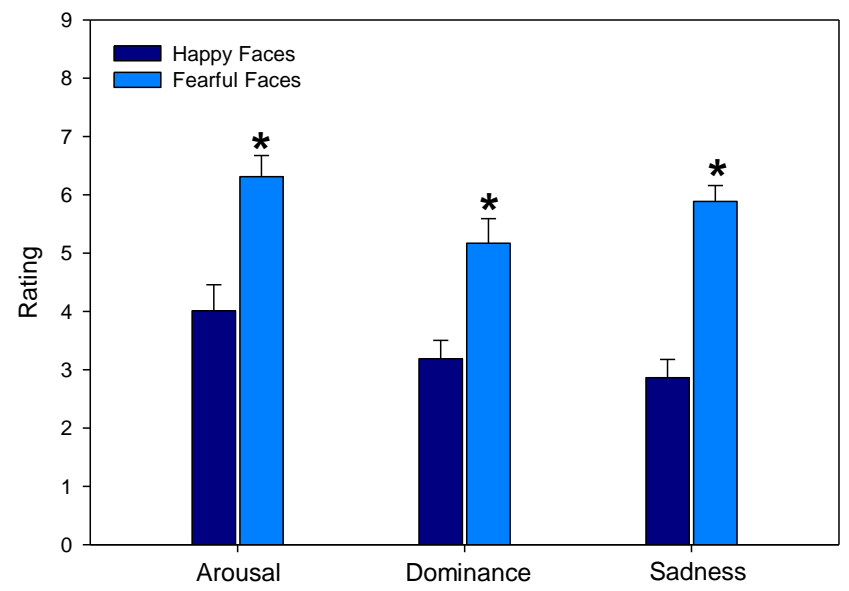

Figure 3: Ratings for stimuli used in the masked faces fMRI paradigm. Following the scan, participants were presented with the happy and fearful faces used in the masked faces paradigm for 3 sec each, and given 8 sec to rate their arousal level $(9=$ highly arousal, $1=$ very calm), how dominated the image made them feel $(9=$ highly dominated, $1=$ not dominated at all $)$, and their pleasure or sadness upon viewing the face $(9=\operatorname{sad}, 1=$ pleasure), using the self-assessment mannikin (SAM). Fearful faces were rated higher than happy faces on all three scales $(* P<0.001)$.
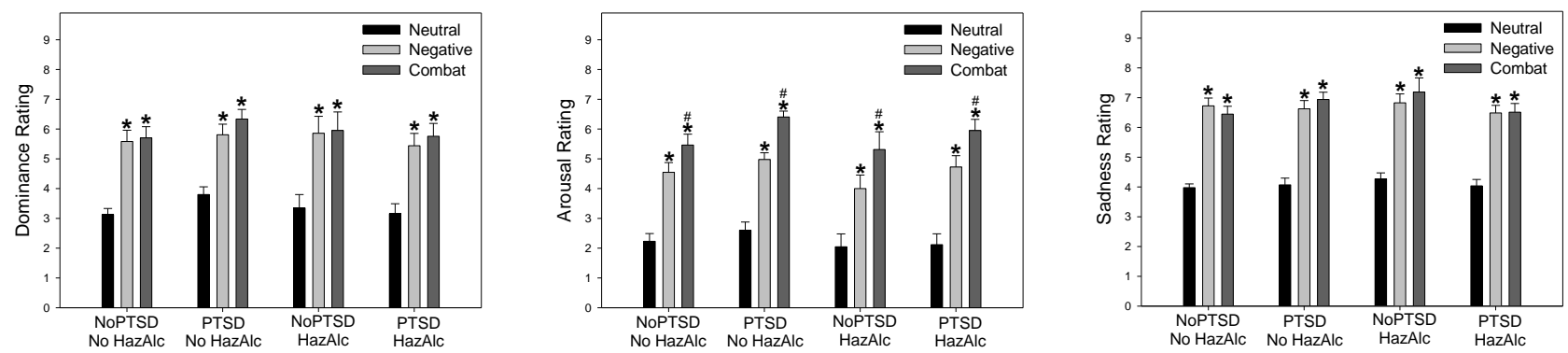

Figure 4: Ratings for stimuli used in the emotional counting stroop fMRI paradigm $(N=102)$. Following the scan, participants were presented with the neutral, negative and the combat-related words used in the emotional counting stroop paradigm for 3 sec each, and given 8 sec to rate their arousal level $(9=$ highly arousal, $1=$ very calm $)$, how dominated the image made them feel $(9=$ highly dominated, $1=$ not dominated at all), and their pleasure or sadness upon viewing the face ( $9=\operatorname{sad}, 1=$ pleasure), using the self-assessment mannikin (SAM). Combat and negative words were rated as more dominating than neutral words. Combat words were rated as more arousing than all other conditions, while negative words were rated as more arousing than neutral. Combat and negative words were rated as inducing more feelings of sadness than neutral words. ${ }^{*} P<0.05$ compared to neutral; ${ }^{\#} P<0.05$ compared to negative.

To further address the masked faces paradigm, we focused on the faces used to mask the emotional faces. A review of the literature revealed that some investigators use a different neutral face mask from the individual used to display the emotional face (see Figure 5). We conducted a study with 6 trial (non-veteran) participants, using separate runs with both types of masks (same or different face mask - compare Figure $2 \mathrm{~A}$ 
with Figure 5). The participants reported that a mask from the same individual made the face look more animated than when the mask was from a different individual, thus drawing their attention away from the center fixation to the eyes and mouth of the stimulus. Variation in the degree to which this distracted the participants may have caused the variation among participants in amygdala activity.

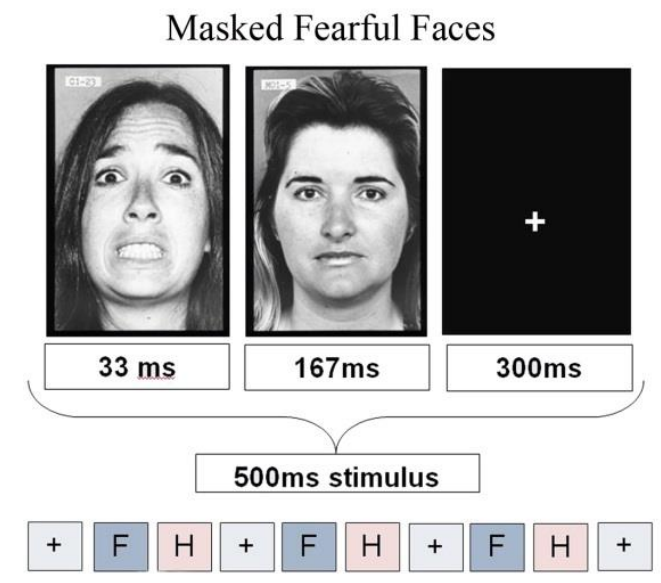

Figure 5: Modified masked faces paradigm: participants were presented with 56 masked happy or fearful faces per block with the mask from an individual other than that displaying the emotional face, or presented with a fixation block (+), based on Whalen et al., (1998).

To increase the reliability of our task in eliciting amygdala activity, we also addressed reducing the artifact inherent in imaging the amygdala at 3 Tesla using a gradient-echo (GE) EPI-sequence. Following suggestions made by Morawetz et al (2006), we reduced the TE to $27 \mathrm{~ms}$, reduced the slice thickness to $2.5 \mathrm{~mm}$ and increased the number slices to 38 . These still matched the TR of $2000 \mathrm{~ms}$, so that the paradigm did not need to be changed, and data collected from the modified masked paradigm prior to these changes in scanning parameters could be analyzed with the data collected with new scanning parameters. One problem with this sequence is that there is less coverage of the brain (approximately $13.3 \mathrm{~cm}$ from top to bottom), but the parameters would be optimal for the amygdala. As illustrated by Figure 6, there was very robust activation of the right amygdala using the new stimulus paradigm and scanning parameters, which was most apparent in the first block of the paradigm. We continued to use the modified paradigm and sequence for the remainder of the study. This change requires 12 more participants to be recruited and tested with the masked faces paradigm than originally planned, and this was achieved within the final year of the award.

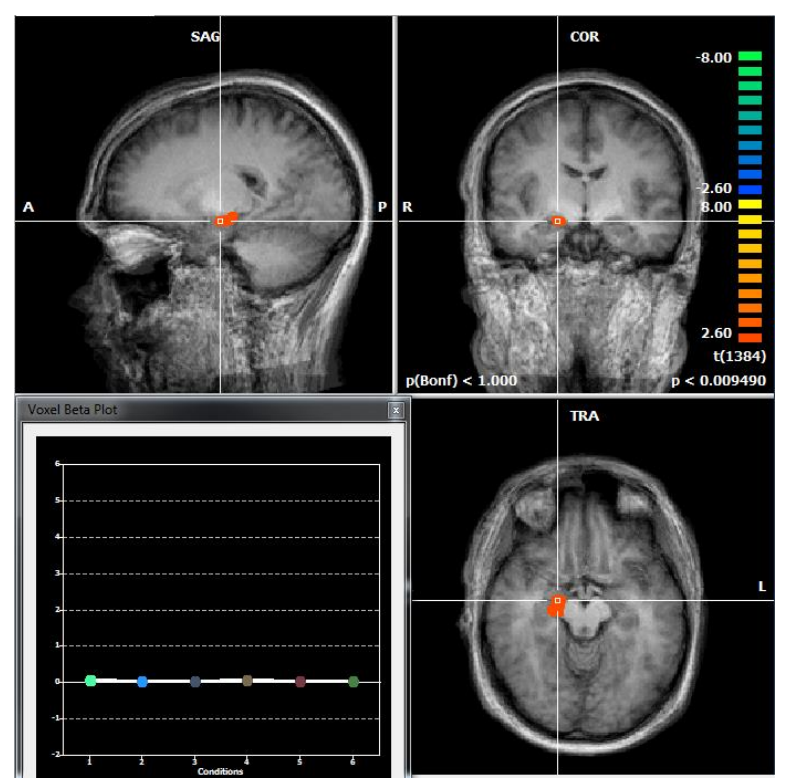

Figure 6: Right amygdala activation (fearful vs. happy faces contrast, block 1) in non-veteran student participants using the modified masked faces paradigm as illustrated by Figure 3, and new scanning parameters as described above. $(N=6)$ 
Objective 2 Task 9: Analysis of Images:

Analysis of fMRI behavioral and imaging data was completed in the last weeks of the award period. A groupwise analysis was initially performed on data obtained from the emotional counting stroop task. There was a significant effect of word condition $(\mathrm{F} 2,154=8.936 ; \mathrm{P}<0.01)$ and a significant interaction between group and word condition $(\mathrm{F} 6,154=2.254 ; \mathrm{P}=0.041)$ on reaction time (Figure 6). Within the PTSD group without hazardous alcohol use, there was no significant difference in reaction time between the neutral and negative condition ( $\mathrm{SNK}, \mathrm{P}=0.416$ ) but the combat word condition was significantly greater than both neutral (SNK, $\mathrm{P}$ $=0.003)$ and negative $(\mathrm{SNK}, \mathrm{P}<0.001)$ word conditions. Within the PTSD group with hazardous alcohol use, there was a significant difference in reaction time between the neutral and negative condition $(\mathrm{SNK}, \mathrm{P}=0.025)$ but the combat word condition was significantly greater than both neutral (SNK, P $<0.001$ ) and negative (SNK, $\mathrm{P}=0.048$ ) word conditions. Groups without PTSD showed no effect of word condition on reaction time (SNK, $\mathrm{P}>0.05)$

There were also group differences in reaction time for the emotional counting stroop task (Figure 6), with a significant effect of PTSD (F 1, 76 = 4.042; P = 0.048) but no significant effect of hazardous alcohol (F $1,76=1.797 ; \mathrm{P}=0.184)$ or significant interaction $(\mathrm{F} 1,76=3.222 ; \mathrm{P}=0.077)$ between $\mathrm{PTSD}$ and hazardous alcohol use on reaction time for combat words. PTSD groups had significantly slower reaction times to combat words than non-PTSD groups ( $\mathrm{SNK}, \mathrm{P}=0.048)$. For the negative condition of the emotional counting stroop task there was a significant interaction $(\mathrm{F} 1,78=4.299 ; \mathrm{P}=0.041)$ between PTSD and hazardous alcohol use on reaction time. Post hoc analysis did not reveal any pairwise differences between groups (SNK, P $>0.05)$. For the neutral condition there was no significant effect of PTSD (F 1, 78 =1.046; P $=0.309)$ or hazardous alcohol ( $\mathrm{F} 1,78=2.536 ; \mathrm{P}=0.115)$ nor a significant interaction $(\mathrm{F} 1,78=2.909 ; \mathrm{P}=0.092)$ between $\mathrm{PTSD}$ and hazardous alcohol use on reaction time.

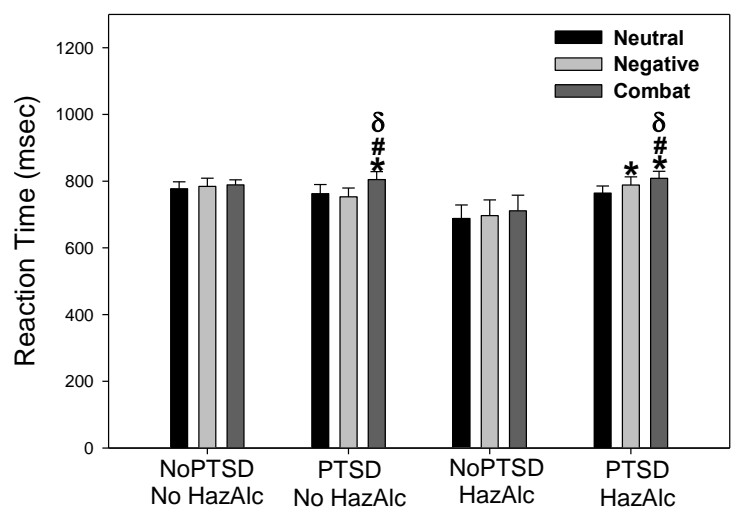

Figure 6: Behavioral measures from the emotional counting stroop task performed during image acquisition $(N=102)$. Reaction time was increased for combat words in PTSD groups only, and an increase in reaction time was also noted for negative words in the PTSD with hazardous alcohol use group. $* P<0.05$ compared to neutral; ${ }^{\#} P<0.05$ compared to negative; ${ }^{\delta} P<0.05$ compared to no-PTSD groups within the combat condition.

Imaging (BOLD) data were analyzed using non-parametric randomization analysis, threshold $\mathrm{p}<0.05$, corrected for multiple comparisons using a family wise error correction. All of the significant changes to BOLD signal during the emotional counting stroop task during the combat condition (as normalized to either the neutral or negative conditions) are detailed in Tables 5-8. All changes were a significant increase compared to control group (no PTSD and no hazardous alcohol group) during the combat condition of the task. Of importance are the effects observed in the region of interest, the anterior cingulate (Figures 7-9). PTSD in the absence of hazardous alcohol use exhibited significant increase in BOLD signal in the right anterior cingulate as compared to controls (Figure 7A; Table 5), which was greater in size when combat condition was normalized to general negative condition (Figure 7B; Table 6). Hazardous alcohol use in the absence of PTSD produced a different pattern of BOLD signal in the bilateral anterior cingulate (Figure 8; Table 7) during combat condition 
(normalized to neutral condition). Furthermore, individuals within the PTSD and hazardous alcohol group exhibited greater BOLD signal in the bilateral ACC extending into the middle frontal gyrus (Figure 9; Table 8) during the combat condition (normalized to neutral condition).
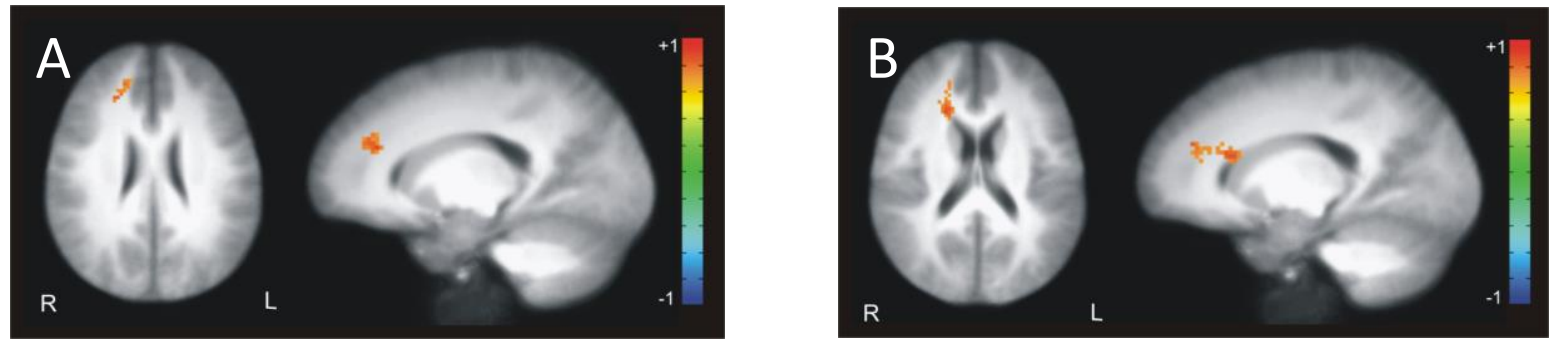

Figure 7: Significant increases in BOLD signal within the right anterior cingulate of participants with PTSD in the absence of hazardous alcohol use, as compared to controls (no PTSD or hazardous alcohol use) during the combat condition of the emotional counting stroop task. (A) Combat condition relative to the neutral condition. (B) Combat condition relative to the general negative condition. Cluster size, coordinates of the peak activation and $t$ values are given in Tables

5 and 6. Statistical maps are overlaid on an average of normalized T1 images from all participants. Despite apparent mapping onto white matter, clusters are located within cortical tissue as according to MNI coordinates.

Table 5. Significant Increase in BOLD signal for PTSD with No Hazardous Alcohol vs. No PTSD with No Hazardous Alcohol (Control), within the Combat Condition Normalized to Neutral Condition.

\begin{tabular}{lllc}
\hline Region & $\begin{array}{l}\text { Cluster Size } \\
\left(\mathbf{m m}^{\mathbf{3}}\right)\end{array}$ & Coordinates $(\mathbf{m m})$ & Max $\boldsymbol{T}$-value \\
\hline Right Anterior Cingulate & 44 & $+17,+38,+18$ & 4.49 \\
\hline
\end{tabular}

Table 6. Significant Increase in BOLD signal for PTSD with No Hazardous Alcohol vs. No PTSD with No Hazardous Alcohol (Control), within Combat Condition Normalized to General Negative Condition.

\begin{tabular}{lllc}
\hline Region & $\begin{array}{l}\text { Cluster Size } \\
\left(\mathbf{m m}^{\mathbf{3}}\right)\end{array}$ & Coordinates & Max $\mathbf{T}$-value \\
\hline Right Anterior Cingulate/Caudate & 72 & $+20,+28,+18$ & 5.00 \\
\hline
\end{tabular}

For each cluster of activation, the volume of activation, MNI coordinates for the peak response, and maximum Ts values are given. MNI coordinates are listed as $x ; y ; z$, with $x<0$ indicating left of the midsagittal plane, $y<0$ indicating posterior to the anterior commissure and $z<0$ indicating inferior to the anterior commissure-posterior commissure plane.

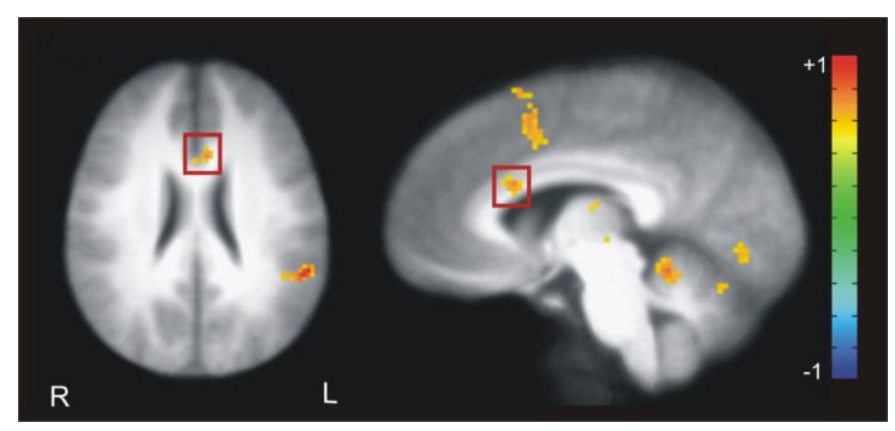

Figure 8: Significant increase in BOLD signal within the bilateral anterior cingulate (red square) of participants with hazardous alcohol use in the absence of PTSD, as compared to controls (no PTSD or hazardous alcohol use) during the combat condition of the emotional counting stroop task. Combat condition was normalized to the neutral condition. Cluster size, coordinates and $t$ values are given in Table 7. Statistical maps are overlaid on an average of normalized T1 images from all participants. Despite apparent mapping onto white matter, the cluster is located within cortical tissue as according to MNI coordinates. 
Table 7. Significant Increases in BOLD signal for No PTSD with Hazardous Alcohol vs. No PTSD with No Hazardous Alcohol (Control), within Combat Condition Normalized to Neutral Condition.

\begin{tabular}{llll}
\hline Region & $\begin{array}{l}\text { Cluster Size } \\
\left(\mathbf{m m}^{\mathbf{3}}\right)\end{array}$ & Coordinates $\mathbf{( m m )}$ & Max $\boldsymbol{T}$-value \\
\hline Right Fusiform Gyrus & 1719 & $-10,+48,-59$ & 6.12 \\
Left Insula & 1055 & $-35,+10,-3$ & 6.40 \\
Right Putamen & 274 & $+24,+3,+9$ & 5.62 \\
Left Superior Frontal Gyrus & 228 & $-8,+16,+52$ & 5.38 \\
Left Precentral Gyrus & 200 & $-33,-27,+52$ & 4.98 \\
Right Insula & 142 & $+29,+30,-5$ & 6.18 \\
Right Parahippocampal Gyrus & 138 & $+20,-25,-10$ & 5.33 \\
Left Inferior Frontal Gyrus & 128 & $-44,+40,-1$ & 4.55 \\
Left Superior Temporal Gyrus & 123 & $-61,-26,+15$ & 6.04 \\
Left Inferior Parietal Lobule & 78 & $-57,-44,+26$ & 5.31 \\
Left Cerebellum Lobule V & 78 & $-8,-49,-13$ & 6.37 \\
Left Precuneus & 77 & $-25,-64,+48$ & 5.40 \\
Right Postcentral Gyrus & 71 & $+31,-38,+53$ & 4.62 \\
Left Lingual Gyrus & 68 & $-1,-73,-2$ & 4.72 \\
Left Superior Frontal Gyrus & 59 & $-25,+52,-4$ & 4.44 \\
Right Putamen & 54 & $26+-21,+17$ & 4.18 \\
Left Middle Frontal Gyrus & 54 & $-46,+13,+40$ & 4.60 \\
Bilateral Anterior Cingulate & 52 & $-5,20+, 22+$ & 5.03 \\
\hline
\end{tabular}

For each cluster of activation, the volume of activation, MNI coordinates for the peak response, and maximum Ts values are given. MNI coordinates are listed as $x ; y ; z$, with $x<0$ indicating left of the midsagittal plane, $y<0$ indicating posterior to the anterior commissure and $z<0$ indicating inferior to the anterior commissure-posterior commissure plane.

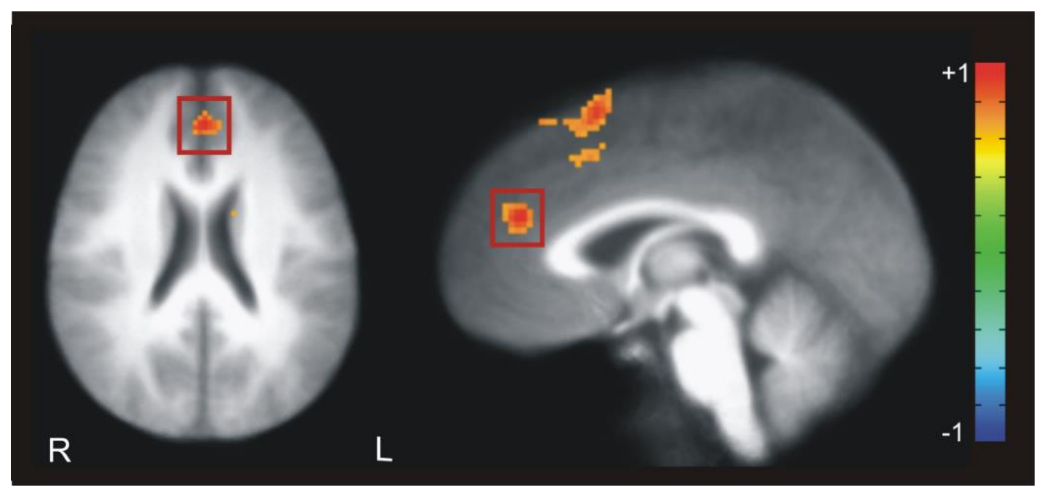

Figure 9: Significant increase in BOLD signal within the bilateral anterior cingulate (red square) of participants with PTSD and hazardous alcohol use as compared to controls (no PTSD or hazardous alcohol use) during the combat condition of the emotional counting stroop task. Combat condition was normalized to the neutral condition. Cluster size, coordinates and $t$ values are given in Table 8.

Statistical maps are overlaid on an average of normalized T1 images from all participants.

Table 8. Significant Increases in BOLD signal for No PTSD with Hazardous Alcohol vs. No PTSD with No Hazardous Alcohol (Control), within Combat Condition Normalized to General Negative Condition.

\begin{tabular}{llll}
\hline Region & $\begin{array}{l}\text { Cluster Size } \\
\left(\mathbf{m m}^{\mathbf{3}}\right)\end{array}$ & Coordinates & Max $\boldsymbol{T}$-value \\
\hline Bilateral Thalamus & 500 & $+5,-4,+16$ & 6.15 \\
Right Postcentral Gyrus & 269 & $+69,-12,+12$ & 5.66 \\
Right Middle Frontal Gyrus & 221 & $+24,-6,+53$ & 5.76 \\
Left Parahippocampal Gyrus & 183 & $-10,-1,-16$ & 6.87 \\
Left Lingual Gyrus & 164 & $-3,-76,-6$ & 5.32 \\
Left Cerebellum Lobule VIIa & 87 & $-20,-86,-28$ & 4.88 \\
Right Precuneus & 62 & $+29,-41,+44$ & 5.19
\end{tabular}


Right Insula $\quad 59$

Right Fusiform Gyrus $\quad 46$

Right Parahippocampus Gyrus
$+39,+4,-5$

$+46,-43,-15$

$+10,-37,0$
6.19

5.18

5.28

For each cluster of activation, the volume of activation, MNI coordinates for the peak response, and maximum Ts values are given. MNI coordinates are listed as $x ; y$; $z$, with $x<0$ indicating left of the midsagittal plane, $y<0$ indicating posterior to the anterior commissure and $z<0$ indicating inferior to the anterior commissure-posterior commissure plane.

The findings from the group-wise comparison of the emotional counting stroop task suggest that the modifications of this task for OEF/OIF veterans were sufficient to produce a stroop interference effect, with PTSD groups showing greater reaction times to respond in the combat-related word condition (Figure 6). PTSD was associated with increased activity in the right rostral ACC during the interference (combat) condition (Figure 7), opposite to the reduced right rostral ACC activation seen in Vietnam veterans under similar task conditions (Shin et al., 2001). The current findings, combined with another study of OEF/OIF veterans (Morey et al., 2008) suggests that activity of the ACC during emotional processing may be related to the chronicity of PTSD, initially characterized by hyperactivity and subsequently typified by hyporeactivity in more chronic cases. Hazardous alcohol use was also associated with increased activity in the rostral ACC during the interference (combat) condition (Figure 8), despite failing to show a stroop effect (Figure 6). Furthermore, PTSD with hazardous alcohol use was characterized by a greater extent of frontal cortex activity (ACC to middle frontal gyrus) during the combat condition (Figure 9), which is normally associated with working memory and executive attention (Courtney et al., 1997; Andersson et al., 2009). Overall, findings suggest that heightened ACC activity during an emotional interference task is characteristic of recently returned OEF/OIF veterans with either PTSD or hazardous alcohol use, and comorbidity of the two results in more expansive recruitment of frontal regions involved in executive function when required to suppress emotional information.

\section{Objective 2 Task 10: Statistical analysis/modeling of fMRI \& behavioral data:}

The statistical modeling was recently completed and was conducted to determine the relationships between combat experience, PTSD symptoms, brain activity and performance on the emotional counting stroop task or affective ratings in the masked faces task. Multilevel structural equation models were tested for each ROI (left and right dorsal ACC, rostral ACC, and amygdala) during the emotional counting Stroop test (see Figures 1012). Analyses were conducted in Mplus 7.1 (Muthen \& Muthen, 2012) with the maximum likelihood robust estimator. Approximately $94 \%$ of the variance in Stroop reaction times were at the between-person level. For the ROI activation data 83\% (left rostral ACC) - 91\% (right dorsal ACC) of the variance was at the between person level. The models fit well CFI ranged from .94 - .98, RMSEA ranged from 0.028 - 0.049 - , and SRMR ranged from $0.028-0.033$ (within) and $0.039-0.047$ (between).

For each analysis, combat severity was positively associated with PCL scores (p's $<.001)$. Predeployment drinking did not significantly predict PCL scores at the between-person level (p's $>=.202$ ). Combat severity did not significantly predict activation in the ROI at the between-person level (p's $>=.229$ ). Predeployment drinking was significantly associated with activation in the left and right dorsal ACC (b's $=-0.01$, p's $<.027)$ but not the rostral ACC or amygdala. Controlling for effects of combat and pre-deployment drinking, activation in the ROI did not predict PCL scores at the between-person level (p's $>=.068$ ). Activation in the ROI did not predict reaction times at the within-person level ( $\mathrm{p}$ 's $>=.109$ ).

There were several cross-level interaction effects such that severity of combat exposure moderated the effect of combat stimuli (relative to neutral or general negative stimuli) resulting in hyperactivation in the Rostral ACC and Dorsal ACC (Figures 10-11). Combat severity did not significantly moderate effects of condition on activation in the amygdala, though there were some significant simple effects of condition on left amygdala hyperactivation (Figure 12). Moderation effects of pre-deployment drinking were primarily not significant, except for the dorsal ACC analyses. Pre-deployment drinking appeared to have a protective effect reducing the effect of condition on activation in the Dorsal ACC (Figure 11). PCL scores did not predict Stroop reaction time at the between-person level ( $p$ 's $>.104$ ), but did moderate the effects of condition on reaction times. Higher PTSD symptoms were associated with a stronger emotional counting Stroop effect, suggesting greater interference associated with combat words. 


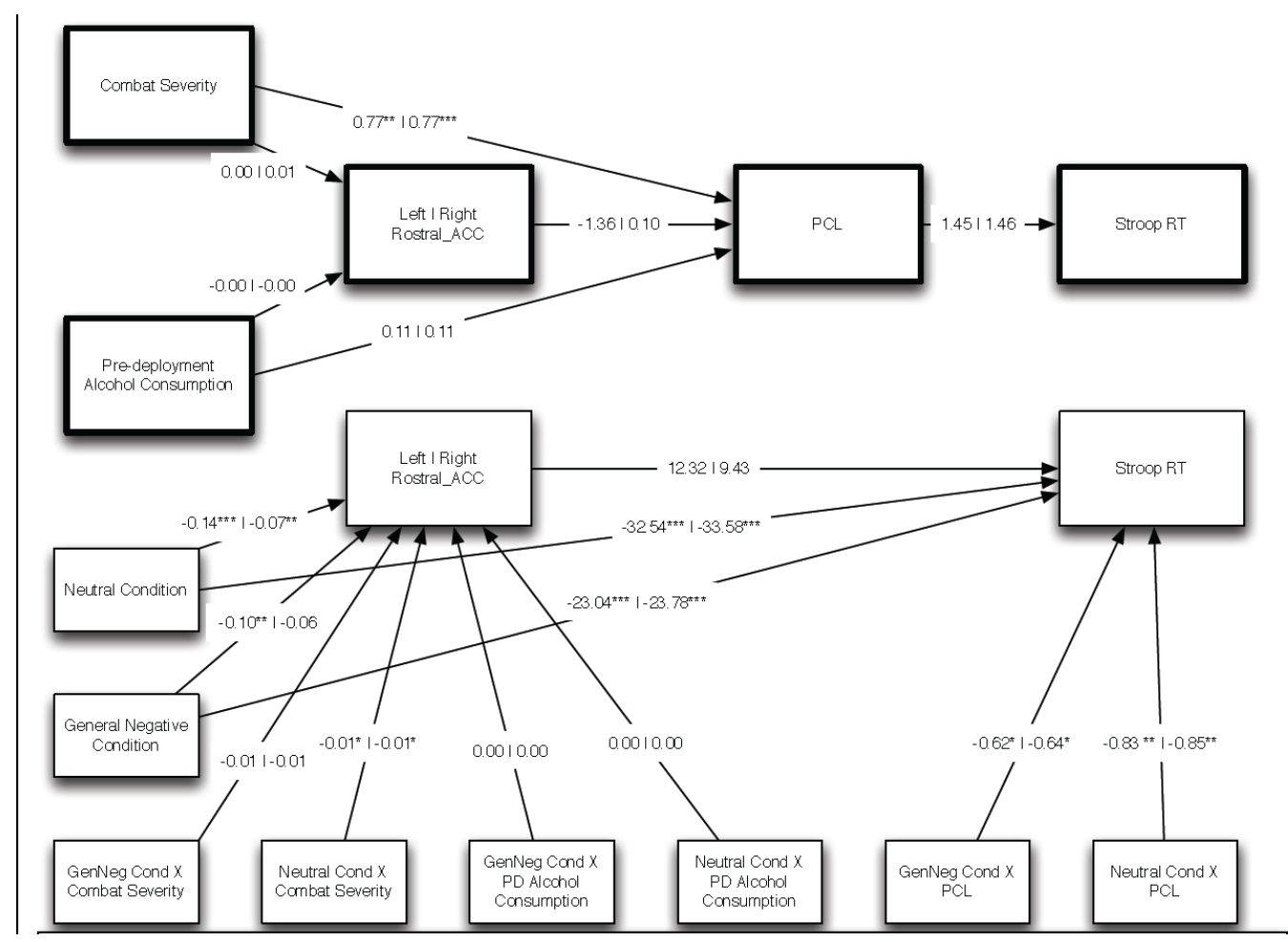

Figure 10: Multilevel structural equation models for the rostral ACC during the emotional counting stroop task. Upper, bold construct are between subject variables, lower, non-bold are within-subject and interaction effects. The combat word condition is the reference group. Two models are depicted, one for the left rostral ACC and one for the right rostral ACC, coefficients are depicted on the left and right, respectively, of the horizontal dividers. Left: $\chi 2(9, N=282)=11.40, p=.2495, C F I=.98, R M S E A=.031, S R M R=.033(W)$ $.041(B)$. Right: $\chi 2(9, N=282)=11.06, p=.2720, C F I=.98, R M S E A=.028 S R M R=.030(W) .047(B)$

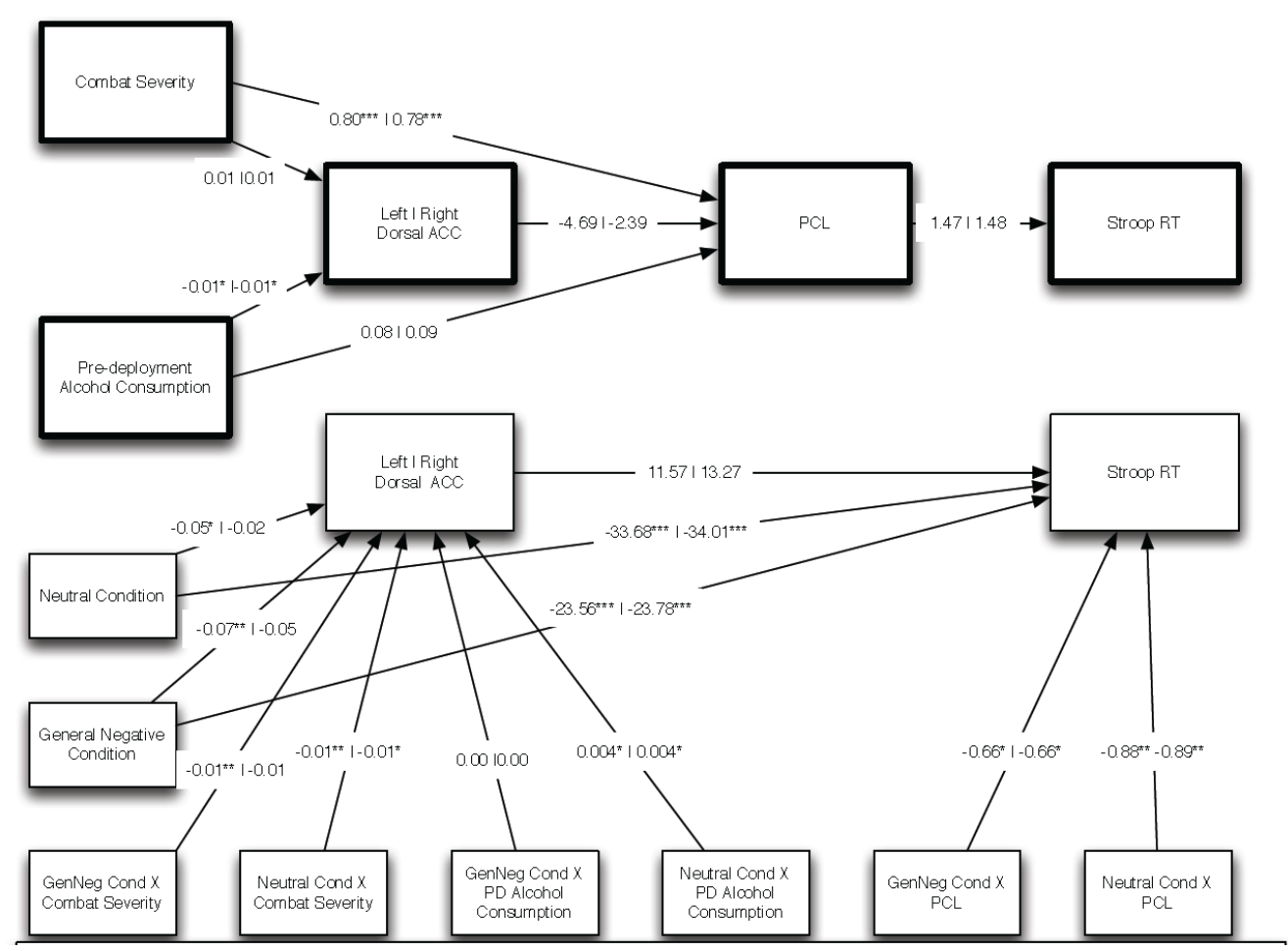

Figure 11: Multilevel structural equation models for the dorsal ACC during the emotional counting stroop task. Upper, bold construct are between subject variables, lower, non-bold are within-subject and interaction effects. The combat word condition is the reference group. Two models are depicted, one for the left dorsal $A C C$ and one for the right dorsal ACC, coefficients are depicted on the left and right, respectively, of the 
horizontal dividers. Left: $\chi 2(9, N=282)=13.91, p=.126, C F I=.96, R M S E A=.044, S R M R=.032(W) .043(B)$. Right: $\chi 2(9, N=282)=15.01, p=.090, C F I=.94, R M S E A=.049, S R M R=.034(W) .041(B)$

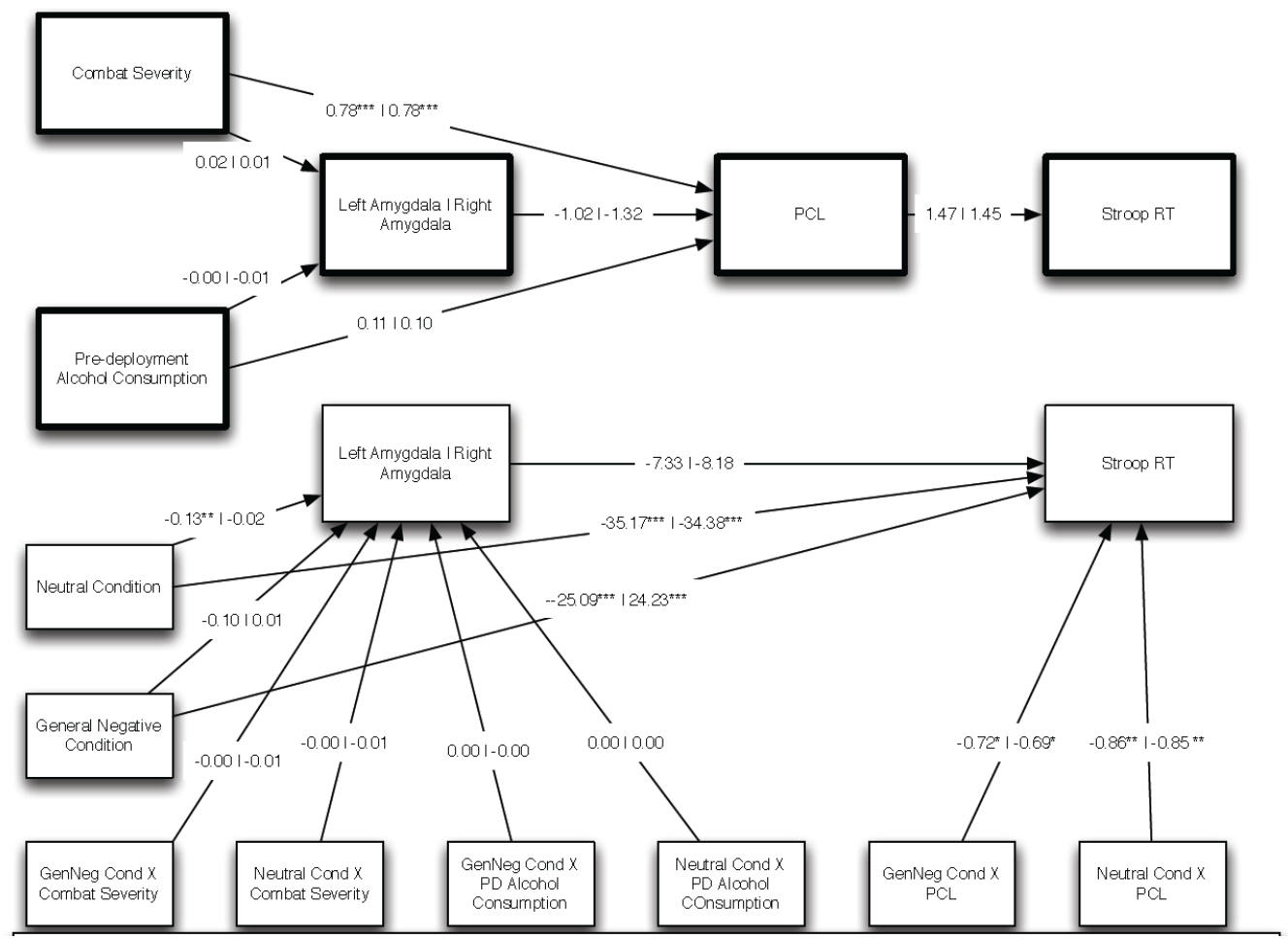

Figure 12: Multilevel structural equation models for the amygdala during the emotional counting stroop task. Upper, bold construct are between subject variables, lower, non-bold are within-subject and interaction effects. The combat word condition is the reference group. Two models are depicted, one for the left amygdala and one for the right amygdala, coefficients are depicted on the left and right, respectively, of the horizontal dividers. Left: $\chi 2(9, N=282)=12.48, p=.1877, C F I=.96, R M S E A=.037, S R M R=.028(W) .046(B)$. Right:

$$
\chi 2(9, N=282)=11.00, p=.2758, C F I=.98, R M S E A=.028, S R M R=.029(W) .039(B) \text {. }
$$

We tested three alternative models to determine, (1) whether a model whereby PTSD symptoms predicts brain activation is a better fit to the data than the converse, (2) whether the moderating effects of combat severity on the association between stimulus condition and brain activation are better accounted for PTSD symptoms, and, (3) whether the moderating effects of PTSD symptoms on the association between stimulus condition and reaction time are better accounted for combat severity. In the first set of models (Figures 10-12), combat severity and pre-deployment drinking were exogenous variables predicting PCL scores, which in turn predicted brain activation. Brain activation predicted reaction time at both the between- and within-person level. In addition, predeployment drinking had a direct effect on brain activation and PCL scores had a direct effect on reaction time at the between-person level. The within-person model was the same as in the initial analyses, with the exception that the combat severity $\mathrm{x}$ condition interactions were replaced with PCL $\mathrm{x}$ condition interactions. This model thus tests the between-person effect of PCL symptoms on brain activation and the moderating effects of PCL on the associations between condition and brain activation without controlling for shared variance in combat severity. The second set of models added combat severity $\mathrm{x}$ condition interactions at the within-person level and a direct effect form combat severity to ROI activation at the between person level to alternate model 1. This model thus tests the simultaneous effects of combat severity and PCL scores on the outcomes. The third model was identical to the base model with the exception of adding two paths from the CES $x$ condition interactions to reaction time. The alternative models and base model set are not nested and so direct comparisons of model fit are not possible. However, AIC and BIC can be used to compare non-nested models, with lower values indicating a better fit to the data. The base model and alternative model 2 and 3 each have 10 independent predictors. Alternative model 1 has 8 independent predictors. The base model and alternative model 1 each have 25 parameters, while alternative models 2 and 3 have 28 parameters. Hence alternative models 2 and 3 are the most complex and alternative model 1 is the least complex. 
Results of alternative model 1: Table 9 provides comparison information for the base and alternative model 1. For alternative model 1, differences in model fit and AIC, BIC relative to the base model were very modest. For the amygdala and left dorsal ACC, AIA, BIC, and the fit indices all favored the base model. For the left and right rostral ACC, there was a slight preference for the more parsimonious model (indicated by AIC, BIC) however the fit indices for the base model were slightly better. The converse was true for right dorsal ACC (fit was slightly better in the alternative model but AIC and BIC favored the base model). Given this pattern, there does not appear to be empirical evidence to favor the alternative model over the original hypothesized structure. In addition, for the right rostral ACC, right dorsal ACC, and left dorsal ACC, combat severity (in the base model) but not PCL scores (in the alternative model) moderate the effects of condition on ROI activation. For the left rostral ACC, there was evidence of both combat severity in the base model and PCL scores in the alternative model moderating effects of stimulus condition.

Results of alternative model 2: Table 10 provides comparison information for the base and alternative model 2. For alternative model 2, the fit indices, AIC, and BIC favored the less complex base model in almost every analysis (the right dorsal ACC being a minor exception). In addition, the moderation effects of combat severity remained significant in both the left and right dorsal ACC analyses. In the rostral ACC analyses neither combat severity nor PCL scores had significant moderation effects (likely owing to the correlation between the two). Only in the right dorsal ACC analysis did a significant moderation effect of PCL scores on condition emerge.

Results of alternative model 3. For each ROI analysis, the added combat severity $\mathrm{x}$ condition interactions did not significantly predict reaction time and the PCL x condition interactions remained significant predictors of reaction time.

Table 9. Comparison Alternative Model 1 and Base Model Used to Test Emotional Counting Stroop Data

\begin{tabular}{|c|c|c|c|}
\hline ROI & Base model & Alt model 1 & PCL effects \\
\hline R_R_ACC & $\mathrm{AIC}=3931.80$ & $\mathrm{AIC}=3931.41$ & PCL->ROI, \\
\hline & $\mathrm{BIC}=4022.85$ & $\mathrm{BIC}=4022.46$ & $b=0.00, p=.492$ \\
\hline & $\mathrm{CFI}=.98$ & $\mathrm{CFI}=.96$ & PCLxNeu, \\
\hline & $\mathrm{RMSEA}=.028$ & $\mathrm{RMSEA}=.051$ & $\mathrm{~b}=-0.00, p=.069$ \\
\hline & $\mathrm{SRMR}=.030(\mathrm{~W})$ & $\mathrm{SRMR}=.033(\mathrm{~W})$ & PCLxNeg, \\
\hline & $.047(\mathrm{~B})$ & $.038(\mathrm{~B})$ & $\mathrm{b}=-0.00, p=.142$ \\
\hline \multirow[t]{6}{*}{ L_R_ACC } & $\mathrm{AIC}=3928.74$ & $\mathrm{AIC}=3926.30$ & PCL->ROI, \\
\hline & $\mathrm{BIC}=4019.78$ & $\mathrm{BIC}=4017.34$ & $b=0.00, p=.700$ \\
\hline & $\mathrm{CFI}=.98$ & $\mathrm{CFI}=.96$ & PCLxNeu, \\
\hline & $\mathrm{RMSEA}=.031$ & $\mathrm{RMSEA}=.050$ & $\mathrm{~b}=-0.00, p=.029$ \\
\hline & $\mathrm{SRMR}=.033(\mathrm{~W})$ & $\mathrm{SRMR}=.033(\mathrm{~W})$ & PCLxNeg, \\
\hline & $.041(\mathrm{~B})$ & $.037(\mathrm{~B})$ & $\mathrm{b}=-0.01, p=.046$ \\
\hline
\end{tabular}

AIC, BIC minimally

favor alt. model. Fit

indices favor base

model. CES (in the base

model) but not PCL (in

the alt. model)

moderates the neutral

contrast.

AIC, BIC slightly favor

alt. model. Fit indices

favor base model. CES

(in the base model) and

PCL (in the alt. model)

moderate the neutral

contrast. PCL in the alt.

model also moderates

the neg. contrast

\begin{tabular}{|c|c|c|c|}
\hline R_D_ACC & $\begin{array}{l}\mathrm{AIC}=3810.82 \\
\mathrm{BIC}=3901.87 \\
\mathrm{CFI}=.94 \\
\mathrm{RMSEA}=.049 \\
\mathrm{SRMR}=.034(\mathrm{~W}) \\
.041(\mathrm{~B})\end{array}$ & $\begin{array}{l}\mathrm{AIC}=3819.87 \\
\mathrm{BIC}=3910.92 \\
\mathrm{CFI}=.95 \\
\mathrm{RMSEA}=.058 \\
\mathrm{SRMR}=.034(\mathrm{~W}) \\
.038(\mathrm{~B})\end{array}$ & $\begin{array}{l}\text { PCL->ROI, } \\
b=-0.00, p=.472 \\
\text { PCLxNeu, } \\
\mathrm{b}=0.00, p=.415 \\
\text { PCLxNeg, } \\
\mathrm{b}=-0.00, p=.365\end{array}$ \\
\hline L_D_ACC & $\begin{array}{l}\mathrm{AIC}=3815.44 \\
\mathrm{BIC}=3906.49 \\
\mathrm{CFI}=.96\end{array}$ & $\begin{array}{l}\mathrm{AIC}=3824.99 \\
\mathrm{BIC}=3916.03 \\
\mathrm{CFI}=.95\end{array}$ & $\begin{array}{l}\text { PCL->ROI, } \\
b=-0.00, p=.209 \\
\text { PCLxNeu, }\end{array}$ \\
\hline
\end{tabular}

AIC, BIC slightly favor base model. Fit indices favor alt. model. CES (in the base model) but not PCL (in the alt. model) moderates the condition effects.

AIC, BIC and fit indices all slightly favor base model. CES (in the base 


$\begin{array}{lll}\text { RMSEA }=.044 & \text { RMSEA }=.062 & \mathrm{~b}=0.00, p=.797 \\ \text { SRMR }=.032(\mathrm{~W}) & \text { SRMR }=.034(\mathrm{~W}) & \text { PCLxNeg, } \\ .043(\mathrm{~B}) & .042(\mathrm{~B}) & \mathrm{b}=-0.00, p=.211\end{array}$

$\begin{array}{llll}\text { R_Amy } & \text { AIC }=4312.59 & \text { AIC }=4315.40 & \text { PCL->ROI, } \\ & \text { BIC }=4403.64 & \text { BIC }=4406.45 & b=-0.01, p=.360 \\ & \text { CFI }=.98 & \text { CFI }=.94 & \text { PCLxNeu, } \\ & \text { RMSEA }=.028 & \text { RMSEA }=.060 & \mathrm{~b}=0.00, p=.555 \\ & \text { SRMR }=.029(\mathrm{~W}) & \text { SRMR }=.032(\mathrm{~W}) & \text { PCLxNeg, } \\ & .039(\mathrm{~B}) & .041(\mathrm{~B}) & \mathrm{b}=-0.00, p=.649 \\ \text { L_Amy } & \mathrm{AIC}=4269.76 & \mathrm{AIC}=4268.28 & \mathrm{PCL}->\mathrm{ROI}, \\ & \mathrm{BIC}=4360.81 & \mathrm{BIC}=4359.32 & b=-0.01, p=.360 \\ & \mathrm{CFI}=.96 & \mathrm{CFI}=.95 & \text { PCLxNeu, } \\ & \mathrm{RMSEA}=.037 & \mathrm{RMSEA}=.054 & \mathrm{~b}=0.00, p=.922 \\ & \mathrm{SRMR}=.028(\mathrm{~W}) & \mathrm{SRMR}=.031(\mathrm{~W}) & \mathrm{PCLxNeg}, \\ & .046(\mathrm{~B}) & .046(\mathrm{~B}) & \mathrm{b}=-0.01, p=.102\end{array}$

model) but not PCL (in the alt. model)

moderates the condition effects.

AIC, BIC and fit indices all slightly favor base model. Neither CES nor PCL moderate condition effects

AIC, BIC and fit indices all slightly favor base model. Neither CES nor PCL moderate condition effects

Table 10. Comparison of Alternative Model 2 with Base Model Used to Test Emotional Counting Stroop Data

\begin{tabular}{llll}
\hline ROI & Base model & Alt model 2 & PCL effects \\
\hline R_R_ACC & AIC $=3931.80$ & AIC $=3935.49$ & PCL->ROI, \\
& BIC $=4022.85$ & BIC $=4037.46$ & $b=0.00, p=.760$ \\
& CFI $=.98$ & CFI $=.96$ & PCLxNeu, \\
& RMSEA $=.028$ & RMSEA $=.044$ & $b=-0.00, p=.354$ \\
& SRMR $=.030(\mathrm{~W})$ & SRMR $=.027(\mathrm{~W})$ & PCLxNeg, \\
& $.047(\mathrm{~B})$ & $.039(\mathrm{~B})$ & $b=-0.00, p=.436$ \\
& & & \\
L_R_ACC & AIC $=3928.74$ & AIC $=3931.28$ & PCL->ROI, \\
& BIC $=4019.78$ & BIC $=4033.26$ & $b=0.00, p=.904$ \\
& CFI $=.98$ & CFI $=.97$ & PCLxNeu, \\
& RMSEA $=.031$ & RMSEA $=.043$ & $b=-0.00, p=.148$ \\
& SRMR=.033(W) & SRMR $=.027(\mathrm{~W})$ & PCLxNeg, \\
& $.041(\mathrm{~B})$ & $.037(\mathrm{~B})$ & $b=-0.01, p=.220$ \\
& & & \\
& & & PCL->ROI, \\
R_D_ACC & AIC $=3810.82$ & AIC $=3812.44$ & $b=-0.00, p=.232$ \\
& BIC $=3901.87$ & BIC $=3914.41$ & PCLxNeu, \\
& CFI $=.94$ & CFI $=.97$ & $b=0.00, p=.047$ \\
& RMSEA $=.049$ & RMSEA $=.046$ & PCLxNeg, \\
& SRMR=.034(W) & SRMR=.028(W) & $b=-0.00, p=.396$
\end{tabular}

Comments

AIC, BIC favor base model. Fit indices favor base model. CES (in the base model) but not PCL nor CES (in the alt. model) moderates the neutral contrast.

AIC, BIC slightly favor base model. Fit indices favor base model. CES (in the base model) but not PCL nor CES (in the alt. model) moderate the neutral contrast.

AIC, BIC slightly favor base model. Fit indices favor alt. model. CES (in the base and alt model) moderates the condition effects. PCL moderates the neutral contrast in the alt model.

AIC, BIC slightly favor base model. Fit indices are mixed. CES (in the base and alt model) but not PCL (in the alt. model) moderates the condition effects.

AIC, BIC and fit indices all slightly favor base model. Neither CES nor PCL moderate condition 


\begin{tabular}{lllll} 
& SRMR $=.029(\mathrm{~W})$ & SRMR $=.027(\mathrm{~W})$ & PCLxNeg, & effects. \\
L_Amy & $.039(\mathrm{~B})$ & $.035(\mathrm{~B})$ & $b=0.00, p=.759$ & \\
$\mathrm{AIC}=4269.76$ & $\mathrm{AIC}=4272.11$ & PCL->ROI, & AIC, BIC slightly favor \\
& $\mathrm{BIC}=4360.81$ & $\mathrm{BIC}=4374.08$ & $b=-0.01, p=.500$ & base model. Fit indices \\
$\mathrm{CFI}=.96$ & $\mathrm{CFI}=.98$ & PCLxNeu, & favor alt. model. Neither \\
$\mathrm{RMSEA}=.037$ & $\mathrm{RMSEA}=.035$ & $b=0.00, p=.609$ & CES nor PCL moderate \\
& SRMR $=.028(\mathrm{~W})$ & SRMR $=.025(\mathrm{~W})$ & PCLxNeg, & condition effects \\
$.046(\mathrm{~B})$ & $.033(\mathrm{~B})$ & $b=-0.00, p=.265$ & \\
\hline
\end{tabular}

Summary of models for emotional counting Stroop: Overall, investigation of alternative models did not suggest making changes to the hypothesized model. There is stronger evidence that individual differences in combat severity, rather than PTSD symptoms, moderate the effects of stimulus condition on activation in the ACC regions (Figures 10-12). Greater severity of combat exposure resulted in hyperactivation in the ACC regions in response to combat related stimuli (Figures 10-11). This effect was more pronounced on the neutral vs. combat stimuli contrast, which was significant in each target ACC region (i.e., left, right, dorsal, ventral). The effect on the general negative vs. combat contrast was more modest and significant in the dorsal but not rostral ACC analyses. During the emotional counting Stroop tasks, there was greater evidence of stimulus condition effects on the ACC regions than the amygdala, though some evidence of hyperactivation in the left Amygdala in response to the combat stimuli (Figure 12). In contrast to the effects on brain activation, PTSD symptoms but not combat severity moderated the effect of stimulus condition on reaction time. Individuals with higher scores on the PCL exhibited a stronger interference effect of the combat related words (Figures 10-12).

Multilevel structural equation models were also tested for each ROI during the masked faces task (see Figures 13-15). Analyses were conducted in Mplus 7.1 (Muthen \& Muthen, 2012) with the maximum likelihood robust estimator. For the negative affect ratings, only $2 \%$ of the variance was at the between-person level. For the activation data in the ROI, 71\% (right dorsal ACC) - 82\% (left amygdala) of the variance was at the between-person level. The models generally fit well; CFI ranged from .94 - .99, RMSEA ranged from .031.088 , and SRMR ranged from .036 - .043 (within) and .037 - .232 (between). None of the combat severity X condition ( $p$ 's $>=.101$ ), predeployment drinking X condition ( $p$ 's $>=.217$ ), or PCL X condition ( $p$ 's $>=.133$ ), interactions were significant. Furthermore, the effects of condition (at mean levels of the between-person variables) on activation in the ROI were not significant (p's $>=.066$ ). However, the fearful face condition was associated with more negative ratings of the stimuli at the within-person level (Figures 13-15). At the withinperson level, activation in the right amygdala was inversely associated with negative affect ratings (Figure 15). In addition, activation in the right rostral ACC was positively associated with negative affect ratings (Figure 13). At the between-person level, there were inverse associations between pre-deployment drinking and activation in the dorsal ACC (Figure 14). This is consistent with the effect seen with predeployment drinking in the dorsal ACC analyses of the emotional counting Stroop analyses. In addition, activation in the amygdala was inversely associated with scores on the PCL (Figure 15). There were no significant between-person effects with the rostral ACC. PCL scores did not predict negative affect or arousal ratings at the between-person level. 


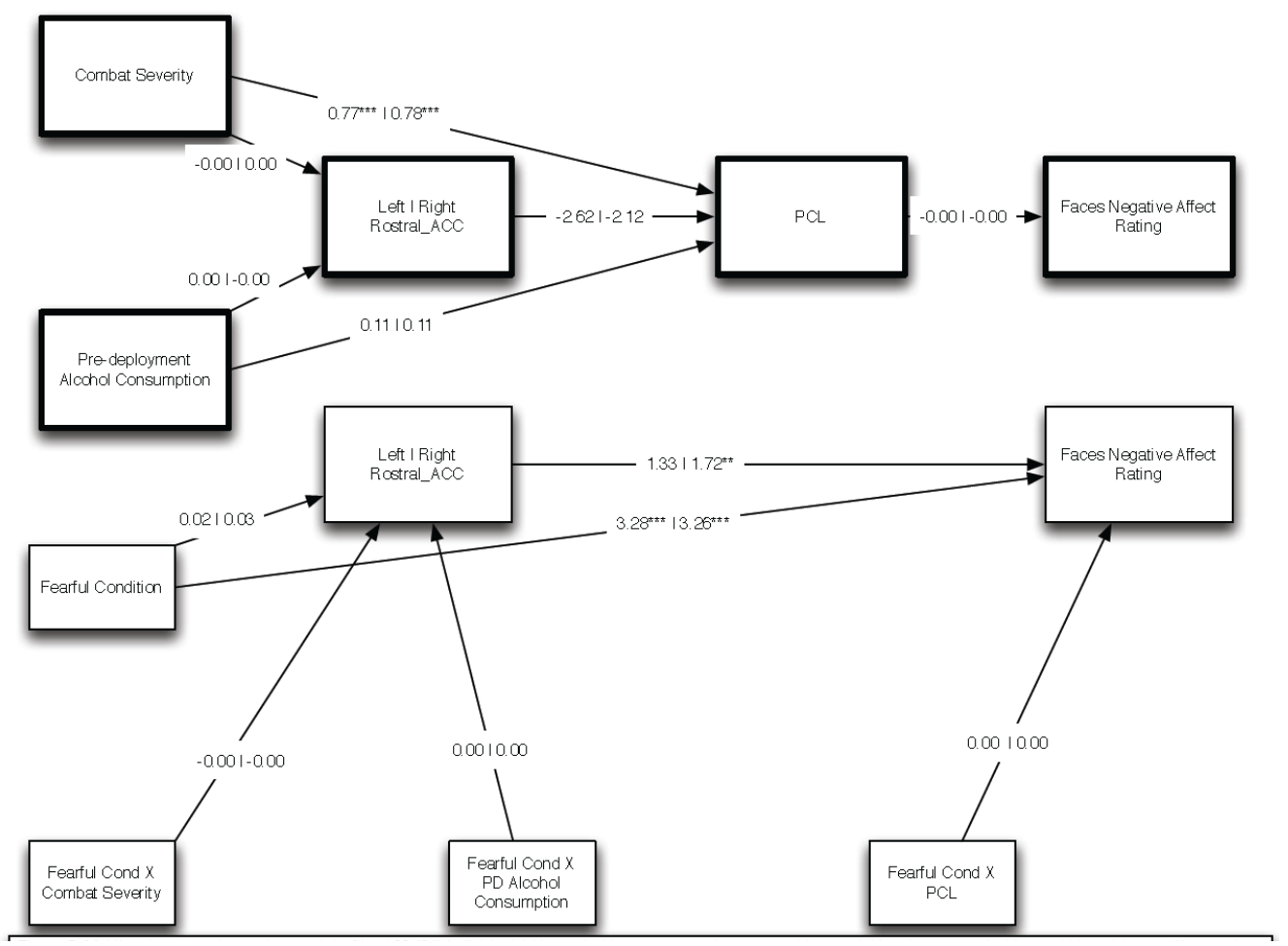

Figure 13: Multilevel structural equation models for the rostral ACC during the masked faces task. Upper, bold construct are between subject variables, lower, non-bold are within-subject and interaction effects. The happy faces condition is the reference group. Two models are depicted, one for the left rostral ACC and one for the right rostral ACC, coefficients are depicted on the left and right, respectively, of the horizontal dividers. Left: $\chi 2(6, N=182)=12.39, p=.0538, C F I=.96, R M S E A=.077, S R M R=.039(W) .217(B)$. Right: $\chi 2(6, N=182)=12.33, p=.0551, C F I=.96, R M S E A=.076, S R M R=.040(\mathrm{~W}) .217(B)$

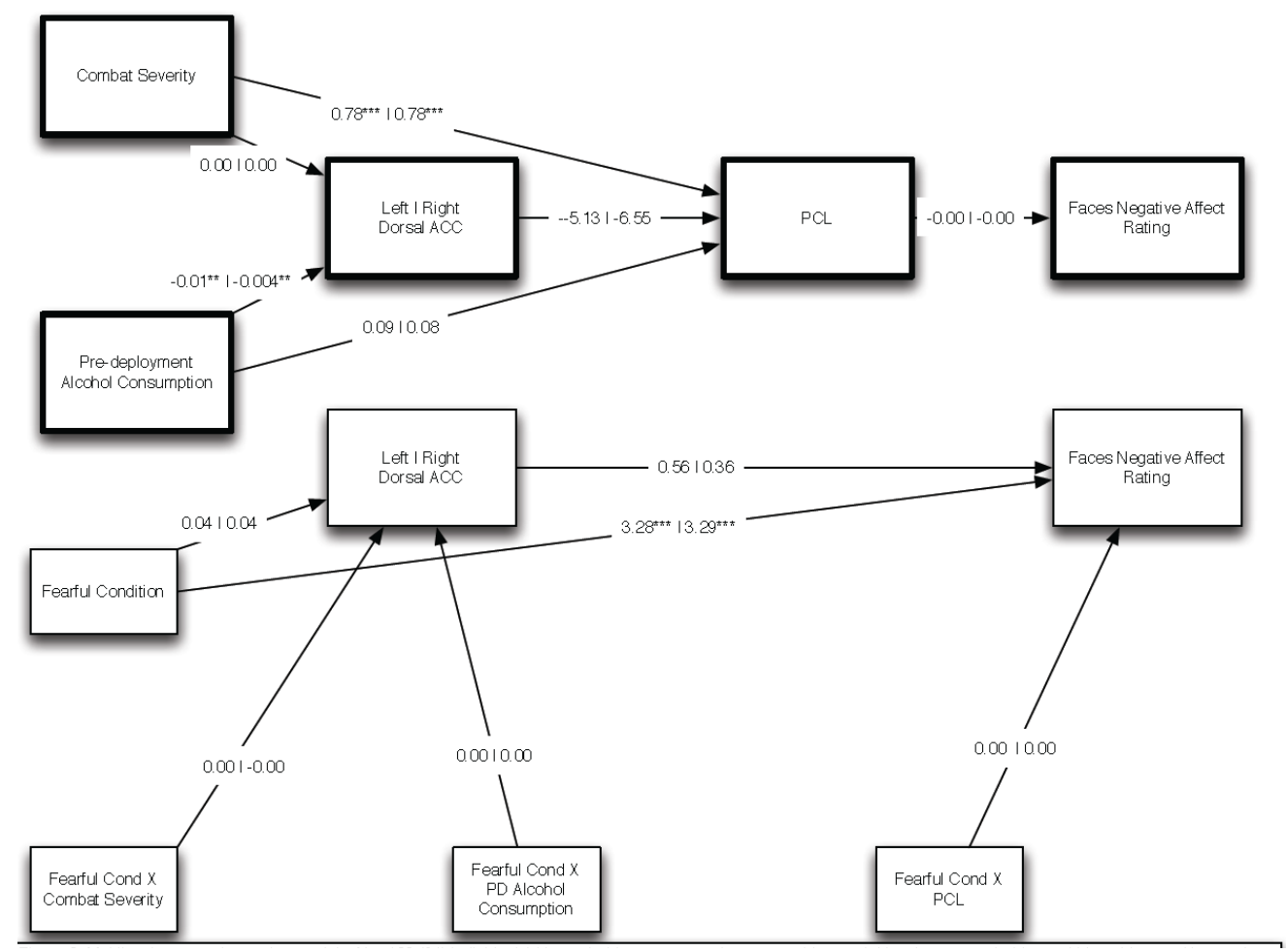

Figure 14: Multilevel structural equation models for the dorsal ACC during the masked faces task. Upper, bold construct are between subject variables, lower, non-bold are within-subject and interaction effects. The happy faces condition is the reference group. Two models are depicted, one for the left dorsal ACC and one for the right dorsal ACC, coefficients are depicted on the left and right, respectively, of the horizontal 
dividers. Left: $\chi 2(6, N=182)=12.10, p=.0597 C F I=.97, R M S E A=.075$, SRMR $=.036(W) .224(B)$. Right: $\chi 2(6, N=182)=11.98, p=.0625, C F I=.97, R M S E A=.074, S R M R=.036(W) .224(B)$

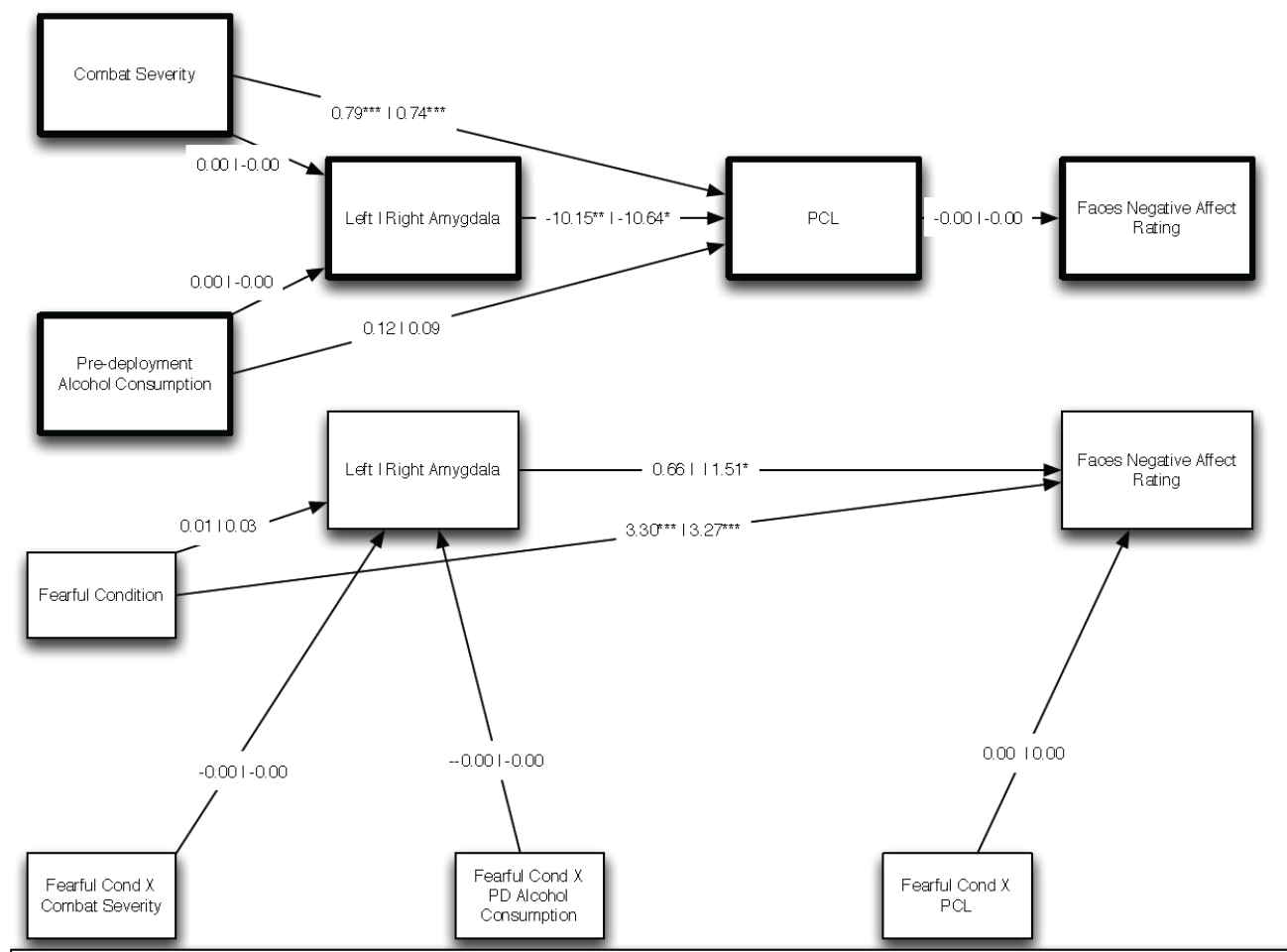

Figure 15: Multilevel structural equation models for the amygdala during the masked faces task. Upper, bold construct are between subject variables, lower, non-bold are within-subject and interaction effects. The happy faces condition is the reference group. Two models are depicted, one for the left amygdala and one for the right amygdala, coefficients are depicted on the left and right, respectively, of the horizontal dividers. Left: $\chi 2(6, N=182)=13.85, p=.0314, C F I=.96, R M S E A=.085, S R M R=.041(W) .232(B)$. Right: $\chi 2(6, N=182)=14.54, p=.024, C F I=.96, R M S E A=.088, S R M R=.038(\mathrm{~W}) .218(\mathrm{~B})$

Objective 2 Task 11: Manuscript/s for fMRI study prepared for publication.

The fMRI data analysis was completed in the last week of the award period. A manuscript describing and discussing the group-wise comparisons of ACC activity during the emotional counting stroop task (Figures 6-9) is currently being prepared. Furthermore, a manuscript based on the model linking combat exposure with brain activity, PTSD symptoms, alcohol use and task performance (Figures 10-15) will be prepared and submitted early 2015. The investigators are highly motivated to publish the work in a prompt fashion to ensure dissemination of the findings.

\section{Key Research Accomplishments:}

In relation to the objectives and tasks in Table 1, key accomplishments were:

- Development of infrastructure to examine human brain function via fMRI technology in South Dakota.

- Successful recruitment of mid-west Iraq/Afghanistan war veterans to participate in a study assessing the relationship between alcohol use, PTSD symptoms and neural processing of emotions.

- Validation of paradigms modified for OEF/OIF veterans used during brain imaging to elicit affect and that require suppression of emotional content.

- Successful testing of a model demonstrating that affect lability mediates the effect of PTSD symptoms on alcohol dependence whereas the negative consequences of alcohol use were mediated by PTSD symptoms via behavioral disinhibition in OEF/OIF veterans. 
- Findings suggesting that heightened anterior cingulate activity during an emotional interference task is characteristic of recently returned OEF/OIF veterans with either PTSD or hazardous alcohol use, and comorbidity of the two results in more expansive recruitment of frontal regions involved in executive function when required to suppress emotional information.

- Identification of important factors (such as predeployment drinking and combat exposure intensity) that mediate the effects of PTSD on ability to perform tasks requiring emotional suppression, or that directly affect brain activity during the performance of such tasks.

\section{Study Personnel (receiving pay from award):}

Gina Forster, PhD. Division of Basic Biomedical Sciences, University of South Dakota Dawne Olson, BS. Division of Basic Biomedical Sciences, University of South Dakota Jamie Scholl, MS. Division of Basic Biomedical Sciences, University of South Dakota Shaydie Engel, BS. Division of Basic Biomedical Sciences, University of South Dakota Raluca Gaher, PhD. Department of Psychology, University of South Dakota Jeffrey Simons, PhD. Department of Psychology, University of South Dakota Nicole Hoffman, MA. Department of Psychology, University of South Dakota Jamie Hanson, MA. Department of Psychology, University of South Dakota Vincent Magnotta, PhD. Department of Radiology, University of Iowa

\section{Reportable Outcomes:}

- Review Article Published (see Appendix):

Forster, G., Novick, A., Scholl, J., Watt, M. (2012). The role of the amygdala in anxiety disorders. In Ferry, B (Ed.), The Amygdala - A Discrete Multitasking Manage (pp. 61-102). Rejeka: InTech.

- Presentation at the Substance Abuse Research IRA, 24 ${ }^{\text {th }}$ Sept 2013, Ft. Detrick, MD: Forster, G. Neural and Behavioral Correlates of PTSD and Alcohol Use

- Conference Presentation at the Society for Neuroscience Annual Meeting, November $12^{\text {th }} 2013$, San Diego, CA:

Forster, G.L., Olson, D.M., Baugh, L.A., Hansen, J.M., Gaher, R, Simons, J, Magnotta, V. (2013). Effects of heavy alcohol use on frontal cortex activity and behavior during emotional processing in veterans with PTSD. Society for Neuroscience Abstracts, 543.24.

- $\quad$ Presentation at the Substance Abuse Research IRA, $23^{\text {rd }}$ Sept 2014, Frederick, MD: Forster, G. Neural and Behavioral Correlates of PTSD and Alcohol Use

- Conference Presentation at the Society for Neuroscience Annual Meeting, November $14^{\text {th }} 2014$, Washington, DC (Abstract accepted): Forster, G.L., Olson, D.M., Baugh, L.A., Hansen, J.M., Engel, S., Gaher, R, Simons, J, Magnotta, V. (2013). Frontal cortex activity during emotional processing is altered in veterans with hazardous alcohol use and posttraumatic stress disorder Society for Neuroscience Abstracts, 427.06.

Further manuscripts ( 3 in total) will be submitted for publication based on the data presented in this final report.

\section{Conclusions:}

Hazardous use of alcohol negatively impacts the treatment of PTSD. However, the mechanisms that underlie the association between PTSD and hazardous alcohol use in veterans are poorly understood. The current 
research takes a multi-level approach to study the psychological, behavioral, cognitive and neural relationships between PTSD and alcohol use in OEF/OIF veterans. Findings suggest a strong link between PTSD, alcohol dependence and negative consequences of alcohol, and these associations are mediated by factors such as affect lability and behavioral disinhibition. Furthermore, participants with PTSD showed greater difficulty in suppressing emotional content in favor of a cognitive output when presented with combat-associated stimuli, with higher levels of PTSD symptoms predicting poorer performance. The anterior cingulate cortex is important in switching attention to allow suppression of emotive content in the performance of a cognitive task. In contrast to what is observed in Vietnam veterans, the participants of the current study exhibited heightened anterior cingulate activity during an emotional interference task, suggestive that the time between combat and testing may be an important factor in establishing effects on brain function. Heightened anterior cingulate activity was also noted in those participants with hazardous alcohol use, and comorbidity of PTSD with hazardous alcohol use resulted in more expansive recruitment of frontal regions involved in executive function when required to suppress emotional information. Further analysis identified factors such as predeployment drinking and combat exposure intensity as being important in mediating the effects of PTSD on ability to perform tasks requiring emotional suppression, or that directly affect brain activity during the performance of such tasks. Overall, findings elucidate behavioral and neural relationships between PTSD and hazardous alcohol use. The results suggest that targeting the factors underlying these relationships (affect liability, behavioral disinhibition, anterior cingulate activity) or recognizing factors that mediate effects on emotional expression and suppression and underlying brain regions (predeployment drinking, combat exposure intensity) may represent important treatment strategies for PTSD and hazardous alcohol use in recently returned combat veterans.

\section{References:}

Dao-Castellana, M.H., Samson, Y., Legault, F., Martinot, J.L., Aubin, H.J., Crouzel, C., Feldman, L., Barrucand, D., Rancurel, G., Feline, A. \& Syrota, A. (1998) Frontal dysfunction in neurologically normal chronic alcoholic subjects: metabolic and neuropsychological findings. Psychological Medicine, 28, 1039-1048.

Gilman, J.M. \& Hommer, D.W. (2008) Modulation of brain response to emotional images by alcohol cues in alcohol-dependent patients. Addiction Biology, 13, 423-434.

Hoge, C. W., Castro, C. A., Messer, S. C., McGurk, D., Cotting, D. I., \& Koffman, R. L. (2004). Combat Duty in Iraq and Afghanistan, Mental Health Problems, and Barriers to Care. New England Journal of Medicine, 351(1), 13-22.

Hoge, C.W., McGurk, D., Thomas, J.L., Cox, A.L., Engel, C.C. \& Castro, C.A. (2008) Mild traumatic brain injury in U.S. Soldiers returning from Iraq. The New England Journal of Medicine, 358, 453-463.

Hopper JW, Frewen PA, van der Kolk BA, Lanius RA (2007) Neural correlates of reexperiencing, avoidance, and dissociation in PTSD: Symptom dimensions and emotion dysregulation in responses to scriptdriven trauma imagery. Journal of Traumatic Stress 20,713-725.

Jacobsen, L. K., Southwick, S. M., \& Kosten, T. R. (2001). Substance use disorders in patients with posttraumatic stress disorder: A review of the literature. American Journal of Psychiatry, 158(8), 1184-1190.

Kensinger EA, Schacter DL (2006) Processing emotional pictures and words: effects of valence and arousal. Cognitive, Affective \& Behavioral Neuroscience 6:110-126.

McDevitt-Murphy, M. E., Williams, J. L., Bracken, K. L., Fields, J. A., et al., (2010). PTSD symptoms, hazardous drinking, and functioning among U. S. OEF and OIF Veterans present to primary care. Journal of Traumatic Stress, 23 (1), 108-111.

Morawetz,C., Lange, C., Holz, P, Baudewig, J., Weniger, G., Irle, E \& Dechent, P. (2006) Functional MRI of the human amygdala avoiding susceptibility artefacts. Proc. Intl. Soc. Mag. Reson. Med. 14, 2831.

Morey RA, Petty CM, Cooper DA, LaBar KS, McCarthy G (2008) Neural systems for executive and emotional processing are modulated by symptoms of posttraumatic stress disorder in Iraq War 
veterans. Psychiatry Research: Neuroimaging 162, 59-72.

Ouimette. P., Coolhart, D., Schum Funderburk, J., Wade, M., \& Brown P. J. (2007). Precipitants of first substance use in recently abstinent substance use disorder patients with PTSD. Addictive Behaviors, 32, 1719-1727.

Rauch SL, Whalen PJ, Shin LM, McInerney SC, Macklin ML, Lasko NB, Orr SP, Pitman RK (2000) Exaggerated amygdala response to masked facial stimuli in posttraumatic stress disorder: a functional MRI study. Biological Psychiatry 47, 769-776.

Sabatinelli D, Fortune EE, Li Q, Siddiqui A, Krafft C, Oliver WT, Beck S, Jeffries J (2011) Emotional perception: meta-analyses of face and natural scene processing. NeuroImage 54:2524-2533.

Schafer, I., \& Najavits, L. M. (2007). Clinical challenges in the treatment of patients with posttraumatic stress disorder and substance abuse. Current Opinion in Psychiatry, 20(6), 614-618.

Shin LM, Whalen PJ, Pitman RK, Bush G, Macklin ML, Lasko NB, Orr SP, McInerney SC, Rauch SL (2001) An fMRI study of anterior cingulate function in posttraumatic stress disorder. Biological Psychiatry 50:932-942.

Shin LM, Wright CI, Cannistraro PA, Wedig MM, McMullin K, Martis B, Macklin ML, Lasko NB, Cavanagh SR, Krangel TS, Orr SP, Pitman RK, Whalen PJ, Rauch SL (2005) A functional magnetic resonance imaging study of amygdala and medial prefrontal cortex responses to overtly presented fearful faces in posttraumatic stress disorder. Archives of General Psychiatry 62:273-281.

Whalen PJ, Rauch SL, Etcoff NL, McInerney SC, Lee MB, Jenike MA (1998) Masked presentations of emotional facial expressions modulate amygdala activity without explicit knowledge. J Neurosci 18, 411-418.

\section{Appendix:}

Forster, G., Novick, A., Scholl, J., Watt, M. (2012). The role of the amygdala in anxiety disorders. In Ferry, B (Ed.), The Amygdala - A Discrete Multitasking Manage (pp. 61-102). Rejeka: InTech. 


\title{
The Role of the Amygdala in Anxiety Disorders
}

\author{
Gina L. Forster, Andrew M. Novick, Jamie L. Scholl and Michael J. Watt
}

Additional information is available at the end of the chapter

http://dx.doi.org/10.5772/50323

\section{Introduction}

\subsection{Defining anxiety and fear}

Anxiety is a term often used to encompass feelings of apprehension, dread, unease or similarly unpleasant emotions. Trait anxiety defines the affect of an organism over time and across situations, whereas state anxiety is the response or adaptation to a given situation [1]. Anxiety can be differentiated from fear, both biologically and behaviorally [see 1 for an extensive review]. Converging theories and evidence from clinical psychology and comparative neuroscience suggest that fear can be considered a negatively-valenced emotion that is brief, focused on the present, occurs in situations of specific threat, and aids in avoidance or escape [1,2]. Anxiety, on the other hand, is a negatively-valenced emotion that is characterized by sustained hyperarousal in response to uncertainty, is thus futurefocused, and aids in defensive approach or risk assessment [1,2]. Both anxiety and fear are emotions experienced by all individuals and can serve to be adaptive in shaping decisions and behaviors related to survival of an organism [1,3]. However, when excessive, or pathological, or triggered inappropriately, fear and anxiety form the basis of a variety of anxiety disorders [3,4,5; Table 1]. As illustrated by Table 1, some anxiety disorders such as generalized anxiety disorder (GAD) or obsessive-compulsive disorder (OCD) are characterized by excessive anxiety as defined above [1]. However, other anxiety disorders are characterized, at least in part, by excessive and inappropriate fear, such as posttraumatic stress disorder (PTSD), specific phobias and social anxiety disorder [1,3; Table 1]. Thus, it is important to understand the neurobiology of both anxiety and fear to obtain a comprehensive picture of the physiological basis of anxiety disorders.

\subsection{Anxiety disorders}

One in three people will develop one of the anxiety disorders outlined by Table 1 within their life-time, with the life-time prevalence at least two times more likely for women $[5,6]$. 
Furthermore, individuals may present with one or more comorbid anxiety disorders, and anxiety disorders are highly likely to be comorbid with other psychiatric illnesses, such as major depressive disorder, psychosis, mania, and substance abuse disorder [4-6]. Several non-psychiatric disorders are also associated with anxiety disorders, and these include hyperthyroidism, Cushing's disease and mitral value prolapse [4,5]. Thus, anxiety disorders are one of the most prevalent psychiatric disorders, posing great personal, economic, and societal burdens [4-6].

\section{Generalized Anxiety Disorder (GAD)}

Excessive worry occurring more days than not over at least a 6 month period, accompanied by restlessness, fatigue, sleep disturbances, muscle tension or irritability.

\section{Posttraumatic Stress Disorder (PTSD)}

Characterized by a history of trauma and symptoms related to avoidance, re-experiencing, and physiological hyperarousal in the face of triggering cue.

\section{Obsessive-Compulsive Disorder (OCD)}

Compulsions (repeated actions) produced to reduce anxiety associated with obsessions (unwanted, intrusive thoughts).

\section{Panic Disorder}

Characterized by panic attacks; a period of intense fear or discomfort accompanied by a variety of physiological symptoms (e.g. sweating, trembling, chest pains, tachycardia).

\section{Agoraphobia}

Fear and avoidance of situations from which escape would be difficult in the event of having panic-like symptoms.

\section{Specific Phobia}

Excessive or unreasonable fear in anticipation or in response to a specific object or situation.

\section{Social Anxiety Disorder (Social Phobia)}

Excessive/unreasonable fear and avoidance of social situations (including performances) in which the person is exposed to unfamiliar people or possible scrutiny by others.

Table 1. Major Classes of Anxiety Disorders [4,5,7]

\subsection{Goals of the current review}

The neurobiological bases of anxiety and fear appear to be very similar across species [1], thus complementary findings from both animal models (most often rodents) and human studies can contribute to theories of the neurobiological basis of anxiety disorders. State fear within animal models is most often studied by measures of freezing and fear-potentiated startle, both acquired via classical conditioning of rodents [1,8]. State anxiety, on the other hand, is most often studied using apparatus such as an open field, elevated plus maze, or light-dark box, which all take advantage of the rodent's preference for familiar, dark, and/or enclosed areas [1,9]. Notably, these paradigms do not rely on the processes underlying classical conditioning, although McNaughton and Corr [2] caution against defining fear verses anxiety as conditioned versus unconditioned responses. While trait fear is not well- 
defined by animal studies [1], trait anxiety is often examined in animal models by the use of selective breeding, resulting in high- and low-anxiety strains and lines of rodents [for example, see 1, 10]. However, one can argue that experimental manipulations (such as earlylife stress or amphetamine withdrawal) that drive a group of animals towards greater fearand anxiety-like phenotypes also examine the underlying basis of trait fear or anxiety [e.g. 11, 12]. As noted by Sylver et al [1] clinical studies most often examine trait anxiety, whereas experiments involving animal models most often focus on state anxiety and fear, and then relate these findings to concepts associated with trait anxiety. Regardless, both human and animal studies suggest an important role for the amygdala, and subregions within, in mediating fear and anxiety, and in the manifestation of anxiety disorders (Sections 2 and 3). Therefore, the goals of this review are to first evaluate and integrate classical and recent findings from human studies and relevant animal models that reveal the specific role the amygdala plays in fear and anxiety, and then to elucidate how anxiolytic drugs may affect the amygdala function to ameliorate heightened fear and/or anxiety. This is important, given that traditional drug and cognitive behavioral therapy (CBT) are effective in reducing symptoms of the various anxiety disorders for many individuals, but often do not provide long-term relief, and relapse is a common post-treatment outcome [as reviewed by 3]. Therefore, the final goal of the current review is to identify future potential therapeutic targets for the treatment of anxiety disorders.

\section{Human imaging studies: Amygdala hyperfunction and anxiety disorders}

\subsection{Amygdala reactivity and anxiogenic or fearful stimuli}

Human imaging studies that explore the neurobiological bases of anxiety or fear processing typically use functional magnetic resonance imaging (fMRI) or positron emission tomography (PET) as measures of neural activity or cerebral blood flow. Imaging experiments that are designed to study neural reactivity to fearful stimuli utilize either conditioned fear paradigms similar to those used in animal models, or involve the presentation of unconditioned stimuli such as fearful faces [1]. It has become clear that masked stimuli can elicit conditioned and unconditioned fear responses from human subjects, suggesting unconscious, implicit processing of these cues [as reviewed by 1]. Similarly, increased activity of the amygdala is observed in response to both conditioned and unconditioned fearful stimuli, independent of whether the subject is aware of the stimulus [1,13-16].

Comparable studies that have examined neural correlates of anxiety in healthy controls are limited. One of the reasons for this is that many studies use fearful stimuli, such as the fearful faces or conditioned fear paradigms [1], blurring the distinction between fear and anxiety. Therefore, conclusions regarding neural bases of anxiety are better drawn from studies that include trait anxiety as a variable while utilizing fearful stimuli, or those fewer studies in which an anxiogenic situation is created within the experimental design. Like for studies of fear processing, the majority of these studies show a relationship between trait anxiety and greater amygdala reactivity [as reviewed by 17]. For example, a study of healthy 
subjects found that reactivity of the amygdala was positively correlated with anticipatory anxiety, and when the anticipated event was imminent, amygdala activation positively correlated with the degree of trait anxiety [18]. Furthermore, college students who scored in the upper $15^{\text {th }}$ percentile for trait anxiety show greater amygdala reactivity to emotional faces as compared to students who scored in the normative range, suggesting that anxietyprone individuals have greater amygdala reactivity [19]. A similar hyperactivity of the amygdala in high trait anxiety participants is noted when a masked emotional faces or unattended faces paradigm are used [20,21], suggesting the individual does not need to be aware of the stimulus to exhibit heightened amygdala activity. Interestingly, Etkin et al., [21] differentiate between different subregions of the amygdala (see Section 3.1 for more details on amygdala subregions), with the basolateral amygdala activated during masked presentations of emotional faces while the dorsal/central amygdala was activated during unmasked presentations. Thus, there may be subregion specificity within the amygdala when processing unconscious versus conscious emotionally-valenced stimuli.

When gender has been examined as a factor in populations of healthy subjects, higher trait anxiety is associated with greater amygdala responses to unattended fearful faces in female but not male participants [22]. A further factor potentially mediating the relationship between trait anxiety and amygdala reactivity appears to be perceived social support. To illustrate, Hyde et al. [17] show a positive correlation between the degree of trait anxiety and amygdala reactivity to fearful faces in subjects that report below-average social support, but not in those who report above average support. Related, it is also thought that the degree of social anxiety rather than trait anxiety may be more closely related to amygdala reactivity to emotional faces [23]. These factors, and other similar considerations, may explain why some, but not all, studies show a positive correlation between trait anxiety and amygdala reactivity in non-patient populations [18-21,23].

\subsection{Amygdala reactivity in anxiety disorders}

Hyperactivity of the amygdala in response to negatively-valenced stimuli also appears to be a common finding from a variety of clinical anxiety populations [16]. For example, individuals suffering from social anxiety disorder show heightened amygdala responses to both social and non-social highly emotive stimuli as compared to healthy control groups, with the degree of social anxiety positively correlated with amygdala reactivity [24-27]. Furthermore, activation of the amygdala by non-social stimuli has been correlated with trait anxiety in social anxiety disorder, leading to the conclusion that social anxiety disorder is characterized by a more general dysfunction in emotional processing in addition to altered processing of social stimuli and situations [26]. Importantly, reduced symptoms in a public speaking situation following either CBT or antidepressant treatment was associated with reduced amygdala reactivity [24], further suggesting a tight link between symptomology and amygdala reactivity in social anxiety disorder.

Like social anxiety disorder, a commonly replicated finding from various PTSD populations is hyperactivity of the amygdala in response to masked fearful faces or trauma-related 
stimuli $[3,28,29]$. This manifests as higher amygdala reactivity as compared to non-PTSD groups and/or a positive correlation between severity of PTSD symptoms and amygdala reactivity [28,30-33]. Furthermore, in a group of unmedicated acute PTSD subjects (1 month post trauma), the degree of PTSD symptoms also positively correlated with activity of the amygdala in response to masked fearful faces [34]. Thus, amygdala hyperactivity observed in chronic PTSD appears early in the disorder. However, it should be noted that in these same individuals, the degree of PTSD symptoms negatively correlated with activity in the amygdala in response to unmasked fearful faces [34]. This suggests amygdala hypoactivity in response to consciously-processed fearful stimuli in the early stages of PTSD, further implying a dissociation in amygdala activity in response to consciously-processed versus unconsciously-processed fearful stimuli. Interestingly, activity of the amygdala in response to fearful stimuli might not only be characteristic of PTSD, but might predict treatment outcome. Bryant et al [33] show that individuals diagnosed with PTSD that do not respond to CBT (8 one weekly sessions) show significantly greater pre-treatment amygdala activation in response to masked fearful faces as compared to those PTSD subjects who did respond to $\mathrm{CBT}$, as defined by a $50 \%$ or more reduction in scores on the ClinicianAdministered PTSD Scale (CAPS). Therefore, hyper-function of the amygdala might provide a useful tool for future selections of treatment options for PTSD.

Similar to PTSD and social anxiety disorder, amygdala hyperactivity as a result of highly emotional stimuli presentation or symptom provocation has been observed in specific phobia, panic disorder, and OCD [35-38]. Given the prevalence of GAD, it is surprising that few studies have assessed amygdala reactivity in GAD participants. Somewhat more surprising is that of those studies that have determined amygdala activity in response to emotive stimuli in adult GAD populations, a lack of amygdala hyperactivity has been observed $[27,39,40]$. This stands in contrast to findings from pediatric GAD, where hyperactivity of the amygdala is apparent in response to emotional stimuli and positively correlated with symptom severity [41,42]. However, recent findings examining amygdala function within paradigms that elicit anticipatory anxiety or emotional conflict have implicated a role for amygdala hyper-reactivity in adult GAD populations. For example, Nitschke et al. [43] report greater anticipatory amygdala activation in response to both emotional and neutral images in adult GAD subjects. Furthermore, Etkin et al [44] found that adult participants with GAD exhibited poor performance on a task that involved emotional conflict (incongruent visual emotional stimuli), accompanied by a failure of the frontal cortex to exert negative top-down control of amygdala activity (see Section 3.1 for more on top-down control of the amygdala). Therefore, amygdala hypofunction in adult GAD might be better revealed by imaging studies that create anxiogenic or conflict situations, rather than the standard presentation of fearful stimuli. While this conclusion requires direct testing, the findings that anxiogenic but not fearful stimuli reveal hypofunction of the amygdala in GAD, whereas fearful stimuli consistently elicit amygdala hyper-reactivity in other anxiety disorders (such as social anxiety disorder, PTSD and also pediatric GAD), suggests a neural dichotomy between GAD and other anxiety disorders on the anxiety to fear continuum. 
In summary, there appears to be reasonable overlap across various experimental paradigms and study populations to conclude that the amygdala is reactive to fearful stimuli and anxiogenic situations, and exhibits hyper-function to emotive stimuli, anxiogenic situations and/or symptom provocation in anxiety disorders. However, which neurotransmitters and subregions of the amygdala mediate these responses if often better answered by animal studies, where spatial and neurochemical resolution is greatly improved over human imaging studies.

\section{Amygdala subregions, connectivity, neurotransmission and fear/anxiety}

\subsection{The role of amygdala subregions in mediating fear and anxiety}

As discussed above, hyper-function of the amygdala appears to be a key component of human anxiety disorders. However, the contribution of particular amygdalar subregions in the development and maintenance of this hyperactive state in humans is still being established. Only very recently have refinements in the acquisition and analysis of fMRI data allowed subregion function to be segregated effectively during emotional tasks such as avoidance learning [45] and facial expression recognition [21,46]. Similarly, effective structural identification of human amygdalar subregions and assessment of their functional connectivity using imaging techniques is still fairly new [for example, see 47-51]. Therefore, most of our understanding of causal neurochemical pathways in amygdalar circuitry related to fear and anxiety has derived from extensive studies using rodent and non-human primate models [for example, see 9,52-58].

Anatomical arrangement of the mammalian amygdala appears to have been evolutionarily conserved, with particular subregions being connected to homologous brain structures across species [as reviewed by 59]. The lateral (LA) nucleus of the amygdala is reciprocally connected with the auditory, somatosensory and visual sensory association centers in the temporal and insular cortices [59], and in rats also receives further auditory information via projections from the posterior thalamus $[59,60]$. The medial amygdala (MeA) is reciprocally connected with the accessory olfactory bulb and many hypothalamic and preoptic nuclei [59,61], creating a locus for assimilation of olfactory stimuli and information regarding internal hormonal state [62,63]. Information summated within the LA and MeA is then conveyed to the adjacent basal (B) and accessory basal (AB) nuclei [64], which also receive projections from the CA1 and subiculum areas of the ventral hippocampus [65-67]. The $\mathrm{B} / \mathrm{AB}$ nuclei send excitatory and inhibitory projections back to the LA and MeA $[64,68]$, creating a localized circuit that may assist in fine-tuning the filtering of sensory input into these regions [64]. Excitatory projections from this basolateral (BLA) complex target the central nucleus of the amygdala (CeA) either directly or via a series of GABAergic interneurons known as intercalated (ITC) cells located between the BLA and CeA [69], providing an effective means of gating CeA activity and output through a combination of direct excitation and feed-forward inhibition [64,70,71]. The CeA itself, principally the medial sector, sends GABAergic projections to brainstem, hypothalamic and basal forebrain regions 
that control expression of autonomic, hormonal and behavioral responses to emotive situations 72,73]. It should also be noted that in addition to activating the CeA, the BLA projects to the adjacent bed nucleus of the stria terminalis (BNST), which in turn targets many of the same regions as the CeA to produce similar behavioral and physiological responses [73]. The MeA is also able to regulate these responses not only via its influence on hypothalamic nuclei and brainstem targets, but by modulating activity in the BNST and CeA $[61,64]$.

The functional connectivity between the BLA, MeA and CeA ensures that sensory and contextual information associated with emotional situations, such as fearful or anxiogenic circumstances, is channeled to effector regions to produce appropriate responses necessary for survival. The BLA and CeA, unlike the MeA, do not appear necessary for expression of unconditioned fear responses to olfactory stimuli in rodents, e.g., to novel presentation of predator odor [74-76], although the BLA does appear to play a role in responses to other types of unconditioned stimuli $[77,78]$. However, the functional arrangement of the BLA and CeA with other regions facilitates learning about the situation, such that appropriate reactions are maintained if cues associated with initial exposure are experienced again. The BLA in particular appears to play a crucial role in encoding positive or negative salience to relevant stimuli for future reference, as indicated by numerous studies showing that the BLA is required for fear learning and acquisition of conditioned fear responses [see 56,60]. Once fear conditioning is acquired, the CeA is necessary for expression of the conditioned response [56,60], the magnitude of which will be influenced by BLA gating of CeA activity and output. Similarly, the BLA is needed for acquisition and expression of fear extinction $[79,80]$, which requires a subject to learn that expression of a previously conditioned fear response is no longer necessary when the conditioned stimulus no longer predicts an aversive event $[57,81]$. To achieve this, the BLA must integrate new sensory information (absence of the unconditioned aversive stimulus) that will result in a dampening of CeA excitation. This may result from increased BLA excitation of ITC cells during fear extinction acquisition to enhance feed-forward inhibition of the CeA [79,82,83], followed by structural remodeling within the BLA during consolidation of the extinction memory to inhibit later BLA output [79]. However, while the roles of the BLA and CeA in fear behaviors are well established, their contribution to anxiety is less clear, especially for the CeA. Animal studies suggest that changes in BLA and CeA activity can alter state anxiety [9; also see Section 3.2.]. However, most investigations have focused on the BLA with the exact role of the CeA remaining ill-defined [for example, see 84,85], although it appears that BLA to CeA circuitry can directly regulate anxiety-like behavior as measured on the elevated plus maze [EPM, 86]. This direct control is thought to result from BLA excitation of GABAergic neurons in the lateral CeA to induce feed-forward inhibition of output from the medial CeA [86], similar to that induced by BLA excitation of ITC cells during fear extinction. Thus, suppression of CeA output may be equally important for mediating expression of both fear and anxiety. Alternatively, some studies have suggested that it is BLA activation of the BNST, not of the $\mathrm{CeA}$, that is responsible for mediating anxiety-like behavior as measured using lightpotentiated startle responses in rodents $[56,87,88]$. Startle responses are also potentiated by corticotropin releasing factor (CRF) infused into the BNST [56]. This effect is presumed to result through facilitation of glutamate release from BLA afferents by CRF neurons that 
originate in the lateral CeA $[88,89]$, implying that even if BNST is the principal output center for certain types of anxiety-like behaviors, the CeA may still play some modulatory role. Furthermore, the MeA has been strongly implicated in animal models of state anxiety [for example, see 90-93 and see Section 3.2], but whether its effects involve modulation of CeA activity is unknown. To direct translational research into the neurological underpinning of anxiety disorders more effectively, animal studies employing as wide a range of state anxiety paradigms as possible, along with animal models that generate trait anxiety, are required to establish the exact nature of $\mathrm{CeA}$ involvement and of amygdala subregion interplay in mediating anxiety-like behavior.

It is important to remember that while the amygdala can mediate fear and anxiety-like behavior, other brain regions play a major role in expression of these states, presumably by influencing activity in particular amygdalar subregions to alter the balance of output from the CeA. For example, input from the ventral hippocampus to the $\mathrm{B} / \mathrm{AB}$ nuclei within the BLA is required for expression of conditioned fear responses to contextual cues in rodents and humans $[60,94,95]$, and so receipt of this information presumably increases BLA activity, to in turn enhance CeA output in the aversive context. In rodents, the ventromedial prefrontal cortex (vmPFC) also appears to be crucial in regulating amygdalar activity, especially during fearful experiences [79]. The prelimbic (PL) subregion of the vmPFC can enhance conditioned fear expression via excitatory projections to the BLA and CeA [96-98]. In contrast, expression of conditioned fear appears to be decreased by activation of the infralimbic (IL) subregion of the vmPFC [99, but see 100]. The IL cortex is also required for effective consolidation and recall of fear extinction memories [79,98]. Both decreased conditioned fear responding and fear extinction require suppression of CeA output, which is thought to result in part via IL cortex stimulation of the series of inhibitory ITC cells that project to the CeA $[71,79,96,101]$. The bidirectional roles of the PL and IL cortices in regulating conditioned fear through opposing influences on CeA activity and output imply that imbalance in the influence of either cortical structure could contribute to amygdala hyperactivity seen in anxiety disorders characterized by excessive and inappropriate fear (see Table 1). This is supported by fMRI studies investigating neural correlates of impaired fear extinction in PTSD patients, who compared to healthy subjects show hyperactivity of the amygdala during extinction learning [102]. This enhanced amygdala function in PTSD patients is accompanied by greater activation of the dorsal anterior cingulate cortex (dACC, functionally equivalent to the rodent PL cortex, [3,57], which is also present during recall of the extinction memory [102]. This is in line with rodent studies demonstrating potentiated fear conditioning upon PL cortex activation [98]. However, PTSD individuals exhibit hypoactivation of the ventral portion of the vmPFC (equivalent to rodent IL cortex, [3,57]) during extinction learning and recall $[102,103]$. Human imaging studies also suggest that impaired regulation of amygdala activity by the ventral vmPFC may contribute to anxiety disorders characterized by hypervigilance in the absence of conditioned stimuli, such as in GAD. Specifically, the strength of the connection between the vmPFC and the amygdala, as measured using diffusion tensor imaging, predicts levels of self-reported trait anxiety, such that weaker connections are seen in more anxious individuals [104]. As mentioned earlier (Section 2.2), participants with GAD exhibited a failure of the vmPFC to exert negative top- 
down control of amygdala activity during a task that involved emotional conflict [44]. Further, resting state fMRI revealed that in anxious individuals, vmPFC activity was negatively correlated with amygdala activity, while a positive relationship was observed for low anxious subjects [105]. The combination of animal and human studies strongly indicates that inadequate suppression by the ventral portion of the vmPFC, most likely of the CeA, is a key factor in amygdala hyperactivity underlying the emergence of excessive fear and anxiety states.

\subsection{Monoaminergic neurotransmission in the amygdala: Relation to fear and anxiety}

The monoamine neurotransmitters (serotonin, dopamine and norepinephrine) have long been associated with fear and anxiety, and drugs that alter monoaminergic function are often effective across the range of anxiety disorders [8, 9, 52, 55]. Animal studies suggest a variety of anxiogenic stressors or fearful stimuli increase monoamine levels in the amygdala. To illustrate, increased serotonin (5-HT) release or increased activity of 5-HT neurons in the amygdala have been observed in response to restraint or footshock, or in association with expression of conditioned fear behavior [106-110]. Similarly, dopamine (DA) and norepinephrine (NE) levels in the amygdala are increased following restraint, handling stress, footshock or during the expression of conditioned fear behavior [107,111-118]. The source of monoamines to the amygdala arise from monoaminergic cell body regions in the brainstem. Specifically, the dorsal raphe nucleus (dRN) provides 5-HT innervation to the amygdala, while NE and DA innervation of the amygdala arise from the locus coeruleus (LC) and ventral tegmental area (VTA) respectively $[55,119,120]$. Regulation of monoaminergic activity in the amygdala thus can occur at the level of these brainstem cell body regions, or within the terminal regions of the amygdala.

One of the important mediators of amygdala monoaminergic activity in response to anxiogenic or fearful stimuli is CRF. A strong body of evidence implicates central CRF in mediating fear and anxiety [12,121-128], and recent clinical studies suggest an important role for CRF in anxiety disorders [129]. Like anxiogenic and fearful stimuli, central infusion of CRF or CRF receptor agonists increases 5-HT, NE and DA levels in the amygdala [130133], and stress-induced increases in monoamine levels in the amygdala are prevented by CRF receptor antagonists $[108,111]$. It is thought that CRF regulation of monoaminergic activity in the amygdala occurs at the level of the monoaminergic cell bodies. The monoaminergic cell body regions receive CRF innervation from the CeA and BNST, and CRF type 1 and $2\left(\mathrm{CRF}_{1}\right.$ and $\left.\mathrm{CRF}_{2}\right)$ receptors are localized to the dRN, LC and VTA [134140]. Direct infusion of CRF or CRF receptor agonists into the dRN stimulates 5-HT release in the CeA or BLA [131-133]. Interestingly, CRF-induced 5-HT release in the amygdala appears to be dependent on $\mathrm{CRF}_{2}$ receptor activation in the $\mathrm{dRN}$ [131,133], and $\mathrm{CRF}_{2}$ receptors are known to increase 5-HT neuronal firing rates in the dRN [141]. Importantly, increased neuronal surface expression of $\mathrm{CRF}_{2}$ receptors occurs in the $\mathrm{dRN}$ as a result of stress [142], and increased expression of $\mathrm{CRF}_{2}$ receptors in the $\mathrm{dRN}$ has been observed in rat models of high anxiety [11,128,137,143]. Furthermore, $\mathrm{CRF}_{2}$ receptor antagonists infused 
directly into the $\mathrm{dRN}$ reduce heightened anxiety-like behavior in rat models of amphetamine withdrawal or early life stress $[12,128]$. Combined, these findings suggest that $\mathrm{CRF}_{2}$ receptor modulation of $5-\mathrm{HT}$ activity in the amygdala may play an important role in heightened anxiety. While similar studies have not been performed to elucidate the role of CRF receptors in the LC and VTA in mediating NE and DA activity in the amygdala and anxiety states, some indirect evidence suggests an important role for CRF receptors in the LC and VTA stress responses [136,138,144]. Overall, it is clear that further investigations are needed to ascertain the role of CRF receptors in mediating NE and DA activity in the amygdala and how CRF modulation of this activity could relate to fear or anxiety.

Studies demonstrating increased monoamine activity in the amygdala in response to anxiogenic or fearful stimuli, and CRF modulation of these responses (as described above) do not allow conclusions to be made about the specific role of each monoamine in mediating anxiety or fear. Direct manipulation of monoaminergic activity within the amygdala or specific amygdala subregions, and the measurement of resultant anxiety-like or fear-related behaviors, have gone some way to providing a picture of how monoamine function in the amygdala might translate to anxiety or fear. Table 2 summarizes such studies directly manipulating 5-HT levels or 5-HT receptor activity in the amygdala. When 5-HT or 5-HT activity is decreased in the entire amygdala [145,146], a consistent increase in anxiety-like behavior is observed (Table 2). This would suggest that increased 5-HT activity in the amygdala would thus be associated with decreased anxiety, implying an anxiolytic role of 5HT. However, this does not appear to be supported by experiments that directly manipulate 5-HT receptor activity in the amygdala with 5-HT receptor ligands (Table 2). For example, activation of postsynaptic excitatory $5-\mathrm{HT}_{2}$ or $5-\mathrm{HT}_{3}$ receptors in the amygdala decreases social interaction and increases anxiety-like behavior, whereas antagonism of 5- $\mathrm{HT}_{3}$ receptors in particular increases social interaction and decreases anxiety-like behaviors, suggesting that 5-HT actions on postsynaptic receptors is anxiogenic (Table 2), although, see [147] for an exception to this pattern. Similarly, activation of excitatory $5 \mathrm{HT}_{2}$ receptors in the BLA generally increases anxiety-like behavior (Table 2), suggesting an anxiogenic role for postsynaptic 5-HT receptors in the BLA (although an exception to this is observed, [148]). In contrast, inhibitors of $5-\mathrm{HT}_{2}$ receptors in the MeA increase anxiety-like behavior while activation of these receptors increases social interaction and decreases anxiety behavior (Table 2). Thus like the some findings from the amygdala as a whole (Table 2), 5-HT activity in the MeA appears to play an anxiolytic role. The role of 5-HT or 5-HT receptors has not been well studied in the CeA. However, rats undergoing amphetamine withdrawal that exhibit greater anxiety-like behavior have greater 5-HT release in the CeA [12,133], suggesting a similar anxiogenic relationship between 5-HT and anxiety as for the BLA. Future work should determine whether $5-\mathrm{HT}$ in the CeA reduces anxiety-like behaviors as is suggestive for the MeA, or in contrast, increases anxiety-like behaviors as appears to be the case for the BLA. Overall, the findings summarized in Table 2 suggest a dichotomy in the potential role of 5-HT in the amygdala in mediating anxiety depending on whether the entire amygdala or a specific subregion is targeted. Potential confounds in comparing the studies listed in Table 2 could be the different paradigms used to measure anxiety-like 
behaviors and the relative selectivity of 5-HT receptor ligands across different experiments. Future studies directly comparing the effects of 5-HT manipulations within the different amygdala subregions across several well-validated tests of anxiety-like behaviors will better elucidate the role of amygdala 5-HT in mediating anxiety.

\begin{tabular}{|c|c|c|c|}
\hline Amygdala Subregion & $\begin{array}{l}\text { Monoamine or } \\
\text { Receptor Involvement }\end{array}$ & Behavioral Outcome & Citation \\
\hline \multicolumn{4}{|l|}{ Anxiety-like Behavior } \\
\hline Amygdala & $\begin{array}{l}\text { Decreased 5-HT } \\
\text { (induced by MDMA) }\end{array}$ & $\begin{array}{l}\text { Increased anxiety } \\
\text { behavior }\end{array}$ & Faria et al. [145] \\
\hline Amygdala & $\begin{array}{l}\text { Decreased 5-HIAA } \\
\text { (induced by stress) }\end{array}$ & $\begin{array}{l}\text { Increased anxiety } \\
\text { behavior }\end{array}$ & Niwa et al. [146] \\
\hline Amygdala & 5-HT1A agonist & $\begin{array}{l}\text { No change in anxiety } \\
\text { behavior }\end{array}$ & $\begin{array}{l}\text { Zangrossi and Graeff } \\
\text { [149] }\end{array}$ \\
\hline Amygdala & 5- $\mathrm{HT}_{2 \mathrm{~B} / 2 \mathrm{C}}$ agonist & $\begin{array}{l}\text { Increased anxiety } \\
\text { behavior }\end{array}$ & $\begin{array}{l}\text { Cornelio and Nunes- } \\
\text { De-Souza [150] }\end{array}$ \\
\hline Amygdala & 5- $\mathrm{HT}_{3}$ agonist & $\begin{array}{l}\text { Decreased social } \\
\text { interaction }\end{array}$ & Higgans et al. [151] \\
\hline Amygdala & 5- $\mathrm{HT}_{3}$ agonist & $\begin{array}{l}\text { Decreased anxiety } \\
\text { behavior }\end{array}$ & Costall et al. [147] \\
\hline Amygdala & 5-HT3 antagonist & $\begin{array}{l}\text { Increased social } \\
\text { interaction }\end{array}$ & Higgans et al. [151] \\
\hline Amygdala & 5- $\mathrm{HT}_{3}$ antagonist & $\begin{array}{l}\text { Decreased anxiety } \\
\text { behavior }\end{array}$ & Costall et al. [147] \\
\hline Amygdala & 5- $\mathrm{HT}_{3}$ antagonist & $\begin{array}{l}\text { Decreased anxiety } \\
\text { behavior }\end{array}$ & Tomkins et al. [152] \\
\hline BLA & 5- $\mathrm{HT}_{1 \mathrm{~A}}$ agonist & $\begin{array}{l}\text { Decreased social } \\
\text { interaction }\end{array}$ & Gonzalez et al. [153] \\
\hline BLA & 5-HT $1 \mathrm{~A}$ agonist & $\begin{array}{l}\text { No change in anxiety } \\
\text { behavior }\end{array}$ & Gonzalez et al. [153] \\
\hline BLA & 5- $\mathrm{HT}_{2 \mathrm{~A}}$ agonist & $\begin{array}{l}\text { Increased anxiety } \\
\text { behavior }\end{array}$ & $\begin{array}{l}\text { Zangrossi and Graeff } \\
\text { [149] }\end{array}$ \\
\hline BLA & $5-\mathrm{HT}_{2 \mathrm{~A}} / 2 \mathrm{C}$ agonist & $\begin{array}{l}\text { No change in anxiety } \\
\text { behavior }\end{array}$ & Cruz et al [148] \\
\hline BLA & 5- $\mathrm{HT}_{2 \mathrm{C}}$ agonist & $\begin{array}{l}\text { Increased anxiety } \\
\text { behavior }\end{array}$ & Vincente et al. [154] \\
\hline $\mathrm{MeA}$ & 5-HT2A antagonist & $\begin{array}{l}\text { Increased anxiety } \\
\text { behavior }\end{array}$ & $\begin{array}{l}\text { Zangrossi and Graeff } \\
\text { [149] }\end{array}$ \\
\hline $\mathrm{MeA}$ & 5- $\mathrm{HT}_{2}$ agonist & $\begin{array}{l}\text { No change in anxiety } \\
\text { behavior }\end{array}$ & Duxon et al. [155] \\
\hline $\mathrm{MeA}$ & 5- $\mathrm{HT}_{2 \mathrm{~B}}$ agonist & $\begin{array}{l}\text { Increased social } \\
\text { interaction }\end{array}$ & Duxon et al. [156] \\
\hline $\mathrm{MeA}$ & 5- $\mathrm{HT}_{2 \mathrm{~B}}$ agonist & $\begin{array}{l}\text { Decreased anxiety } \\
\text { behavior }\end{array}$ & Duxon et al. [155] \\
\hline
\end{tabular}




\begin{tabular}{|c|c|c|c|}
\hline Amygdala Subregion & $\begin{array}{l}\text { Monoamine or } \\
\text { Receptor Involvement }\end{array}$ & Behavioral Outcome & Citation \\
\hline $\mathrm{MeA}$ & 5- $\mathrm{HT}_{2 \mathrm{~B} / 2 \mathrm{C}}$ agonist & $\begin{array}{l}\text { No change in anxiety } \\
\text { behavior }\end{array}$ & Duxon et al. [155] \\
\hline \multicolumn{4}{|l|}{ Fear-related Behavior } \\
\hline $\mathrm{CeA}$ & Increased 5-HT & $\begin{array}{l}\text { Increased } \\
\text { unconditioned } \\
\text { freezing }\end{array}$ & Forster et al. [132] \\
\hline BLA & Increased 5-HT & $\begin{array}{l}\text { Decreased } \\
\text { conditioned freezing }\end{array}$ & Inoue et al. [157] \\
\hline BLA & Increased 5-HT & $\begin{array}{l}\text { Decreased } \\
\text { unconditioned tonic } \\
\text { immobility }\end{array}$ & $\begin{array}{l}\text { Leite-Panissi et al. } \\
\text { [158] }\end{array}$ \\
\hline BLA & 5-HT1A agonist & $\begin{array}{l}\text { Decreased } \\
\text { conditioned freezing }\end{array}$ & Li et al. [159] \\
\hline BLA & 5-HT1A agonist & $\begin{array}{l}\text { Decreased acquisition } \\
\text { and expression of } \\
\text { conditioned defeat }\end{array}$ & Morrison et al. [160] \\
\hline BLA & 5-HT1A/2 agonist & $\begin{array}{l}\text { Decreased } \\
\text { unconditioned tonic } \\
\text { immobility }\end{array}$ & $\begin{array}{l}\text { Leite-Panissi et al. } \\
\text { [158] }\end{array}$ \\
\hline
\end{tabular}

Abbreviations: 5-HIAA = 5-Hydroxyindoleacetic acid (5-HT metabolite); 5-HT = serotonin; BLA = basolateral amygdala; $\mathrm{CeA}=$ central nucleus of the amygdala; $\mathrm{MDMA}=3,4$-methylenedioxy-N-methylamphetamine; $\mathrm{MeA}=$ medial amygdala.

Table 2. The Role of Serotonin in Anxiety-Like and Fear-Related Behaviors

Determining the role of amygdala 5-HT in fear-related behavior has mainly utilized studies of freezing or immobility responses in rodents, and of 5-HT manipulation in the BLA (Table 2). From these studies, it seems clear that 5-HT in the BLA decreases the expression of unconditioned and conditioned fear responses, likely via activation of the inhibitory postsynaptic $5-\mathrm{HT}_{1 \mathrm{~A}}$ receptor (Table 2). Thus, it has been suggested that $5-\mathrm{HT}$ in the BLA/amygdala ameliorates fear [8]. This conclusion is in contrast to the apparent role for BLA 5-HT in enhancing anxiety (Table 2), suggesting a fear versus anxiety dissociation for the role of 5-HT in the BLA. This dissociation, if upheld by more in-depth future work, could prove important information for the development of treatment strategies for the various anxiety disorders that differ in the degree of anxiety-like and fear-like symptomology (as discussed in Section 1.1).

A role for amygdala DA in anxiety has not been as well explored as for 5-HT. However, a summary of studies that have manipulated DA function in the amygdala provides a consistent picture of the role of amygdala DA in mediating anxiety in animal models (Table 3). Indirect evidence suggests that decreased DA in the amygdala leads to increased anxiety, and this is supported by direct manipulation of the CeA (Table 3). For example, decreased DA or DA receptor antagonism within the CeA all increase anxiety-like behavior (Table 3), 
suggesting that DA activity in the CeA is anxiolytic. This role for DA in the CeA is in direct contrast to the BLA, where converging evidence suggests that decreased DA function in the BLA decreases anxiety-like behaviors while increased DA receptor activity in the BLA increases anxiety (Table 3). Thus, DA activity in the BLA is anxiogenic, revealing an opposite role for DA activity in the CeA and BLA in mediating anxiety-like behaviors in animal models.

\section{Monoamine or}

Amygdala Subregion Receptor Involvement Behavioral Outcome Citation

Anxiety-like Behavior

Amygdala Decreased DA

Decreased rearing in Summavielle et al. open field indicative [163]

of increased anxiety

behavior

\begin{tabular}{|c|c|c|c|}
\hline $\mathrm{CeA}$ & Decreased DA & $\begin{array}{l}\text { Decreased voluntary } \\
\text { activity indicative of } \\
\text { increased anxiety } \\
\text { behavior }\end{array}$ & Izumo et al. [164] \\
\hline $\mathrm{CeA}$ & $\mathrm{D}_{1}$ antagonist & $\begin{array}{l}\text { Increased anxiety } \\
\text { behavior }\end{array}$ & Rezayof et al. [165] \\
\hline $\mathrm{CeA}$ & $\mathrm{D}_{2 / 3}$ antagonist & $\begin{array}{l}\text { Increased anxiety } \\
\text { behavior }\end{array}$ & de la Mora et al. [166] \\
\hline BLA & DA depletion & $\begin{array}{l}\text { Decreased anxiety in } \\
\text { males but not females }\end{array}$ & Sullivan et al. [167] \\
\hline BLA & $\mathrm{D}_{1}$ agonist & $\begin{array}{l}\text { Increased anxiety } \\
\text { behavior }\end{array}$ & Banaej et al. [168] \\
\hline BLA & $\mathrm{D}_{2}$ agonist & $\begin{array}{l}\text { Increased anxiety } \\
\text { behavior }\end{array}$ & Banaej et al. [168] \\
\hline BLA & $\mathrm{D}_{1}$ antagonist & $\begin{array}{l}\text { Decreased anxiety } \\
\text { behavior }\end{array}$ & Banaej et al. [168] \\
\hline BLA & $\mathrm{D}_{1}$ antagonist & $\begin{array}{l}\text { Decreased anxiety } \\
\text { behavior }\end{array}$ & de la Mora et al. [169] \\
\hline BLA & $\mathrm{D}_{2}$ antagonist & $\begin{array}{l}\text { Decreased anxiety } \\
\text { behavior }\end{array}$ & Banaej et al. [168] \\
\hline \multicolumn{4}{|c|}{ Fear-related Behavior } \\
\hline Amygdala & $\mathrm{D}_{2}$ antagonist & $\begin{array}{l}\text { Decreased acquisition } \\
\text { and retention of fear } \\
\text { conditioning }\end{array}$ & Greba et al. [170] \\
\hline $\mathrm{CeA}$ & $\mathrm{D}_{1}$ agonist & $\begin{array}{l}\text { Increased conditioned } \\
\text { fear behavior }\end{array}$ & Guarraci et al. [171] \\
\hline $\mathrm{CeA}$ & $\mathrm{D}_{1}$ antagonist & $\begin{array}{l}\text { Inhibited conditioned } \\
\text { fear behavior }\end{array}$ & Guarraci et al. [171] \\
\hline $\mathrm{CeA}$ & $\mathrm{D}_{2}$ antagonist & Decreased & Guarraci et al. [172] \\
\hline
\end{tabular}




\begin{tabular}{llll} 
Amygdala Subregion & $\begin{array}{l}\text { Monoamine or } \\
\text { Receptor Involvement }\end{array}$ & Behavioral Outcome & Citation \\
BLA & DA depletion & $\begin{array}{l}\text { conditioned fear } \\
\text { behavior } \\
\text { Decreased fear } \\
\text { conditioning }\end{array}$ & Seldon et al. [173] \\
BLA & $\mathrm{D}_{1}$ antagonist & $\begin{array}{l}\text { Inhibited acquisition } \\
\text { of fear conditioning }\end{array}$ & $\begin{array}{l}\text { Greba and Kokkinidis } \\
\text { [174] }\end{array}$ \\
BLA & $\mathrm{D}_{2}$ antagonist & $\begin{array}{l}\text { Inhibited fear } \\
\text { potentiated startle }\end{array}$ & De Oliveira et al. [175] \\
\hline
\end{tabular}

Abbreviations: $\mathrm{BLA}=$ basolateral amygdala; $\mathrm{CeA}=$ central nucleus of the amygdala; $\mathrm{DA}=$ dopamine.

Table 3. The Role of Dopamine in Anxiety-Like and Fear-Related Behaviors

In contrast, the role of DA in mediating fear-related behaviors does not appear to differ based on amygdala subregion (Table 3). Reducing DA function in the amygdala reduces or inhibits processes associated with fear conditioning, while increasing DA receptor activity increases conditioned fear (Table 3). Thus, DA in the amygdala is required for fear conditioning, and enhanced DA levels in the amygdala as elicited by fearful stimuli and conditioned cues $[107,112]$ would thus facilitate fear conditioning. It should be noted that the studies summarized by Table 3 indicate a role for both excitatory D 1 receptors and inhibitory $\mathrm{D}_{2}$ receptors. Dopamine $\mathrm{D}_{2}$ receptors are localized both pre- and postsynaptically, with pre-synaptic $\mathrm{D}_{2}$ autoreceptors limiting DA neuronal activity and DA release $[161,162]$. Thus, antagonism of presynaptic $\mathrm{D}_{2}$ receptors would actually increase DA within the amygdala. Since the effects of $\mathrm{D}_{2}$ receptor antagonism on fear-related behaviors is characteristic of reduced, not enhanced, DA function in the amygdala, it may be concluded that the results of $\mathrm{D}_{2}$ receptor antagonism summarized by Table 3 are due to postsynaptic $\mathrm{D}_{2}$ receptor effects. However, this conclusion requires direct testing.

Very few studies have examined the role of amygdala NE in mediating anxiety-like behavior in animal models, surprising given that anxiogenic stimuli increase NE in this region [for example, see 111,115,116] and drugs that alter NE neurotransmission are used to treat anxiety disorders [8]. There appears to be little role for NE receptors in the CeA in mediating anxiety-like behavior, although infusion of a $\alpha_{1}$ antagonist can increase social interaction following an anxiogenic stimulus [restraint; 176; Table 4]. It is clear that more experiments are required to delineate the role of amygdala NE in mediating anxiety.

Studies determining the role of NE in fear-related behaviors have concentrated on the BLA, due to the importance of this amygdala subregion in conditioned fear responses (see Section 3.1.). The major focus of the studies summarized by Table 4 has been on the role of NE in fear conditioning and reconsolidation of fear memories in conditioned fear paradigms. Taken as a whole, findings suggest that NE in the BLA facilitates fear conditioning and fear memory, via activation of adrenergic $\beta$ receptors (Table 4). Recent evidence suggests a role for $\alpha_{1}$ receptors in the BLA in mediating fear memory, in this case, activation of $\alpha_{1}$ receptors by NE would appear to decrease fear memory (Table 4). Thus, it is possible that NE in the 
BLA could have opposing effects on reconsolidation of fear memory based on the balance of $\alpha_{1}$ versus $\beta$ receptor activity - a hypothesis that requires direct testing. The role of NE in the BLA (and $\beta$ receptors in particular) in fear memory has generated interest in targeting this NE system for the treatment of anxiety disorders where enhancement in fear memory is apparent, such as PTSD [for example, see 177]. Whether NE within the BLA plays a role in other aspects of fear processing (e.g. unconditioned fear responses to non-olfactory based stimuli) or NE within other amygdala subregions mediate fear should be subjects of future investigations to fully elucidate the role of amygdala NE in fear.

\begin{tabular}{|c|c|c|c|}
\hline Amygdala Subregion & $\begin{array}{l}\text { Monoamine or } \\
\text { Receptor Involvement }\end{array}$ & Behavioral Outcome & Citation \\
\hline \multicolumn{4}{|l|}{ Anxiety-like Behavior } \\
\hline $\mathrm{CeA}$ & $\alpha_{1}$ antagonist & $\begin{array}{l}\text { Increased social } \\
\text { interaction }\end{array}$ & Cecchi et al. [176] \\
\hline $\mathrm{CeA}$ & $\alpha_{1}$ antagonist & $\begin{array}{l}\text { No effect on anxiety } \\
\text { behavior }\end{array}$ & Cecchi et al. [176] \\
\hline $\mathrm{CeA}$ & $\beta_{1 / 2}$ antagonist & $\begin{array}{l}\text { No effect on social } \\
\text { interaction }\end{array}$ & Cecchi et al. [176] \\
\hline $\mathrm{CeA}$ & $\beta_{1 / 2}$ antagonist & $\begin{array}{l}\text { No effect on anxiety } \\
\text { behavior }\end{array}$ & Cecchi et al. [176] \\
\hline \multicolumn{4}{|l|}{ Fear-related Behavior } \\
\hline BLA & Increased NE & $\begin{array}{l}\text { Increased memory } \\
\text { and retention of fear } \\
\text { conditioning }\end{array}$ & LaLumiere et al. [178] \\
\hline BLA & Decreased NE & $\begin{array}{l}\text { Impaired fear } \\
\text { conditioning }\end{array}$ & Seldon et al. [173] \\
\hline BLA & Decreased NE & $\begin{array}{l}\text { Impaired fear } \\
\text { memory }\end{array}$ & $\begin{array}{l}\text { Debiec and LeDoux } \\
\text { [177] }\end{array}$ \\
\hline BLA & $\alpha_{1}$ antagonist & $\begin{array}{l}\text { Increased fear } \\
\text { memory }\end{array}$ & Lazzaro et al. [179] \\
\hline BLA & $\beta_{1 / 2}$ antagonist & $\begin{array}{l}\text { Impaired of fear } \\
\text { memory }\end{array}$ & $\begin{array}{l}\text { Debiec and LeDoux } \\
\text { [180] }\end{array}$ \\
\hline BLA & $\beta_{1}$ antagonist & $\begin{array}{l}\text { Impaired fear } \\
\text { memory (as enhanced } \\
\text { by glucocorticoids) }\end{array}$ & $\begin{array}{l}\text { Roozendaal et al. } \\
\text { [181] }\end{array}$ \\
\hline
\end{tabular}

Abbreviations: $\mathrm{BLA}=$ basolateral amygdala; $\mathrm{CeA}=$ central nucleus of the amygdala; $\mathrm{NE}=$ norepinephrine.

Table 4. The Role of Norepinephrine in Anxiety-Like and Fear-Related Behaviors

In summary, it is clear that more work is required to fully understand the role of amygdala monoamines in mediating fear and anxiety. However, several patterns of interest emerge from the current literature, namely that there are distinct subregion differences in the role 
each monoamine plays in mediating anxiety and fear, with the one monoamine possibly playing opposing roles depending on subregion or depending on whether anxiety or fear measures are employed. Therefore, these findings suggest neurochemical dissociations between amygdala subregions and monoamines in mediating fear or anxiety.

\section{The amygdala as a potential site of anxiolytic drug action}

Psychopharmacological management of anxiety disorders includes the benzodiazepines, antidepressants, 5-HT1A agonists and various "off-label" drugs such as $\beta$-blockers, mood stabilizers and antipsychotics. The mechanism by which these drugs produce anti-anxiety effects has yet to be definitively established and represents a frequently updated field of research. Because these drugs bind to target receptors throughout the brain, it is unlikely that their efficacy can be attributed to action in one particular region. However, given the role that the amygdala plays in fear and anxiety, modification of amygdala function by pharmacological agents represents a likely mechanism of action as well as a target to guide future drug development. The evidence for amygdala involvement in anxiolytic action comes from both human imaging studies as well as work in animal models.

\subsection{Human imaging studies: Effects of anxiolytics on amygdala activity and emotion}

Given the highly complex and subjective nature of anxiolytic drug response in humans, neuroimaging represents an invaluable tool for drug evaluation and discovery.

Benzodiazepines: Benzodiazepines exert their anxiolytic action through binding to GABAA receptors, which leads to enhanced GABA activity and a subsequent increase in inhibitory tone. Despite the long history and current prevalence of benzodiazepine use for anxiety disorders [182,183], there is a paucity of human neuroimaging studies utilizing this class of drug, especially compared to those using antidepressants. This may have to do with eclipse of benzodiazepines by antidepressants as first line agents for many anxiety disorders [182].

Various studies have utilized healthy volunteers undergoing experimental challenges in an attempt to elucidate the neurobiology underlying the anxiolytic effect of benzodiazepines. These studies have found that benzodiazepines have the ability to impair functions related to amygdala activity including fear conditioning [184-186], recognition of fearful emotional faces [187], and memory for emotional stimuli relative to neutral stimuli [188,189].

Neuroimaging work appears to support a role for the amygdala in benzodiazepine action, although this may be dependent upon the nature of the accompanying neuropsychological challenge. Specifically, lorazepam was found to decrease amygdala activation during an emotional face assessment task without modifying baseline levels of anxiety or task recognition [190]. A similar finding was found with diazepam, which decreased amygdala response to fearful faces, and also impaired fearful face recognition [191]. However, during anticipation of aversive electrical stimulation, lorazepam failed to produce changes in amygdala activity [192]. Thus, while there is support for benzodiazepine induced 
modulation of the amygdala during processing of threatening/emotional stimuli, further studies are needed to clarify the neural correlates of benzodiazepine-induced anxiolysis.

$\beta$-Blockers: The $\beta$-blocker propranolol has a substantial history of being utilized to reduce somatic symptoms of fear and anxiety in situations such as stage fright [193] and acute panic [194-195]. More recently, research on the role of amygdala NE and $\beta$-receptors in facilitating emotional memory formation (see Table 4 and associated text) has caused much excitement and controversy about the use of propranolol to prevent PTSD [196-198]. Thus far, initial trials have demonstrated limited efficacy $[199,200]$. Despite lack of success in the application of propranolol to PTSD, neuroimaging studies in healthy human subjects have confirmed the ability of propranolol to modulate amygdala activation to emotional stimuli. Propranolol was found to decrease amygdala activation to emotional faces irrespective of emotional valence [201]. Furthermore, supporting a role for the amygdala NE in the encoding and consolidation of emotional stimuli, a separate study found that propranolol was able to decrease amygdala reactivity to emotional pictures of high valence as well as decrease the subject's memory for them [202].

Selective Serotonin Re-uptake Inhibitors: Antidepressant drugs, and selective serotonin reuptake inhibitors (SSRIs) in particular, have become first line drugs for many of the anxiety disorders [182,203]. As such, there has been comparatively more work investigating these drugs in humans using advanced imaging techniques.

Most antidepressants are unique from benzodiazepines and $\beta$-blockers in that a time lag exists between initial treatment and onset of anxiolytic effects. In line with a potential anxiogenic role of serotonin in the amygdala (see Table 2 and associated text), some patients have reported an initial exacerbation of anxiety upon acute dosing of SSRIs [203]. In studies on healthy subjects, acute dosing of the SSRI citalopram can enhance recognition of fearful faces as well as increase emotion-potentiated startle response [204-206]. These effects are reversed when citalopram treatment is continued for 7 days $[207,208]$.

Attempts to correlate the acute versus sub-chronic effects of SSRIs with neural activation have resulted in unexpected findings. On one hand, sub-chronic citalopram treatment was found to decrease amygdala activation to unconscious fearful stimuli [209], suggesting a relationship between repeated SSRI treatment, changes in emotional processing, and decreased amygdala activity. However, acute doses of citalopram have also been found to decrease amygdala activation to fearful faces [208,210,211]. Divergent effects of acute versus sub-chronic citalopram on emotional recognition but similar effects on amygdala response could suggest that the amygdala does not play a core role in acute SSRI-induced anxiety or chronic SSRI-induced anxiolysis. However, it has been emphasized that the effects of serotonergic challenge on fear recognition and amygdala activation appear to be dependent upon the individual's baseline sensitivity to threat [212], gender [213] and genotype [214]. Thus differences in subject profiles both between and within studies could have confounded results.

Overall, it appears that pharmacotheraputics commonly used to treat anxiety disorders may modulate amygdala function. In particular, it appears that anxiolytics can reduce amygdala 
reactivity to highly emotive or fearful stimuli. Given that amygdala hyper-reactivity to similar stimuli is the most common finding across all anxiety disorders (with the exception of adult GAD - see Section 2.2), it is possible that the anxiolytic effects of these drugs may be in part, mediated by dampening amygdala function.

\subsection{Evidence delineating effects of anxiolytic drugs on amygdala function in animal models of anxiety states}

Benzodiazepines: While benzodiazepine receptors exist throughout the brain, there is a particularly high density in amygdala regions [215,216]. There is much evidence from animal models to suggest that it is the action of benzodiazepines in the amygdala that mediates their anxiolytic effect. For example, early evidence demonstrated that local amygdala infusion of benzodiazepines produces anxiolytic-like effects in conflict models of anxiety [217-220]. These effects can be reversed by systemic [217,219] or direct amygdala administration of benzodiazepine antagonists [220]. Anti-conflict effects are most apparent when the benzodiazepines are injected into the BLA, and are absent when injected into the CeA $[219,220]$. While anti-conflict effects of benzodiazepines have been observed in the CeA, these were with substantially higher doses [221]. Further studies suggest that the BLA and not the CeA is essential for the anxiolytic effects of benzodiazepines in the EPM $[149,222,223]$. However, with regards to the shock probe burying test, it appears that the $\mathrm{CeA}$ is responsible for benzodiazepine-induced impairment of passive avoidance [223]. Although contradictory results exist on the role of benzodiazepines in the BLA versus CeA, particularly when animals are tested on the EPM $[9,84,224]$ have suggested that distinct benzodiazepine receptor subtypes located within subregions of the amygdala may differentially alter avoidance responses to "potential threat" (EPM and BLA) versus "discrete, unambiguous threat" (shock probe burying and CeA).

As discussed in the human studies in Section 4.1 above [184,188,189], a key aspect of benzodiazepine action may be the ability to modulate emotional memory. Here the BLA once again appears to be a main site of benzodiazepine action. Lesions of the BLA, but not the CeA, block the benzodiazepine induced deficits in inhibitory avoidance memory $[225,226]$. Similar impairments were seen by direct injection of benzodiazepine into the BLA and not the CeA [227]. Enhancement of memory consolidation could be induced by BLA infusion of a benzodiazepine antagonist [228]. Given that individuals with anxiety disorders may be hypervigilant to cues associated with threatening stimuli and biased to form memories regarding such stimuli $[229,230]$, the pro-amnestic effects of benzodiazepines in the BLA may represent a putative mechanism of action.

$\beta$-Blockers: The evaluation of $\beta$-blockers (with propranolol being the prototypical agent) in animal models has revolved mainly around their utility in models of memory and fear conditioning. Within the BLA, stress hormone elicited increases in norepinephrine have been found to enhance the consolidation of emotionally relevant memories [231,232]. This appears to be particularly true with contextual fear conditioning [178] and reconsolidation of fear memory following extinction [180,197,233; Table 4]. In particular, local infusions of 
propranolol are able to block reconsolidation of fear [180,233]. Recently, it has been demonstrated that $\beta$-adrenoreceptor activation within the BLA decreases surface expression of GABAA receptors, and this phenomenon is necessary for the reinstatement of fear following extinction [234]. It is proposed that propranolol, through blocking the decrease in GABAA receptor surface expression, prevents fear reinstatement by maintaining feed forward inhibition from BLA interneurons and thus dampening activity of BLA projections [234]. This finding is noteworthy as it suggests that hyperactive noradrenergic activity in PTSD $[235,236]$ may lead to reduced GABAA availability, explaining a potential mechanism for the relative ineffectiveness of benzodiazepines in PTSD populations [237,238].

Despite the action of $\beta$-blockers within the amygdala to modulate fear conditioning (see Table 4), attempts at testing propranolol in other animal models of PTSD have met with mixed results, echoing the mixed efficacy seen thus far in humans [199,200,239,240]. One such model is exposure to predator odor in rodents, which produces long lasting increases in anxiety like behavior [241-243]. The increases in anxiety like behavior following exposure to predator odor is influenced by a long lasting potentiation in BLA activity [243], supporting the role of the amygdala in mediating the consequences of fear and trauma. Propranolol administered 1 minute following exposure to predator odor to rats blocks the development of anxiogenesis in various tests, including the EPM, one week later [241]. However, when propranolol administration is delayed to 1 hour following predator odor exposure, no effects are seen when rats are subsequently tested on the EPM 30 days later [242]. These results highlight once again a potential key role of timing if propranolol is to be effectively implemented in clinical patients. Similarly, findings that propranolol seems most effective in blocking the reconsolidation of fearful memories [233, 180, 197] (also see Table 4) suggests that future work should be aimed at establishing protocols for the integration of propranolol during exposure therapy, in which extinction and reconsolidation processes are most active. Specifically, it would seem important that propranolol not be administered shortly after exposure therapy, as this might interfere reconsolidation processes within the amygdala. On the other hand, propranolol would likely have utility when PTSD patients encounter aversive stimuli outside the context of therapy which could potentially undermine the therapeutic process and lead to reinstatement.

Selective Serotonin Re-uptake Inhibitors: Similar to human studies, animal models of anxietylike behavior demonstrate divergent behavioral effects of acute versus chronic SSRI administration. Increased anxiety-like behavior with acute treatment of SSRIs and its reversal with chronic treatment has been found in novelty-suppressed feeding [244], EPM testing [245,246], and the social interaction test [247]. While a large percentage of studies reveal acute anxiogenic effects and chronic anxiolytic effect, there are exceptions (for review, see [248]).

Much evidence suggests that enhanced activity at 5- $\mathrm{HT}_{2 \mathrm{C}}$ within the BLA by SSRIs produces acute anxiogenic effects, while the eventual downregulation of these receptors by chronic treatment leads to eventual anxiolysis. For example, amygdala or BLA 5- $\mathrm{HT}_{2} \mathrm{C}$ receptors have been found to produce anxiety-like responses in a variety of tests [249,250] (see Table 2). Blockade of $5-\mathrm{HT}_{2} \mathrm{C}$ receptors within the BLA prevents the acute anxiogenic effect of the 
SSRI fluoxetine on the Vogel conflict test [251]. Systemic 5- $\mathrm{HT}_{2 \mathrm{C}}$ antagonism also prevents the increase in fear conditioning [252], decrease in social interaction [247,253], and escape response to airjet [254] following acute SSRI treatment. Following chronic treatment with SSRIs, 5- $\mathrm{HT}_{2 \mathrm{C}}$ agonists have attenuated anxiogenic effects on the exacerbation of OCD symptoms in humans [255,256], on social interaction [257] and hyperlocomotion [258], suggesting down-regulation of the ability to $5-\mathrm{HT}_{2} \mathrm{C}$ receptors in the amygdala to produce anxiogenic responses following chronic SSRI treatment. Thus, the amygdala (BLA in particular) may be an important locus of action for the long-term effects of SSRIs on anxiety.

\subsection{Future potential anxiolytic targets}

The literature reviewed above suggests that in part, the effects of anxiolytic drugs may be mediated by altering amygdala function - either global dampening of the amygdala by benzodiazepines, or specific actions on 5-HT and NE receptors within particular amygdala subregions. However, to improve therapeutic efficacy and reduce relapse, several aspects of amygdala pharmacology discussed above might provide useful potential anxiolytic targets in the future.

Findings suggesting down-regulation of anxiogenic 5- $\mathrm{HT}_{2 \mathrm{C}}$ receptors in the amygdala following chronic SSRI treatment (Section 4.2.) present a potential strategy of reducing onset latency of SSRIs as well as enhancing their effects. Specifically, blocking 5-HT2C receptors at the initiation of SSRI treatment would be expected to produce a faster onset of anxiolytic action. Currently, there are no selective 5- $\mathrm{HT}_{2 \mathrm{C}}$ antagonists available for human use. However, atypical antipsychotics [259] as well as atypical antidepressants such as mirtazapine [260] possess 5- $\mathrm{HT}_{2 \mathrm{C}}$ antagonist activity. While there is evidence that antipsychotic augmentation of SSRIs may improve anxiolytic efficacy, their use has been limited by poor tolerability [for review see 261]. Although research is lacking, mirtazapine and the melatonin receptor agonist/5-HT2C receptor antagonist agomelatine [262] may provide the advantage of targeting anxiogenic 5- $\mathrm{HT}_{2 \mathrm{C}}$ in the amygdala with less side effects.

Furthermore, the recent observation that $\beta$-adrenoreceptor activation within the BLA results in decreased of GABAA receptor surface expression necessary for fear reinstatement [234] (and see Section 4.2.) suggests that the combination of propranolol and a benzodiazepine may have unique benefit for PTSD. By blocking $\beta$-adrenoreceptors with propranolol, one might be able to enhance benzodiazepine receptor availability, and increase benzodiazepine-induced inhibition of fear circuits within the amygdala. While currently speculative, the use of propranolol to enhance benzodiazepine action in the amygdala may represent a potential creative treatment strategy in a population that is traditionally refractory to benzodiazepine treatment.

While current pharmacotherapeutic strategies for the treatment of anxiety disorders target monoamine function, this has predominantly been related to altering 5-HT or NE levels or receptor activity [8]. However, Table 3 clearly shows a role for DA in the amygdala in mediating both fear and anxiety, and the role for DA and both $\mathrm{D}_{1}$ and $\mathrm{D}_{2}$ receptors in acquisition and retention of conditioned fear in particular appears quite robust. Thus, 
reducing DA function might serve as means by which to treat anxiety disorders in which fear plays a major component. The obvious disadvantage of dopaminergic-based pharmacotheraputics is potential for major cognitive and motoric side-effects, limiting the treatment options with the currently available dopaminergic agents. Atypical antipsychotic drugs incorporate DA receptor blocking activity while avoiding many of the motoric and cognitive issues of traditional agents. There is evidence that atypical agents possess anxiolytic activity [261], but metabolic side effects make them poorly tolerated. Furthermore, because atypical antipsychotics also have high affinity for 5-HT receptors, the contribution of DA modulation to their anxiolytic effects in humans is currently unknown. One potential strategy may be the use of partial agonists to reduce DA activity in the amygdala via activation of inhibitory presynaptic $\mathrm{D}_{2}$ autoreceptors. While non-selective for $\mathrm{DA}$, the $\mathrm{D}_{2}$ partial agonist aripiprazole has demonstrated anxiolytic efficacy similar to other atypical antipsychotic drugs [263]. In the future, more selective DA partial agonists may have additional benefit without unwanted side-effects.

Finally, CRF has been identified as an important neuropeptide in the regulation of monoaminergic activity in the amygdala in response to anxiogenic or fearful stimuli (Section 3.2). Furthermore, $\mathrm{CRF}$ and its receptors $\left(\mathrm{CRF}_{1}\right.$ and $\left.\mathrm{CRF}_{2}\right)$ are implicated in fear and anxiety within animal models and in the development of anxiety disorders [12,121-129]. Upon the development of non-peptide $\mathrm{CRF}_{1}$ receptor antagonists that cross the blood-brain barrier, there was great interest in the use of $\mathrm{CRF}_{1}$ receptor antagonist in the treatment of anxiety disorders. To date, there have been limited phase II clinical trials published regarding the use of $\mathrm{CRF}_{1}$ receptor antagonists in anxiety disorders [264]. Of those, preliminary findings suggest the $\mathrm{CRF}_{1}$ receptor antagonist-treated groups did not differ from placebo-treated groups in anxiety symptomology in both social anxiety disorder and GAD [264]. However, it has been suggested that efficacious concentrations have not been established for the various $\mathrm{CRF}_{1}$ receptor antagonists, and it is clear that further clinical trials are necessary. One potential promising area in the treatment of anxiety disorders may actually lie in $\mathrm{CRF}_{2}$ receptor antagonists. As outlined in Section 3.2, $\mathrm{CRF}_{2}$ receptors mediate 5-HT activity in the amygdala, are up-regulated in animal models of anxiety, and an antagonist of this receptor reduces heightened anxiety in rats $[11,12,127,128,131,132,137)$. The challenge lies in developing non-peptide $\mathrm{CRF}_{2}$ receptor antagonists that cross the blood-brain barrier, so that the efficacy of such ligands can be determined for anxiety disorders.

\section{Conclusion}

Human imaging studies in non-patient populations suggest amygdala activation in response to fearful stimuli, and that the magnitude of this response is positively correlated with trait anxiety. Furthermore, individuals suffering from an anxiety disorder (with the possible exception of adult GAD) show exaggerated amygdala responses to fearful or emotive stimuli, which again is positively correlated with the severity of symptoms. Moreover, reactivity of the amygdala to fearful stimuli is reduced by anxiolytic drugs in healthy subjects, and long-term pharmacotherapy or CBT reduces amygdala hyperreactivity in anxiety disorders. Animal studies corroborate an important role for the 
amygdala in fear and anxiety, with specific subregions mediating acquisition and expression of fear, fear memories and anxiety, and the monoamines within each of these regions often playing a very specific role in facilitating or attenuating fear or anxiety. Both human and animal studies suggest dysfunction of the amygdala might arise in part, from inadequate top-down control by regions such as the medial prefrontal cortex, and in part, from altered neuropeptide regulation of amygdala monoaminergic systems. Overall, the amygdala plays a critical role in anxiety disorders, and understanding the function of this region in fear and anxiety states and how dysfunction of the amygdala results in anxiety disorders is critical to improving long-term treatment outcomes.

\section{Author details}

Gina L. Forster*, Andrew M. Novick, Jamie L. Scholl and Michael J. Watt

Division of Basic Biomedical Sciences, Sanford School of Medicine, University of South Dakota, Vermillion, SD, USA

\section{Acknowledgement}

This work was supported by National Institutes of Health grant R01 DA019921, and Department of Defense grants W81XWH-10-1-0925 and W81XWH-10-1-0578.

\section{References}

[1] Sylvers P, Lilienfeld SO, LaPrairie JL (2011) Differences between Trait Fear and Trait Anxiety: Implications for Psychopathology. Clin Psychol Rev. 31, 122-137. S02727358(10)00131-5 [pii] 10.1016/j.cpr.2010.08.004.

[2] McNaughton N, Corr PJ (2004) A Two-Dimensional Neuropsychology of Defense: Fear/Anxiety and Defensive Distance. Neuroscience \& Biobehavioral Reviews. 28, 285305. 10.1016/j.neubiorev.2004.03.005.

[3] Graham BM, Milad MR (2011) The Study of Fear Extinction: Implications for Anxiety Disorders. Am J Psychiatry. 168, 1255-1265.

10.1176/appi.ajp.2011.11040557 appi.ajp.2011.11040557 [pii].

[4] Ninan PT (2001) Recent Perspectives on the Diagnosis and Treatment of Generalized Anxiety Disorder. Am J Manag Care. 7, S367-376.

[5] Alexander JL, Dennerstein L, Kotz K, Richardson G (2007) Women, Anxiety and Mood: A Review of Nomenclature, Comorbidity and Epidemiology. Expert Rev Neurother. 7, S45-58.

[6] Katzman MA (2009) Current Considerations in the Treatment of Generalized Anxiety Disorder. CNS Drugs. 23, 103-120.

[7] American Psychiatric Association. Diagnostic and Statistical Manual of Mental Disorders. 4th ed. Washington, DC: American Psychiatric Association; 1994.

\footnotetext{
${ }^{*}$ Corresponding Author
} 
[8] Inoue T, Kitaichi Y, Koyama T (2011) SSRIs and Conditioned Fear. Progress in NeuroPsychopharmacology and Biological Psychiatry. 35, 1810-1819.

10.1016/j.pnpbp.2011.09.002.

[9] Engin E, Treit D (2008) The Effects of Intra-Cerebral Drug Infusions on Animals' Unconditioned Fear Reactions: A Systematic Review. Prog Neuropsychopharmacol Biol Psychiatry. 32, 1399-1419. 10.1016/j.pnpbp.2008.03.020.

[10] Keck ME, Sartori SB, Welt T, Müller MB, Ohl F, Holsboer F, Landgraf R, Singewald N (2005) Differences in Serotonergic Neurotransmission between Rats Displaying High or Low Anxiety/Depression-Like Behaviour: Effects of Chronic Paroxetine Treatment. J Neurochem. 92, 1170-1179. 10.1111/j.1471-4159.2004.02953.x.

[11] Lukkes JL, Mokin MV, Scholl JL, Forster GL (2009) Adult Rats Exposed to Early-Life Social Isolation Exhibit Increased Anxiety and Conditioned Fear Behavior, and Altered Hormonal Stress Responses. Horm Behav. 55, 248-256.

[12] Vuong SM, Oliver HA, Scholl JL, Oliver KM, Forster GL (2010) Increased Anxiety-Like Behavior of Rats During Amphetamine Withdrawal Is Reversed by Crf2 Receptor Antagonism. Behavioural Brain Research. 208, 278-281.

[13] Furmark T, Fischer H, Wik G, Larsson M, Fredrikson M (1997) The Amygdala and Individual Differences in Human Fear Conditioning. Neuroreport. 8, 3957-3960.

[14] Whalen PJ, Bush G, McNally RJ, Wilhelm S, McInerney SC, Jenike MA, Rauch SL (1998) The Emotional Counting Stroop Paradigm: A Functional Magnetic Resonance Imaging Probe of the Anterior Cingulate Affective Division. Biol Psychiatry. 44, 1219-1228.

[15] Liddell BJ, Brown KJ, Kemp AH, Barton MJ, Das P, Peduto A, Gordon E, Williams LM (2005) A Direct Brainstem-Amygdala-Cortical 'Alarm' System for Subliminal Signals of Fear. Neuroimage. 24, 235-243. 10.1016/j.neuroimage.2004.08.016.

[16] Etkin A,Wager TD (2007) Functional Neuroimaging of Anxiety: A Meta-Analysis of Emotional Processing in Ptsd, Social Anxiety Disorder, and Specific Phobia. Am J Psychiatry. 164, 1476-1488. 10.1176/appi.ajp.2007.07030504.

[17] Hyde LW, Gorka A, Manuck SB, Hariri AR (2011) Perceived Social Support Moderates the Link between Threat-Related Amygdala Reactivity and Trait Anxiety. Neuropsychologia. 49, 651-656. 10.1016/j.neuropsychologia.2010.08.025.

[18] Carlson JM, Greenberg T, Rubin D, Mujica-Parodi LR (2011) Feeling Anxious: Anticipatory Amygdalo-Insular Response Predicts the Feeling of Anxious Anticipation. Soc Cogn Affect Neurosci. 6, 74-81. 10.1093/scan/nsq017.

[19] Stein MB, Simmons AN, Feinstein JS, Paulus MP (2007) Increased Amygdala and Insula Activation During Emotion Processing in Anxiety-Prone Subjects. Am J Psychiatry. 164, 318-327. 10.1176/appi.ajp.164.2.318.

[20] Bishop S, Duncan J, Brett M, Lawrence AD (2004) Prefrontal Cortical Function and Anxiety: Controlling Attention to Threat-Related Stimuli. Nat Neurosci. 7, 184-188.

[21] Etkin A, Klemenhagen KC, Dudman JT, Rogan MT, Hen R, Kandel ER, Hirsch J (2004) Individual Differences in Trait Anxiety Predict the Response of the Basolateral Amygdala to Unconsciously Processed Fearful Faces. Neuron. 44, 1043-1055. 10.1016/j.neuron.2004.12.006. 
[22] Dickie EW, Armony JL (2008) Amygdala Responses to Unattended Fearful Faces: Interaction between Sex and Trait Anxiety. Psychiatry Research: Neuroimaging. 162, 5157. 10.1016/j.pscychresns.2007.08.002.

[23] Ball TM, Sullivan S, Flagan T, Hitchcock CA, Simmons A, Paulus MP, Stein MB (2012) Selective Effects of Social Anxiety, Anxiety Sensitivity, and Negative Affectivity on the Neural Bases of Emotional Face Processing. Neuroimage. 59, 1879-1887. 10.1016/j.neuroimage.2011.08.074.

[24] Furmark T, Tillfors M, Marteinsdottir I, Fischer H, Pissiota A, Langstrom B, Fredrikson M (2002) Common Changes in Cerebral Blood Flow in Patients with Social Phobia Treated with Citalopram or Cognitive-Behavioral Therapy. Arch Gen Psychiatry. 59, 425-433.

[25] Shah SG, Klumpp H, Angstadt M, Nathan PJ, Phan KL (2009) Amygdala and Insula Response to Emotional Images in Patients with Generalized Social Anxiety Disorder. Journal of Psychiatry \& Neuroscience. 34, 296-302.

[26] Brühl AB, Rufer M, Delsignore A, Kaffenberger T, Jäncke L, Herwig U (2011) Neural Correlates of Altered General Emotion Processing in Social Anxiety Disorder. Brain Res. 1378, 72-83. 10.1016/j.brainres.2010.12.084.

[27] Blair K, Shaywitz J, Smith BW, Rhodes R, Geraci M, Jones M, McCaffrey D, Vythilingam M, Finger E, Mondillo K, Jacobs M, Charney DS, Blair RJ, Drevets WC, Pine DS (2008) Response to Emotional Expressions in Generalized Social Phobia and Generalized Anxiety Disorder: Evidence for Separate Disorders. Am J Psychiatry. 165, 1193-1202. 10.1176/appi.ajp.2008.07071060.

[28] Rauch SL, Shin LM, Phelps EA (2006) Neurocircuitry Models of Posttraumatic Stress Disorder and Extinction: Human Neuroimaging Research--Past, Present, and Future. Biol Psychiatry. 60, 376-382.

[29] Jovanovic T, Norrholm SD (2011) Neural Mechanisms of Impaired Fear Inhibition in Posttraumatic Stress Disorder. Frontiers in Behavioral Neuroscience. 5, 10.3389/fnbeh.2011.00044.

[30] Liberzon I, Abelson JL, Flagel SB, Raz J, Young EA (1999) Neuroendocrine and Psychophysiologic Responses in Ptsd: A Symptom Provocation Study. Neuropsychopharmacology. 21, 40-50.

[31] Shin LM, Orr SP, Carson MA, Rauch SL, Macklin ML, Lasko NB, Peters PM, Metzger LJ, Dougherty DD, Cannistraro PA, Alpert NM, Fischman AJ, Pitman RK (2004) Regional Cerebral Blood Flow in the Amygdala and Medial Prefrontal Cortex During Traumatic Imagery in Male and Female Vietnam Veterans with Ptsd. Arch Gen Psychiatry. 61, 168176.

[32] Shin LM, Wright CI, Cannistraro PA, Wedig MM, McMullin K, Martis B, Macklin ML, Lasko NB, Cavanagh SR, Krangel TS, Orr SP, Pitman RK, Whalen PJ, Rauch SL (2005) A Functional Magnetic Resonance Imaging Study of Amygdala and Medial Prefrontal Cortex Responses to Overtly Presented Fearful Faces in Posttraumatic Stress Disorder. Arch Gen Psychiatry. 62, 273-281. 
[33] Bryant RA, Felmingham K, Kemp A, Das P, Hughes G, Peduto A, Williams L (2008) Amygdala and Ventral Anterior Cingulate Activation Predicts Treatment Response to Cognitive Behaviour Therapy for Post-Traumatic Stress Disorder. Psychological Medicine. 38, 555-561. doi:10.1017/S0033291707002231.

[34] Armony JL, Corbo V, Clement MH, Brunet A (2005) Amygdala Response in Patients with Acute Ptsd to Masked and Unmasked Emotional Facial Expressions. Am J Psychiatry. 162, 1961-1963.

[35] Dilger S, Straube T, Mentzel H-J, Fitzek C, Reichenbach JR, Hecht H, Krieschel S, Gutberlet I, Miltner WHR (2003) Brain Activation to Phobia-Related Pictures in Spider Phobic Humans: An Event-Related Functional Magnetic Resonance Imaging Study. Neurosci Lett. 348, 29-32. 10.1016/s0304-3940(03)00647-5.

[36] Schienle A, Schäfer A, Walter B, Stark R, Vaitl D (2005) Brain Activation of Spider Phobics Towards Disorder-Relevant, Generally Disgust- and Fear-Inducing Pictures. Neurosci Lett. 388, 1-6. 10.1016/j.neulet.2005.06.025.

[37] van den Heuvel OA, Veltman DJ, Groenewegen HJ, Witter MP, Merkelbach J, Cath DC, van Balkom AJLM, van Oppen P, van Dyck R (2005) Disorder-Specific Neuroanatomical Correlates of Attentional Bias in Obsessive-Compulsive Disorder, Panic Disorder, and Hypochondriasis. Arch Gen Psychiatry. 62, 922-933. 10.1001/archpsyc.62.8.922.

[38] Straube T, Mentzel H-J, Miltner WHR (2006) Neural Mechanisms of Automatic and Direct Processing of Phobogenic Stimuli in Specific Phobia. Biol Psychiatry. 59, 162-170. 10.1016/j.biopsych.2005.06.013.

[39] Whalen PJ, Johnstone T, Somerville LH, Nitschke JB, Polis S, Alexander AL, Davidson RJ, Kalin NH (2008) A Functional Magnetic Resonance Imaging Predictor of Treatment Response to Venlafaxine in Generalized Anxiety Disorder. Biol Psychiatry. 63, 858-863. 10.1016/j.biopsych.2007.08.019.

[40] Palm ME, Elliott R, McKie S, Deakin JFW, Anderson IM (2011) Attenuated Responses to Emotional Expressions in Women with Generalized Anxiety Disorder. Psychological Medicine. 41, 1009-1018. doi:10.1017/S0033291710001455.

[41] McClure EB, Adler A, Monk CS, Cameron J, Smith S, Nelson EE, Leibenluft E, Ernst M, Pine DS (2007) fMRI Predictors of Treatment Outcome in Pediatric Anxiety Disorders. Psychopharmacology (Berl). 191, 97-105. 10.1007/s00213-006-0542-9.

[42] Monk CS, Telzer EH, Mogg K, Bradley BP, Mai X, Louro HM, Chen G, McClure-Tone EB, Ernst M, Pine DS (2008) Amygdala and Ventrolateral Prefrontal Cortex Activation to Masked Angry Faces in Children and Adolescents with Generalized Anxiety Disorder. Arch Gen Psychiatry. 65, 568-576. 10.1001/archpsyc.65.5.568.

[43] Nitschke JB, Sarinopoulos I, Oathes DJ, Johnstone T, Whalen PJ, Davidson RJ, Kalin NH (2009) Anticipatory Activation in the Amygdala and Anterior Cingulate in Generalized Anxiety Disorder and Prediction of Treatment Response. Am J Psychiatry. 166, 302-310. appi.ajp.2008.07101682 [pii] 10.1176/appi.ajp.2008.07101682.

[44] Etkin A, Prater KE, Hoeft F, Menon V, Schatzberg AF (2010) Failure of Anterior Cingulate Activation and Connectivity with the Amygdala During Implicit Regulation 
of Emotional Processing in Generalized Anxiety Disorder. Am J Psychiatry. 167, 545554. 10.1176/appi.ajp.2009.09070931.

[45] Prevost C, McCabe JA, Jessup RK, Bossaerts P, O'Doherty JP (2011) Differentiable Contributions of Human Amygdalar Subregions in the Computations Underlying Reward and Avoidance Learning. Eur J Neurosci. 34, 134-145. 10.1111/j.14609568.2011.07686.x.

[46] Boll S, Gamer M, Kalisch R, Buchel C (2011) Processing of Facial Expressions and Their Significance for the Observer in Subregions of the Human Amygdala. Neuroimage. 56, 299-306. S1053-8119(11)00160-1 [pii] 10.1016/j.neuroimage.2011.02.021.

[47] Ball T, Rahm B, Eickhoff SB, Schulze-Bonhage A, Speck O, Mutschler I (2007) Response Properties of Human Amygdala Subregions: Evidence Based on Functional MRI Combined with Probabilistic Anatomical Maps. PLoS One. 2, e307. 10.1371/journal.pone.0000307.

[48] Ball T, Derix J, Wentlandt J, Wieckhorst B, Speck O, Schulze-Bonhage A, Mutschler I (2009) Anatomical Specificity of Functional Amygdala Imaging of Responses to Stimuli with Positive and Negative Emotional Valence. J Neurosci Methods. 180, 57-70. S01650270(09)00144-7 [pii] 10.1016/j.jneumeth.2009.02.022.

[49] Etkin A, Prater KE, Schatzberg AF, Menon V, Greicius MD (2009) Disrupted Amygdalar Subregion Functional Connectivity and Evidence of a Compensatory Network in Generalized Anxiety Disorder. Arch Gen Psychiatry. 66, 1361-1372. 66/12/1361 [pii] 10.1001/archgenpsychiatry.2009.104.

[50] Entis JJ, Doerga P, Barrett LF, Dickerson BC (2012) A Reliable Protocol for the Manual Segmentation of the Human Amygdala and Its Subregions Using Ultra-High Resolution MRI. Neuroimage. 60, 1226-1235. S1053-8119(12)00002-X

[pii] 10.1016/j.neuroimage.2011.12.073.

[51] Kim N, Kim HJ, Hwang J, Yoon SJ, Cho HB, Renshaw PF, Lyoo IK, Kim JE (2011) Amygdalar Shape Analysis Method Using Surface Contour Aligning, Spherical Mapping, and Probabilistic Subregional Segmentation. Neurosci Lett. 488, 65-69. S03043940(10)01446-1 [pii] 10.1016/j.neulet.2010.11.005.

[52] Millan MJ (2003) The Neurobiology and Control of Anxious States. Prog Neurobiol. 70, 83-244. S030100820300087X [pii].

[53] Kalin NH, Sheltona SE (2003) Nonhuman Primate Models to Study Anxiety, Emotion Regulation, and Psychopathology. Annals of the New York Academy of Sciences. 1008, 189-200. 10.1196/annals.1301.021.

[54] Kalin NH, Shelton SE, Davidson RJ (2004) The Role of the Central Nucleus of the Amygdala in Mediating Fear and Anxiety in the Primate. J Neurosci. 24, 5506-5515. 10.1523/JNEUROSCI.0292-04.2004 24/24/5506 [pii].

[55] Lowry CA, Johnson PL, Hay-Schmidt A, Mikkelsen J, Shekhar A (2005) Modulation of Anxiety Circuits by Serotonergic Systems. Stress. 8, 233-246.

[56] Davis M (2006) Neural Systems Involved in Fear and Anxiety Measured with FearPotentiated Startle. Am Psychol. 61, 741-756. 2006-21079-027 [pii] 10.1037/0003066X.61.8.741. 
[57] Milad MR, Rauch SL, Pitman RK, Quirk GJ (2006) Fear Extinction in Rats: Implications for Human Brain Imaging and Anxiety Disorders. Biol Psychol. 73, 61-71.

[58] Davis M, Antoniadis EA, Amaral DG, Winslow JT (2008) Acoustic Startle Reflex in Rhesus Monkeys: A Review. Rev Neurosci. 19, 171-185.

[59] Price JL (2003) Comparative Aspects of Amygdala Connectivity. Ann N Y Acad Sci. 985, 50-58.

[60] LeDoux JE (2000) Emotion Circuits in the Brain. Annu Rev Neurosci. 23, 155-184. 10.1146/annurev.neuro.23.1.155.

[61] Canteras NS, Simerly RB, Swanson LW (1995) Organization of Projections from the Medial Nucleus of the Amygdala: A Phal Study in the Rat. J Comp Neurol. 360, 213-245. 10.1002/cne.903600203.

[62] Newman SW (1999) The Medial Extended Amygdala in Male Reproductive Behavior a Node in the Mammalian Social Behavior Network. Annals of the New York Academy of Sciences. 877, 242-257. 10.1111/j.1749-6632.1999.tb09271.x.

[63] Herman JP, Ostrander MM, Mueller NK, Figueiredo H (2005) Limbic System Mechanisms of Stress Regulation: Hypothalamo-Pituitary-Adrenocortical Axis. Progress in Neuro-Psychopharmacology and Biological Psychiatry. 29, 1201-1213. 10.1016/j.pnpbp.2005.08.006.

[64] Pitkanen A, Savander V, LeDoux JE (1997) Organization of Intra-Amygdaloid Circuitries in the Rat: An Emerging Framework for Understanding Functions of the Amygdala. Trends Neurosci. 20, 517-523. S0166223697011259 [pii].

[65] Canteras NS, Swanson LW (1992) Projections of the Ventral Subiculum to the Amygdala, Septum, and Hypothalamus: A Phal Anterograde Tract-Tracing Study in the Rat. J Comp Neurol. 324, 180-194. 10.1002/cne.903240204.

[66] Canteras NS, Simerly RB, Swanson LW (1992) Connections of the Posterior Nucleus of the Amygdala. J Comp Neurol. 324, 143-179. 10.1002/cne.903240203.

[67] Richter-Levin G, Akirav I (2000) Amygdala-Hippocampus Dynamic Interaction in Relation to Memory. Mol Neurobiol. 22, 11-20. MN:22:1-3:011 [pii] 10.1385/MN:22:13:011.

[68] Savander V, Miettinen R, Ledoux JE, Pitkanen A (1997) Lateral Nucleus of the Rat Amygdala Is Reciprocally Connected with Basal and Accessory Basal Nuclei: A Light and Electron Microscopic Study. Neuroscience. 77, 767-781. S0306-4522(96)00513-1 [pii].

[69] Pare D, Smith Y (1993) The Intercalated Cell Masses Project to the Central and Medial Nuclei of the Amygdala in Cats. Neuroscience. 57, 1077-1090. 0306-4522(93)90050-P [pii].

[70] Royer S, Martina M, Pare D (1999) An Inhibitory Interface Gates Impulse Traffic between the Input and Output Stations of the Amygdala. J Neurosci. 19, 10575-10583.

[71] Pare D, Quirk GJ, Ledoux JE (2004) New Vistas on Amygdala Networks in Conditioned Fear. J Neurophysiol. 92, 1-9. 10.1152/jn.00153.2004 92/1/1 [pii].

[72] LeDoux JE, Iwata J, Cicchetti P, Reis DJ (1988) Different Projections of the Central Amygdaloid Nucleus Mediate Autonomic and Behavioral Correlates of Conditioned Fear. J Neurosci. 8, 2517-2529. 
[73] Davis M, Whalen PJ (2001) The Amygdala: Vigilance and Emotion. Mol Psychiatry. 6, 13-34.

[74] Dielenberg RA, McGregor IS (2001) Defensive Behavior in Rats Towards Predatory Odors: A Review. Neuroscience \&amp; Biobehavioral Reviews. 25, 597-609. 10.1016/s0149-7634(01)00044-6.

[75] Müller M, Fendt M (2006) Temporary Inactivation of the Medial and Basolateral Amygdala Differentially Affects Tmt-Induced Fear Behavior in Rats. Behavioural Brain Research. 167, 57-62. 10.1016/j.bbr.2005.08.016.

[76] Rosen JB, Pagani JH, Rolla KL, Davis C (2008) Analysis of Behavioral Constraints and the Neuroanatomy of Fear to the Predator Odor Trimethylthiazoline: A Model for Animal Phobias. Neurosci Biobehav Rev. 32, 1267-1276. S0149-7634(08)00068-7 [pii] 10.1016/j.neubiorev.2008.05.006.

[77] Ramos C, Leite-Panissi R, Monassi R, Menescal-De-Oliveira L (1999) Role of the Amygdaloid Nuclei in the Modulation of Tonic Immobility in Guinea Pigs. Physiol Behav. 67, 717-724. S003193849900133X [pii].

[78] Macedo CE, Martinez RC, Brandao ML (2006) Conditioned and Unconditioned Fear Organized in the Inferior Colliculus Are Differentially Sensitive to Injections of Muscimol into the Basolateral Nucleus of the Amygdala. Behav Neurosci. 120, 625-631. 2006-07279-013 [pii] 10.1037/0735-7044.120.3.625.

[79] Quirk GJ, Mueller D (2008) Neural Mechanisms of Extinction Learning and Retrieval. Neuropsychopharmacology. 33, 56-72.

[80] Zimmerman JM, Maren S (2010) Nmda Receptor Antagonism in the Basolateral but Not Central Amygdala Blocks the Extinction of Pavlovian Fear Conditioning in Rats. Eur J Neurosci. 31, 1664-1670. EJN7223 [pii] 10.1111/j.1460-9568.2010.07223.x.

[81] Sotres-Bayon F, Cain CK, LeDoux JE (2006) Brain Mechanisms of Fear Extinction: Historical Perspectives on the Contribution of Prefrontal Cortex. Biol Psychiatry. 60, 329-336.

[82] Likhtik E, Popa D, Apergis-Schoute J, Fidacaro GA, Pare D (2008) Amygdala Intercalated Neurons Are Required for Expression of Fear Extinction. Nature. 454, 642645. nature07167 [pii] 10.1038/nature07167.

[83] Amano T, Unal CT, Pare D (2010) Synaptic Correlates of Fear Extinction in the Amygdala. Nat Neurosci. 13, 489-494. nn.2499 [pii] 10.1038/nn.2499.

[84] Moreira CM, Masson S, Carvalho MC, Brandao ML (2007) Exploratory Behaviour of Rats in the Elevated Plus-Maze Is Differentially Sensitive to Inactivation of the Basolateral and Central Amygdaloid Nuclei. Brain Res Bull. 71, 466-474. S03619230(06)00305-4 [pii] 10.1016/j.brainresbull.2006.10.004.

[85] Zarrindast MR, Solati J, Oryan S, Parivar K (2008) Effect of Intra-Amygdala Injection of Nicotine and GABA Receptor Agents on Anxiety-Like Behaviour in Rats. Pharmacology. 82, 276-284. 000161129 [pii] 10.1159/000161129.

[86] Tye KM, Prakash R, Kim SY, Fenno LE, Grosenick L, Zarabi H, Thompson KR, Gradinaru V, Ramakrishnan C, Deisseroth K (2011) Amygdala Circuitry Mediating 
Reversible and Bidirectional Control of Anxiety. Nature. 471, 358-362. nature09820 [pii] 10.1038/nature09820.

[87] Walker DL, Toufexis DJ, Davis M (2003) Role of the Bed Nucleus of the Stria Terminalis Versus the Amygdala in Fear, Stress, and Anxiety. Eur J Pharmacol. 463, 199-216. S0014299903012822 [pii].

[88] Walker DL, Miles LA, Davis M (2009) Selective Participation of the Bed Nucleus of the Stria Terminalis and Crf in Sustained Anxiety-Like Versus Phasic Fear-Like Responses. Prog Neuropsychopharmacol Biol Psychiatry. 33, 1291-1308. S0278-5846(09)00212-7 [pii] 10.1016/j.pnpbp.2009.06.022.

[89] Walker DL, Davis M (2008) Role of the Extended Amygdala in Short-Duration Versus Sustained Fear: A Tribute to Dr. Lennart Heimer. Brain Struct Funct. 213, 29-42. 10.1007/s00429-008-0183-3.

[90] Duncan GE, Knapp DJ, Breese GR (1996) Neuroanatomical Characterization of Fos Induction in Rat Behavioral Models of Anxiety. Brain Res. 713, 79-91. 00068993(95)01486-1 [pii].

[91] Herdade KC, Strauss CV, Zangrossi Junior H, Viana MB (2006) Effects of Medial Amygdala Inactivation on a Panic-Related Behavior. Behav Brain Res. 172, 316-323. S0166-4328(06)00292-0 [pii] 10.1016/j.bbr.2006.05.021.

[92] Troakes C, Ingram CD (2009) Anxiety Behaviour of the Male Rat on the Elevated Plus Maze: Associated Regional Increase in C-Fos mRNA Expression and Modulation by Early Maternal Separation. Stress. 12, 362-369. 906308344 [pii] 10.1080/10253890802506391.

[93] Vinkers CH, Bijlsma EY, Houtepen LC, Westphal KG, Veening JG, Groenink L, Olivier B (2010) Medial Amygdala Lesions Differentially Influence Stress Responsivity and Sensorimotor Gating in Rats. Physiol Behav. 99, 395-401. S0031-9384(09)00392-8 [pii] 10.1016/j.physbeh.2009.12.006.

[94] Marschner A, Kalisch R, Vervliet B, Vansteenwegen D, Buchel C (2008) Dissociable Roles for the Hippocampus and the Amygdala in Human Cued Versus Context Fear Conditioning. J Neurosci. 28, 9030-9036. 28/36/9030 [pii] 10.1523/JNEUROSCI.165108.2008 .

[95] Onishi BK, Xavier GF (2010) Contextual, but Not Auditory, Fear Conditioning Is Disrupted by Neurotoxic Selective Lesion of the Basal Nucleus of Amygdala in Rats. Neurobiol Learn Mem. 93, 165-174. S1074-7427(09)00197-X [pii] 10.1016/j.nlm.2009.09.007.

[96] McDonald AJ, Mascagni F, Guo L (1996) Projections of the Medial and Lateral Prefrontal Cortices to the Amygdala: A Phaseolus Vulgaris Leucoagglutinin Study in the Rat. Neuroscience. 71, 55-75. 0306-4522(95)00417-3 [pii].

[97] Vertes RP (2004) Differential Projections of the Infralimbic and Prelimbic Cortex in the Rat. Synapse. 51, 32-58. 10.1002/syn.10279.

[98] Corcoran KA, Quirk GJ (2007) Recalling Safety: Cooperative Functions of the Ventromedial Prefrontal Cortex and the Hippocampus in Extinction. CNS Spectr. 12, 200-206. 
[99] Vidal-Gonzalez I, Vidal-Gonzalez B, Rauch SL, Quirk GJ (2006) Microstimulation Reveals Opposing Influences of Prelimbic and Infralimbic Cortex on the Expression of Conditioned Fear. Learn Mem. 13, 728-733. 13/6/728 [pii] 10.1101/lm.306106.

[100] Sierra-Mercado D, Padilla-Coreano N, Quirk GJ (2011) Dissociable Roles of Prelimbic and Infralimbic Cortices, Ventral Hippocampus, and Basolateral Amygdala in the Expression and Extinction of Conditioned Fear. Neuropsychopharmacology. 36, 529538. npp2010184 [pii] 10.1038/npp.2010.184.

[101] Li G, Amano T, Pare D, Nair SS (2011) Impact of Infralimbic Inputs on Intercalated Amygdala Neurons: A Biophysical Modeling Study. Learn Mem. 18, 226-240. 10.1101/lm.1938011 18/4/226 [pii].

[102] Milad MR, Pitman RK, Ellis CB, Gold AL, Shin LM, Lasko NB, Zeidan MA, Handwerger K, Orr SP, Rauch SL (2009) Neurobiological Basis of Failure to Recall Extinction Memory in Posttraumatic Stress Disorder. Biol Psychiatry. 66, 1075-1082. S0006-3223(09)00896-8 [pii] 10.1016/j.biopsych.2009.06.026.

[103] Rougemont-Bucking A, Linnman C, Zeffiro TA, Zeidan MA, Lebron-Milad K, Rodriguez-Romaguera J, Rauch SL, Pitman RK, Milad MR (2011) Altered Processing of Contextual Information During Fear Extinction in PTSD: An fMRI Study. CNS Neurosci Ther. 17, 227-236. 10.1111/j.1755-5949.2010.00152.x CNS152 [pii].

[104] Kim MJ, Whalen PJ (2009) The Structural Integrity of an Amygdala-Prefrontal Pathway Predicts Trait Anxiety. J Neurosci. 29, 11614-11618. 29/37/11614 [pii] 10.1523/JNEUROSCI.2335-09.2009.

[105] Kim MJ, Gee DG, Loucks RA, Davis FC, Whalen PJ (2011) Anxiety Dissociates Dorsal and Ventral Medial Prefrontal Cortex Functional Connectivity with the Amygdala at Rest. Cereb Cortex. 21, 1667-1673. bhq237 [pii] 10.1093/cercor/bhq237.

[106] Inoue T, Koyama T, Yamashita I (1993) Effect of Conditioned Fear Stress on Serotonin Metabolism in the Rat Brain. Pharmacol Biochem Behav. 44, 371-374. 00913057(93)90476-A [pii].

[107] Yokoyama M, Suzuki E, Sato T, Maruta S, Watanabe S, Miyaoka H (2005) Amygdalic Levels of Dopamine and Serotonin Rise Upon Exposure to Conditioned Fear Stress without Elevation of Glutamate. Neurosci Lett. 379, 37-41. S0304-3940(04)01584-8 [pii] 10.1016/j.neulet.2004.12.047.

[108] Mo B, Feng N, Renner K, Forster G (2008) Restraint Stress Increases Serotonin Release in the Central Nucleus of the Amygdala Via Activation of Corticotropin-Releasing Factor Receptors. Brain Res Bull. 76, 493-498. S0361-9230(08)00039-7 [pii] 10.1016/j.brainresbull.2008.02.011.

[109] Zanoveli JM, Carvalho MC, Cunha JM, Brandão ML (2009) Extracellular Serotonin Level in the Basolateral Nucleus of the Amygdala and Dorsal Periaqueductal Gray under Unconditioned and Conditioned Fear States: An in Vivo Microdialysis Study. Brain Res. 1294, 106-115. S0006-8993(09)01537-6 [pii] 10.1016/j.brainres.2009.07.074.

[110] Spannuth BM, Hale MW, Evans AK, Lukkes JL, Campeau S, Lowry CA (2011) Investigation of a Central Nucleus of the Amygdala/Dorsal Raphe Nucleus Serotonergic 
Circuit Implicated in Fear-Potentiated Startle. Neuroscience. 179, 104-119. S03064522(11)00065-0 [pii] 10.1016/j.neuroscience.2011.01.042.

[111] Emoto H, Koga C, Ishii H, Yokoo H, Yoshida M, Tanaka M (1993) A CRF Antagonist Attenuates Stress-Induced Increases in NA Turnover in Extended Brain Regions in Rats. Brain Res. 627, 171-176. 0006-8993(93)90762-C [pii].

[112] Dunn AJ (1988) Stress-Related Activation of Cerebral Dopaminergic Systems. Ann N Y Acad Sci. 537, 188-205.

[113] Quirarte, GL, Galvez, R, Roozendaal B, McGaugh JL. (1998) Norepinephrine Release in the Amygdala in Response to Footshock and Opioid Peptidergic Drugs. Brain Res. 808, 134-140.

[114] Inglis FM, Moghaddam B (1999) Dopaminergic Innervation of the Amygdala Is Highly Responsive to Stress. J Neurochem. 72, 1088-1094.

[115] Morilak DA, Barrera G, Echevarria DJ, Garcia AS, Hernandez A, Ma S, Petre CO (2005) Role of Brain Norepinephrine in the Behavioral Response to Stress. Prog Neuropsychopharmacol Biol Psychiatry. 29, 1214-1224. S0278-5846(05)00270-8 [pii] 10.1016/j.pnpbp.2005.08.007.

[116] Ma S, Morilak DA (2005) Norepinephrine Release in Medial Amygdala Facilitates Activation of the Hypothalamic-Pituitary-Adrenal Axis in Response to Acute Immobilisation Stress. J Neuroendocrinol. 17, 22-28. JNE1279 [pii] 10.1111/j.13652826.2005.01279.x.

[117] Mitsushima D, Yamada K, Takase K, Funabashi T, Kimura F (2006) Sex Differences in the Basolateral Amygdala: The Extracellular Levels of Serotonin and Dopamine, and Their Responses to Restraint Stress in Rats. Eur J Neurosci. 24, 3245-3254. EJN5214 [pii] 10.1111/j.1460-9568.2006.05214.x.

[118] McIntyre CK, Hatfield T, McGaugh, JL (2002) Amygdala Norepinephrine Levels after Training Predict Inhibitory Avoidance Retention Performance in Rats. Eur J Neurosci. $16,1223-1226$.

[119] Carrasco GA, Van de Kar LD (2003) Neuroendocrine Pharmacology of Stress. Eur J Pharmacol. 463, 235-272.

[120] Feltenstein MW, See RE. (2008) The Neurocircuitry of Addiction: An Overview. British Journal of Pharmacology 154, 261-274.

[121] Butler PD, Weiss JM, Stout JC, Nemeroff CB (1990) Corticotropin-Releasing Factor Produces Fear-Enhancing and Behavioral Activating Effects Following Infusion into the Locus Coeruleus. J Neurosci. 10, 176-183.

[122] Basso AM, Spina M, Rivier J, Vale W, Koob GF (1999) Corticotropin-Releasing Factor Antagonist Attenuates the "Anxiogenic-Like" Effect in the Defensive Burying Paradigm but Not in the Elevated Plus-Maze Following Chronic Cocaine in Rats. Psychopharmacology (Berl). 145, 21-30.

[123] Radulovic J, Ruhmann A, Liepold T, Spiess J (1999) Modulation of Learning and Anxiety by Corticotropin-Releasing Factor (CRF) and Stress: Differential Roles of CRF Receptors 1 and 2. J Neurosci. 19, 5016-5025. 
[124] Kikusui T, Takeuchi Y, Mori Y (2000) Involvement of Corticotropin-Releasing Factor in the Retrieval Process of Fear-Conditioned Ultrasonic Vocalization in Rats. Physiol Behav. 71, 323-328.

[125] Takahashi LK (2001) Role of CRF(1) and CRF(2) Receptors in Fear and Anxiety. Neurosci Biobehav Rev. 25, 627-636.

[126] Bale TL (2005) Sensitivity to Stress: Dysregulation of CRF Pathways and Disease Development. Horm Behav. 48, 1-10.

[127] Lukkes J, Vuong S, Scholl J, Oliver H, Forster G (2009) Corticotropin-Releasing Factor Receptor Antagonism within the Dorsal Raphe Nucleus Reduces Social Anxiety-Like Behavior after Early-Life Social Isolation. The Journal of Neuroscience. 29, 9955-9960. 10.1523/jneurosci.0854-09.2009.

[128] Bledsoe AC, Oliver KM, Scholl JL, Forster GL (2011) Anxiety States Induced by PostWeaning Social Isolation Are Mediated by CRF Receptors in the Dorsal Raphe Nucleus. Brain Res Bull. 85, 117-122. 10.1016/j.brainresbull.2011.03.003.

[129] Risbrough VB, Stein MB (2006) Role of Corticotropin Releasing Factor in Anxiety Disorders: A Translational Research Perspective. Horm Behav. 50, 550-561.

[130] Matsuzaki I, Takamatsu Y, Moroji T (1989) The Effects of Intracerebroventricularly Injected Corticotropin-Releasing Factor (CRF) on the Central Nervous System: Behavioural and Biochemical Studies. Neuropeptides. 13, 147-155.

[131] Amat J, Tamblyn JP, Paul ED, Bland ST, Amat P, Foster AC, Watkins LR, Maier SF (2004) Microinjection of Urocortin 2 into the Dorsal Raphe Nucleus Activates Serotonergic Neurons and Increases Extracellular Serotonin in the Basolateral Amygdala. Neuroscience. 129, 509-519. S0306-4522(04)00718-3

[pii] 10.1016/j.neuroscience.2004.07.052.

[132] Forster GL, Feng N, Watt MJ, Korzan WJ, Mouw NJ, Summers CH, Renner KJ (2006) Corticotropin-Releasing Factor in the Dorsal Raphe Elicits Temporally Distinct Serotonergic Responses in the Limbic System in Relation to Fear Behavior. Neuroscience. 141, 1047-1055. S0306-4522(06)00490-8

[pii] 10.1016/j.neuroscience.2006.04.006.

[133] Scholl JL, Vuong SM, Forster GL (2010) Chronic Amphetamine Treatment Enhances Corticotropin-Releasing Factor-Induced Serotonin Release in the Amygdala. Eur J Pharmacol. 644, 80-87. S0014-2999(10)00705-3 [pii] 10.1016/j.ejphar.2010.07.008.

[134] Gray TS (1993) Amygdaloid CRF Pathways. Role in Autonomic, Neuroendocrine, and Behavioral Responses to Stress. Ann N Y Acad Sci. 697, 53-60.

[135] Day HE, Greenwood BN, Hammack SE, Watkins LR, Fleshner M, Maier SF,Campeau S (2004) Differential Expression of 5HT-1a, Alpha 1b Adrenergic, CRF-R1, and CFR-R2 Receptor mRNA in Serotonergic, Gamma-Aminobutyric Acidergic, and Catecholaminergic Cells of the Rat Dorsal Raphe Nucleus. J Comp Neurol. 474, 364-378.

[136] Wang B, You ZB, Rice KC, Wise RA (2007) Stress-Induced Relapse to Cocaine Seeking: Roles for the CRF(2) Receptor and CRF-Binding Protein in the Ventral Tegmental Area of the Rat. Psychopharmacology (Berl). 193, 283-294. 
[137] Pringle RB, Mouw NJ, Lukkes JL, Forster GL (2008) Amphetamine Treatment Increases Corticotropin-Releasing Factor Receptors in the Dorsal Raphe Nucleus. Neurosci Res. 62, 62-65.

[138] Reyes BA, Valentino RJ, Van Bockstaele EJ (2008) Stress-Induced Intracellular Trafficking of Corticotropin-Releasing Factor Receptors in Rat Locus Coeruleus Neurons. Endocrinology. 149, 122-130.

[139] Wise RA, Morales M (2010) A Ventral Tegmental CRF-Glutamate-Dopamine Interaction in Addiction. Brain Res. 1314, 38-43. 10.1016/j.brainres.2009.09.101.

[140] Tagliaferro P, Morales M (2008) Synapses between Corticotropin-Releasing FactorContaining Axon Terminals and Dopaminergic Neurons in the Ventral Tegmental Area Are Predominantly Glutamatergic. J Comp Neurol. 506, 616-626. 10.1002/cne.21576.

[141] Pernar L, Curtis AL, Vale WW, Rivier JE, Valentino RJ (2004) Selective Activation of Corticotropin-Releasing Factor-2 Receptors on Neurochemically Identified Neurons in the Rat Dorsal Raphe Nucleus Reveals Dual Actions. J Neurosci. 24, 1305-1311.

[142] Waselus M, Nazzaro C, Valentino RJ, Van Bockstaele EJ (2009) Stress-Induced Redistribution of Corticotropin-Releasing Factor Receptor Subtypes in the Dorsal Raphe Nucleus. Biol Psychiatry. 66, 76-83.

[143] Lukkes JL, Summers CH, Scholl JL, Renner KJ, Forster GL (2009) Early Life Social Isolation Alters Corticotropin-Releasing Factor Responses in Adult Rats. Neuroscience. $158,845-855$.

[144] Boyson C, Miguel T, Quadros I, DeBold J, Miczek K (2011) Prevention of Social StressEscalated Cocaine Self-Administration by CRF-R1 Antagonist in the Rat Vta. Psychopharmacology (Berl). 1-13. 10.1007/s00213-011-2266-8.

[145] Faria R, Magalhães A, Monteiro PR, Gomes-Da-Silva J, Amélia Tavares M, Summavielle T (2006) MDMA in Adolescent Male Rats: Decreased Serotonin in the Amygdala and Behavioral Effects in the Elevated Plus-Maze Test. Ann N Y Acad Sci. 1074, 643-649. 1074/1/643 [pii] 10.1196/annals.1369.062.

[146] Niwa M, Matsumoto Y, Mouri A, Ozaki N, Nabeshima T (2011) Vulnerability in Early Life to Changes in the Rearing Environment Plays a Crucial Role in the Aetiopathology of Psychiatric Disorders. Int J Neuropsychopharmacol. 14, 459-477. S1461145710001239 [pii] 10.1017/S1461145710001239.

[147] Costall B, Jones BJ, Kelly ME, Naylor RJ, Oakley NR, Onaivi ES, Tyers MB (1989) The Effects of Ondansetron (Gr38032f) in Rats and Mice Treated Subchronically with Diazepam. Pharmacol Biochem Behav. 34, 769-778.

[148] Cruz APM, Pinheiro G, Alves SH, Ferreira G, Mendes M, Faria L, et al. (2005) Behavioral effects of systemically administered MK-212 are prevented by ritanserin microinfusion into the basolateral amygdala of rats exposed to the elevated plus-maze. Psychopharmacology. 182:345-54.

[149] Zangrossi H, Graeff FG (1994) Behavioral effects of intraamygdala injections of GABA and 5-HT acting drugs in the elevated plus-maze. Braz. J Med Biol Res. 27, 2453-6. 
[150] Cornelio AM, Nunes-de-Souza RL (2007) Anxiogenic-Like Effects of MCPP Microinfusions into the Amygdala (but not Dorsal or Ventral Hippocampus) in Mice Exposed to Elevated Plus-Maze. Behav Brain Res. 178, 82-89. 10.1016/j.bbr.2006.12.003.

[151] Higgins GA, Jones BJ, Oakley NR, Tyers MB (1991) Evidence that the Amygdala Is Involved in the Disinhibitory Effects of 5-HT3 Receptor Antagonists. Psychopharmacology (Berl). 104, 545-551.

[152] Tomkins DM, Costall B, Kelly ME. (1990) Release of Suppressed Behavior of rat on the Elevated X-maze by 5-HT3 Receptor Antagonists injected into the Basolateral Amygdala. J Psychopharmacol.4, 203-5.

[153] Gonzalez LE, Andrews N, File SE (1996) 5-HT1a and Benzodiazepine Receptors in the Basolateral Amygdala Modulate Anxiety in the Social Interaction Test, but Not in the Elevated Plus-Maze. Brain Res. 732, 145-153.

[154] Vicente MA, Zangrossi H (2011) Serotonin-2c Receptors in the Basolateral Nucleus of the Amygdala Mediate the Anxiogenic Effect of Acute Imipramine and Fluoxetine Administration. Int J Neuropsychopharmacol. 1-12. S1461145711000873 [pii] 10.1017/S1461145711000873.

[155] Duxon MS, Beckett SR, Baxter GS, Blackburn TP, Fone KCF. (1995). Intraamygdala Injection of the 5-HT2B Receptor Agonist BW-72386 Produces Anxiolysis on the Elevated Plus-Maze in the Rat. Br J Pharmacol 116, P331-P331.

[156] Duxon MS, Kennett GA, Lightowler S, Blackburn TP, Fone KC (1997) Activation of 5HT2b Receptors in the Medial Amygdala Causes Anxiolysis in the Social Interaction Test in the Rat. Neuropharmacology. 36, 601-608.

[157] Inoue T, Li XB, Abekawa T, Kitaichi Y, Izumi T, Nakagawa S, Koyama T (2004) Selective Serotonin Reuptake Inhibitor Reduces Conditioned Fear through Its Effect in the Amygdala. Eur J Pharmacol. 497, 311-316. S0014-2999(04)00702-2 [pii] 10.1016/j.ejphar.2004.06.061.

[158] Leite-Panissi CR, Ferrarese AA, Terzian AL, Menescal-de-Oliveira L (2006) Serotoninergic Activation of the Basolateral Amygdala and Modulation of Tonic Immobility in Guinea Pig. Brain Res Bull. 69, 356-364. S0361-9230(06)00051-7 [pii] 10.1016/j.brainresbull.2006.02.007.

[159] Li X, Inoue T, Abekawa T, Weng S, Nakagawa S, Izumi T, Koyama T (2006) 5-Ht1a Receptor Agonist Affects Fear Conditioning through Stimulations of the Postsynaptic 5Ht1a Receptors in the Hippocampus and Amygdala. Eur J Pharmacol. 532, 74-80. S00142999(05)01310-5 [pii] 10.1016/j.ejphar.2005.12.008.

[160] Morrison KE, Cooper MA (2012) A Role for 5-Ht1a Receptors in the Basolateral Amygdala in the Development of Conditioned Defeat in Syrian Hamsters. Pharmacol Biochem Behav. 100, 592-600. S0091-3057(11)00312-1 [pii] 10.1016/j.pbb.2011.09.005.

[161] Centonze D, Usiello A, Gubellini P, Pisani A, Borrelli E, Bernardi G, Calabresi P (2002) Dopamine D2 Receptor-Mediated Inhibition of Dopaminergic Neurons in Mice Lacking D21 Receptors. Neuropsychopharmacology. 27, 723-726. 
[162] Rouge-Pont F, Usiello A, Benoit-Marand M, Gonon F, Piazza PV, Borrelli E (2002) Changes in Extracellular Dopamine Induced by Morphine and Cocaine: Crucial Control by D2 Receptors. J Neurosci. 22, 3293-3301.

[163] Summavielle T, Magalhães A, Castro-Vale I, de Sousa L, Tavares MA (2002) Neonatal Exposure to Cocaine: Altered Dopamine Levels in the Amygdala and Behavioral Outcomes in the Developing Rat. Ann N Y Acad Sci. 965, 515-521.

[164] Izumo N, Ishibashi Y, Ohba M, Morikawa T, Manabe T (2012) Decreased Voluntary Activity and Amygdala Levels of Serotonin and Dopamine in Ovariectomized Rats. Behav Brain Res. 227, 1-6. S0166-4328(11)00764-9 [pii] 10.1016/j.bbr.2011.10.031.

[165] Rezayof A, Hosseini SS, Zarrindast MR (2009) Effects of Morphine on Rat Behaviour in the Elevated Plus Maze: The Role of Central Amygdala Dopamine Receptors. Behav Brain Res. 202, 171-178. S0166-4328(09)00193-4 [pii] 10.1016/j.bbr.2009.03.030.

[166] de la Mora MP, Gallegos-Cari A, Crespo-Ramirez M, Marcellino D, Hansson AC, Fuxe K (2012) Distribution of Dopamine D(2)-Like Receptors in the Rat Amygdala and Their Role in the Modulation of Unconditioned Fear and Anxiety. Neuroscience. 201, 252-266. S0306-4522(11)01238-3 [pii] 10.1016/j.neuroscience.2011.10.045.

[167] Sullivan RM, Duchesne A, Hussain D, Waldron J, Laplante F (2009) Effects of Unilateral Amygdala Dopamine Depletion on Behaviour in the Elevated Plus Maze: Role of Sex, Hemisphere and Retesting. Behav Brain Res. 205, 115-122. S01664328(09)00440-9 [pii] 10.1016/j.bbr.2009.07.023.

[168] Bananej M, Karimi-Sori A, Zarrindast MR, Ahmadi S (2011) D1 and D2 Dopaminergic Systems in the Rat Basolateral Amygdala Are Involved in Anxiogenic-Like Effects Induced by Histamine. J Psychopharmacol. 0269881111405556 [pii] 10.1177/0269881111405556.

[169] de la Mora MP, Cardenas-Cachon L, Vazquez-Garcia M, Crespo-Ramirez M, Jacobsen K, Hoistad M, Agnati L, Fuxe K (2005) Anxiolytic Effects of Intra-Amygdaloid Injection of the D1 Antagonist SCH23390 in the Rat. Neurosci Lett. 377, 101-105. 10.1016/j.neulet.2004.11.079.

[170] Greba Q, Gifkins A, Kokkinidis L (2001) Inhibition of Amygdaloid Dopamine D2 Receptors Impairs Emotional Learning Measured with Fear-Potentiated Startle. Brain Res. 899, 218-226. S0006-8993(01)02243-0 [pii].

[171] Guarraci FA, Frohardt RJ, Kapp BS (1999) Amygdaloid D1 Dopamine Receptor Involvement in Pavlovian Fear Conditioning. Brain Res. 827, 28-40. S00068993(99)01291-3 [pii].

[172] Guarraci FA, Frohardt RJ, Falls WA, Kapp BS (2000) The Effects of Intra-Amygdaloid Infusions of a D2 Dopamine Receptor Antagonist on Pavlovian Fear Conditioning. Behav Neurosci. 114, 647-651.

[173] Selden NR, Everitt BJ, Jarrard LE, Robbins TW (1991) Complementary Roles for the Amygdala and Hippocampus in Aversive Conditioning to Explicit and Contextual Cues. Neuroscience. 42, 335-350. 0306-4522(91)90379-3 [pii].

[174] Greba Q, Kokkinidis L (2000) Peripheral and Intraamygdalar Administration of the Dopamine D1 Receptor Antagonist Sch 23390 Blocks Fear-Potentiated Startle but Not 
Shock Reactivity or the Shock Sensitization of Acoustic Startle. Behav Neurosci. 114, 262-272.

[175] de Oliveira AR, Reimer AE, de Macedo CE, de Carvalho MC, Silva MA, Brandão ML (2011) Conditioned Fear Is Modulated by D2 Receptor Pathway Connecting the Ventral Tegmental Area and Basolateral Amygdala. Neurobiol Learn Mem. 95, 37-45. S10747427(10)00172-3 [pii] 10.1016/j.nlm.2010.10.005.

[176] Cecchi M, Khoshbouei H, Morilak DA (2002) Modulatory Effects of Norepinephrine, Acting on Alpha 1 Receptors in the Central Nucleus of the Amygdala, on Behavioral and Neuroendocrine Responses to Acute Immobilization Stress. Neuropharmacology. 43, 1139-1147. S0028390802002927 [pii].

[177] Debiec J, LeDoux JE (2006) Noradrenergic Signaling in the Amygdala Contributes to the Reconsolidation of Fear Memory: Treatment Implications for PTSD. Ann N Y Acad Sci. 1071, 521-524. 1071/1/521 [pii] 10.1196/annals.1364.056.

[178] LaLumiere RT, Buen TV, McGaugh JL (2003) Post-Training Intra-Basolateral Amygdala Infusions of Norepinephrine Enhance Consolidation of Memory for Contextual Fear Conditioning. J Neurosci. 23, 6754-6758. 23/17/6754 [pii].

[179] Lazzaro SC, Hou M, Cunha C, LeDoux JE, Cain CK (2010) Antagonism of Lateral Amygdala Alpha1-Adrenergic Receptors Facilitates Fear Conditioning and Long-Term Potentiation. Learn Mem. 17, 489-493. 17/10/489 [pii] 10.1101/lm.1918210.

[180] Debiec J, Ledoux JE (2004) Disruption of Reconsolidation but Not Consolidation of Auditory Fear Conditioning by Noradrenergic Blockade in the Amygdala. Neuroscience. 129, 267-272. S0306-4522(04)00745-6

[pii] 10.1016/j.neuroscience.2004.08.018.

[181] Roozendaal B, Hui GK, Hui IR, Berlau DJ, McGaugh JL, Weinberger NM (2006) Basolateral Amygdala Noradrenergic Activity Mediates Corticosterone-Induced Enhancement of Auditory Fear Conditioning. Neurobiol Learn Mem. 86, 249-255. S1074-7427(06)00032-3 [pii] 10.1016/j.nlm.2006.03.003.

[182] Cloos J-M, Ferreira V (2009) Current Use of Benzodiazepines in Anxiety Disorders. Curr Opin Psychiatry. 22, 90-95.

[183] Ravindran LN, Stein MB (2010) The Pharmacologic Treatment of Anxiety Disorders: A Review of Progress. J Clin Psychiatry. 71, 839-854.

[184] Brignell CM, Curran HV (2006) Drugs, Sweat and Fears: A Comparison of the Effects of Diazepam and Methylphenidate on Fear Conditioning. Psychopharmacol. 186, 504516. 10.1007/s00213-006-0363-x.

[185] Hellewell JS, Guimaraes FS, Wang M, Deakin JF (1999) Comparison of Buspirone with Diazepam and Fluvoxamine on Aversive Classical Conditioning in Humans. J Psychopharmacol. 13, 122-127.

[186] Scaife JC, Hou RH, Samuels ER, Baqui F, Langley RW, Bradshaw CM, Szabadi E (2007) Diazepam-Induced Disruption of Classically-Conditioned Fear-Potentiation of LateLatency Auditory Evoked Potentials Is Prevented by Flumazenil Given before, but Not after, CS/US Pairing. J Psychopharmacol. 21, 93-101. 
[187] Zangara A, Blair RJR, Curran HV (2002) A Comparison of the Effects of a BetaAdrenergic Blocker and a Benzodiazepine Upon the Recognition of Human Facial Expressions. Psychopharmacology (Berl). 163, 36-41.

[188] Brignell CM, Rosenthal J, Curran HV (2007) Pharmacological Manipulations of Arousal and Memory for Emotional Material: Effects of a Single Dose of Methylphenidate or Lorazepam. J Psychopharmacol. 21, 673-683. 10.1177/0269881107077351.

[189] Buchanan TW, Karafin MS, Adolphs R (2003) Selective Effects of Triazolam on Memory for Emotional, Relative to Neutral, Stimuli: Differential Effects on Gist Versus Detail. Behav Neurosci. 117, 517-525.

[190] Paulus MP, Feinstein JS, Castillo G, Simmons AN, Stein MB (2005) Dose-Dependent Decrease of Activation in Bilateral Amygdala and Insula by Lorazepam During Emotion Processing. Arch Gen Psychiatry. 62, 282-288.

[191] Del-Ben CM, Ferreira CA, Sanchez TA, Alves-Neto WC, Guapo VG, de Araujo DB, Graeff FG (2010) Effects of Diazepam on Bold Activation During the Processing of Aversive Faces. J Psychopharmacol.

[192] Schunck T, Mathis A, Erb G, Namer IJ, Demazieres A, Luthringer R (2010) Effects of Lorazepam on Brain Activity Pattern During an Anxiety Symptom Provocation Challenge. J Psychopharmacol. 24, 701-708.

[193] Brantigan CO, Brantigan TA, Joseph N (1979) The Effect of Beta Blockade on Stage Fright. A Controlled Study. Rocky Mt Med J. 76, 227-233.

[194] Heiser JF, Defrancisco D (1976) The Treatment of Pathological Panic States with Propranolol. Am J Psychiatry. 133, 1389-1394.

[195] Tyrer P (1988) Current Status of Beta-Blocking Drugs in the Treatment of Anxiety Disorders. Drugs. 36, 773-783.

[196] Bell J (2008) Propranolol, Post-Traumatic Stress Disorder and Narrative Identity. J Med Ethics. 34, e23. 10.1136/jme.2008.024752.

[197] Dębiec J, Bush DEA, LeDoux JE (2011) Noradrenergic Enhancement of Reconsolidation in the Amygdala Impairs Extinction of Conditioned Fear in Rats--a Possible Mechanism for the Persistence of Traumatic Memories in PTSD. Depress Anxiety. 28, 186-193.

[198] Fletcher S, Creamer M, Forbes D (2010) Preventing Post Traumatic Stress Disorder: Are Drugs the Answer? The Australian and New Zealand Journal of Psychiatry. 44, 1064-1071.

[199] McGhee LL, Maani CV, Garza TH, Desocio PA, Gaylord KM, Black IH (2009) The Effect of Propranolol on Posttraumatic Stress Disorder in Burned Service Members. Journal of Burn Care \& Research, 30, 92-97.

[200] Stein MB, Kerridge C, Dimsdale JE, Hoyt DB (2007) Pharmacotherapy to Prevent Ptsd: Results from a Randomized Controlled Proof-of-Concept Trial in Physically Injured Patients. Journal of Traumatic Stress. 20, 923-932.

[201] Hurlemann R, Walter H, Rehme AK, Kukolja J, Santoro SC, Schmidt C, Schnell K, Musshoff F, Keysers C, Maier W, Kendrick KM, Onur OA (2010) Human Amygdala 
Reactivity Is Diminished by the B-Noradrenergic Antagonist Propranolol. Psychological Medicine. 40, 1839-1848.

[202] van Stegeren AH, Goekoop R, Everaerd W, Scheltens P, Barkhof F, Kuijer JPA, Rombouts SARB (2005) Noradrenaline Mediates Amygdala Activation in Men and Women During Encoding of Emotional Material. Neuroimage. 24, 898-909.

[203] Kent JM, Coplan JD, Gorman JM (1998) Clinical Utility of the Selective Serotonin Reuptake Inhibitors in the Spectrum of Anxiety. Biol Psychiatry. 44, 812-824.

[204] Browning M, Reid C, Cowen PJ, Goodwin GM, Harmer CJ (2007) A Single Dose of Citalopram Increases Fear Recognition in Healthy Subjects. J Psychopharmacol. 21, 684690. 10.1177/0269881106074062.

[205] Grillon C, Levenson J, Pine DS (2007) A Single Dose of the Selective Serotonin Reuptake Inhibitor Citalopram Exacerbates Anxiety in Humans: A Fear-Potentiated Startle Study. Neuropsychopharmacology. 32, 225-231.

[206] Harmer CJ, Bhagwagar Z, Perrett DI, Völlm BA, Cowen PJ, Goodwin GM (2003) Acute Ssri Administration Affects the Processing of Social Cues in Healthy Volunteers. Neuropsychopharmacology. 28, 148-152.

[207] Harmer CJ, Shelley NC, Cowen PJ, Goodwin GM (2004) Increased Positive Versus Negative Affective Perception and Memory in Healthy Volunteers Following Selective Serotonin and Norepinephrine Reuptake Inhibition. Am J Psychiatry. 161, 1256-1263.

[208] Murphy SE, Yiend J, Lester KJ, Cowen PJ, Harmer CJ (2009) Short-Term Serotonergic but Not Noradrenergic Antidepressant Administration Reduces Attentional Vigilance to Threat in Healthy Volunteers. The International Journal of Neuropsychopharmacology. 12, 169-179.

[209] Harmer CJ, Mackay CE, Reid CB, Cowen PJ, Goodwin GM (2006) Antidepressant Drug Treatment Modifies the Neural Processing of Nonconscious Threat Cues. Biol Psychiatry. 59, 816-820.

[210] Anderson IM, Del-Ben CM, McKie S, Richardson P, Williams SR, Elliott R, Deakin JFW (2007) Citalopram Modulation of Neuronal Responses to Aversive Face Emotions: A Functional MRI Study. Neuroreport. 18, 1351-1355.

[211] Del-Ben CM, Deakin JFW, McKie S, Delvai NA, Williams SR, Elliott R, Dolan M, Anderson IM (2005) The Effect of Citalopram Pretreatment on Neuronal Responses to Neuropsychological Tasks in Normal Volunteers: An fMRI Study. Neuropsychopharmacology. 30, 1724-1734.

[212] Cools R, Calder AJ, Lawrence AD, Clark L, Bullmore E, Robbins TW (2005) Individual Differences in Threat Sensitivity Predict Serotonergic Modulation of Amygdala Response to Fearful Faces. Psychopharmacology (Berl). 180, 670-679.

[213] Attenburrow MJ, Williams C, Odontiadis J, Reed A, Powell J, Cowen PJ, Harmer CJ (2003) Acute Administration of Nutritionally Sourced Tryptophan Increases Fear Recognition. Psychopharmacology (Berl). 169, 104-107. 10.1007/s00213-003-1479-x.

[214] Rhodes RA, Murthy NV, Dresner MA, Selvaraj S, Stavrakakis N, Babar S, Cowen PJ, Grasby PM (2007) Human 5-HT Transporter Availability Predicts Amygdala Reactivity in Vivo. The Journal of Neuroscience. 27, 9233-9237. 
[215] Niehoff DL, Kuhar MJ (1983) Benzodiazepine Receptors: Localization in Rat Amygdala. The Journal of Neuroscience. 3, 2091-2097.

[216] Young WS, 3rd, Kuhar MJ (1980) Radiohistochemical Localization of Benzodiazepine Receptors in Rat Brain. J Pharmacol Exp Ther. 212, 337-346.

[217] Hodges H, Green S, Glenn B (1987) Evidence That the Amygdala Is Involved in Benzodiazepine and Serotonergic Effects on Punished Responding but Not on Discrimination. Psychopharmacology (Berl). 92, 491-504.

[218] Nagy J, Zámbó K, Decsi L (1979) Anti-Anxiety Action of Diazepam after IntraAmygdaloid Application in the Rat. Neuropharmacology. 18, 573-576.

[219] Petersen EN, Braestrup C, Scheel-Krüger J (1985) Evidence That the Anticonflict Effect of Midazolam in Amygdala Is Mediated by the Specific Benzodiazepine Receptors. Neurosci Lett. 53, 285-288.

[220] Scheel-Krüger J, Petersen EN (1982) Anticonflict Effect of the Benzodiazepines Mediated by a Gabaergic Mechanism in the Amygdala. Eur J Pharmacol. 82, 115-116.

[221] Shibata K, Kataoka Y, Gomita Y, Ueki S (1982) Localization of the Site of the Anticonflict Action of Benzodiazepines in the Amygdaloid Nucleus of Rats. Brain Res. 234, 442-446.

[222] Green S, Vale AL (1992) Role of Amygdaloid Nuclei in the Anxiolytic Effects of Benzodiazepines in Rats. Behavioural Pharmacology. 3, 261-264.

[223] Pesold C, Treit D (1995) The Central and Basolateral Amygdala Differentially Mediate the Anxiolytic Effects of Benzodiazepines. Brain Res. 671, 213-221.

[224] Carvalho MC, Moreira CM, Zanoveli JM, Brandão ML (2012) Central, but Not Basolateral, Amygdala Involvement in the Anxiolytic-Like Effects of Midazolam in Rats in the Elevated Plus Maze. J Psychopharmacol. 26, 543-54.

[225] Tomaz C, Dickinson-Anson H, McGaugh JL (1992) Basolateral Amygdala Lesions Block Diazepam-Induced Anterograde Amnesia in an Inhibitory Avoidance Task. Proc Natl Acad Sci U S A. 89, 3615-3619.

[226] Tomaz C, Dickinson-Anson H, McGaugh JL, Souza-Silva MA, Viana MB, Graeff FG (1993) Localization in the Amygdala of the Amnestic Action of Diazepam on Emotional Memory. Behav Brain Res. 58, 99-105.

[227] Silva MA, Tomaz C (1995) Amnesia after Diazepam Infusion into Basolateral but Not Central Amygdala of Rattus Norvegicus. Neuropsychobiology. 32, 31-36.

[228] Da Cunha C, Roozendaal B, Vazdarjanova A, McGaugh JL (1999) Microinfusions of Flumazenil into the Basolateral but Not the Central Nucleus of the Amygdala Enhance Memory Consolidation in Rats. Neurobiology of Learning and Memory. 72, 1-7.

[229] Coles ME, Heimberg RG (2002) Memory Biases in the Anxiety Disorders: Current Status. Clin Psychol Rev. 22, 587-627.

[230] Coles ME, Turk CL, Heimberg RG (2007) Memory Bias for Threat in Generalized Anxiety Disorder: The Potential Importance of Stimulus Relevance. Cognitive Behaviour Therapy. 36, 65-73.

[231] Ferry B, McGaugh JL (2000) Role of Amygdala Norepinephrine in Mediating Stress Hormone Regulation of Memory Storage. Acta Pharmacol Sin. 21, 481-493. 
[232] Ferry B, Roozendaal B, McGaugh J (1999) Role of Norepinephrine in Mediating Stress Hormone Regulation of Long-tern Memory Storage: A Critical Involvement of the Amygdala. Biol Psych. 46, 1140-1152. S0006322399001572 [pii].

[233] Berlau DJ, McGaugh JL (2006) Enhancement of Extinction Memory Consolidation: The Role of the Noradrenergic and Gabaergic Systems within the Basolateral Amygdala. Neurobiology of Learning and Memory. 86, 123-132.

[234] Lin H-C, Tseng Y-C, Mao S-C, Chen P-S, Gean P-W (2011) Gabaa Receptor Endocytosis in the Basolateral Amygdala Is Critical to the Reinstatement of Fear Memory Measured by Fear-Potentiated Startle. The Journal of Neuroscience:. 31, 8851-8861.

[235] Geracioti TD, Jr., Baker DG, Ekhator NN, West SA, Hill KK, Bruce AB, Schmidt D, Rounds-Kugler B, Yehuda R, Keck PE, Jr., Kasckow JW (2001) CSF Norepinephrine Concentrations in Posttraumatic Stress Disorder. Am J Psychiatry. 158, 1227-1230.

[236] Strawn JR, Geracioti TD, Jr. (2008) Noradrenergic Dysfunction and the Psychopharmacology of Posttraumatic Stress Disorder. Depress Anxiety. 25, 260-271.

[237] Asnis GM, Kohn SR, Henderson M, Brown NL (2004) Ssris Versus Non-Ssris in PostTraumatic Stress Disorder: An Update with Recommendations. Drugs. 64, 383-404.

[238] Braun P, Greenberg D, Dasberg H, Lerer B (1990) Core Symptoms of Posttraumatic Stress Disorder Unimproved by Alprazolam Treatment. J Clin Psychiatry. 51, 236-238.

[239] Pitman RK, Sanders KM, Zusman RM, Healy AR, Cheema F, Lasko NB, Cahill L, Orr SP (2002) Pilot Study of Secondary Prevention of Posttraumatic Stress Disorder with Propranolol. Biol Psychiatry. 51, 189-192.

[240] Vaiva G, Ducrocq F, Jezequel K, Averland B, Lestavel P, Brunet A, Marmar CR (2003) Immediate Treatment with Propranolol Decreases Posttraumatic Stress Disorder Two Months after Trauma. Biol Psychiatry. 54, 947-949.

[241] Adamec R, Muir C, Grimes M, Pearcey K (2007) Involvement of Noradrenergic and Corticoid Receptors in the Consolidation of the Lasting Anxiogenic Effects of Predator Stress. Behav Brain Res. 179, 192-207. 10.1016/j.bbr.2007.02.001.

[242] Cohen H, Kaplan Z, Koresh O, Matar MA, Geva AB, Zohar J (2011) Early Post-Stressor Intervention with Propranolol Is Ineffective in Preventing Posttraumatic Stress Responses in an Animal Model for PTSD. European Neuropsychopharmacology. 21, 230-240.

[243] Adamec RE, Blundell J, Collins A (2001) Neural Plasticity and Stress Induced Changes in Defense in the Rat. Neurosci Biobehav Rev. 25, 721-744.

[244] Bodnoff SR, Suranyi-Cadotte B, Quirion R, Meaney MJ (1989) A Comparison of the Effects of Diazepam Versus Several Typical and Atypical Anti-Depressant Drugs in an Animal Model of Anxiety. Psychopharmacology (Berl). 97, 277-279.

[245] Griebel G, Moreau JL, Jenck F, Misslin R, Martin JR (1994) Acute and Chronic Treatment with 5-HT Reuptake Inhibitors Differentially Modulate Emotional Responses in Anxiety Models in Rodents. Psychopharmacology (Berl). 113, 463-470.

[246] Kurt M, Arik AC, Celik S (2000) The Effects of Sertraline and Fluoxetine on Anxiety in the Elevated Plus-Maze Test in Mice. Journal of Basic and Clinical Physiology and Pharmacology. 11, 173-180. 
[247] Dekeyne A, Denorme B, Monneyron S, Millan MJ (2000) Citalopram Reduces Social Interaction in Rats by Activation of Serotonin (5-HT)(2c) Receptors. Neuropharmacology. 39, 1114-1117.

[248] Griebel G (1995) 5-Hydroxytryptamine-Interacting Drugs in Animal Models of Anxiety Disorders: More Than 30 Years of Research. Pharmacology \& Therapeutics. 65, 319-395.

[249] Campbell BM, Merchant KM (2003) Serotonin 2c Receptors within the Basolateral Amygdala Induce Acute Fear-Like Responses in an Open-Field Environment. Brain Res. 993, 1-9.

[250] Christianson JP, Ragole T, Amat J, Greenwood BN, Strong PV, Paul ED, Fleshner M, Watkins LR, Maier SF (2010) 5-Hydroxytryptamine 2c Receptors in the Basolateral Amygdala Are Involved in the Expression of Anxiety after Uncontrollable Traumatic Stress. Biol Psychiatry. 67, 339-345.

[251] Vicente MA, Zangrossi H (2011) Serotonin-2c Receptors in the Basolateral Nucleus of the Amygdala Mediate the Anxiogenic Effect of Acute Imipramine and Fluoxetine Administration. The International Journal of Neuropsychopharmacology. 1-12.

[252] Burghardt NS, Bush DEA, McEwen BS, LeDoux JE (2007) Acute Selective Serotonin Reuptake Inhibitors Increase Conditioned Fear Expression: Blockade with a 5-HT(2c) Receptor Antagonist. Biol Psychiatry. 62, 1111-1118.

[253] Bagdy G, Graf M, Anheuer ZE, Modos EA, Kantor S (2001) Anxiety-Like Effects Induced by Acute Fluoxetine, Sertraline or M-CPP Treatment Are Reversed by Pretreatment with the 5-HT2c Receptor Antagonist Sb-242084 but not the 5-HT1a Receptor Antagonist Way-100635. Int J Neuropsychopharmacol. 4, 399-408. doi:10.1017/S1461145701002632.

[254] Salchner P, Singewald N (2006) 5-HT Receptor Subtypes Involved in the AnxiogenicLike Action and Associated Fos Response of Acute Fluoxetine Treatment in Rats. Psychopharmacology (Berl). 185, 282-288.

[255] Hollander E, DeCaria C, Gully R, Nitescu A, Suckow RF, Gorman JM, Klein DF, Liebowitz MR (1991) Effects of Chronic Fluoxetine Treatment on Behavioral and Neuroendocrine Responses to Meta-Chlorophenylpiperazine in Obsessive-Compulsive Disorder. Psychiatry Res. 36, 1-17.

[256] Zohar J, Insel TR, Zohar-Kadouch RC, Hill JL, Murphy DL (1988) Serotonergic Responsivity in Obsessive-Compulsive Disorder. Effects of Chronic Clomipramine Treatment. Archives of General Psychiatry. 45, 167-172.

[257] Kennedy AJ, Gibson EL, O'Connell MT, Curzon G (1993) Effects of Housing, Restraint and Chronic Treatments with MCPP and Sertraline on Behavioural Responses to MCPP. Psychopharmacology (Berl). 113, 262-268.

[258] Yamauchi M, Tatebayashi T, Nagase K, Kojima M, Imanishi T (2004) Chronic Treatment with Fluvoxamine Desensitizes 5-HT2c Receptor-Mediated Hypolocomotion in Rats. Pharmacol Biochem Behav. 78, 683-689.

[259] Seeman P. (2002) Atypical antipsychotics: mechanism of action. Can J Psychiatry, 47, 27-38. 
[260] de Boet T. (1996) The pharmacological profile of mirtazapine. J Clin Psychiatry. 57, 19-25.

[261] Ravindran LN, Stein MB. (2010) The pharmacologic treatment of anxiety disorders: a review of progress. J Clin Psychiatry. 71, 839-54.

[262] Rainer Q, Xia L, Guilloux JP, Gabriel C, Mocaër E, Hen R, Enhamre E, Gardier AM, David DJ. (2010) Beneficial Behavioural and Neurogenic effects of Agomelatine in a Model of Depression/Anxiety. Int J Neuropsychopharmacol. 8, 1-15.

[263] Katzman MA. (2011) Aripiprazole: a clinical review of its use for the treatment of anxiety disorders and anxiety as a comorbidity in mental illness. J Affect Disord. 128, S11-20.

[264] Kehne JH, Cain CK (2010) Therapeutic Utility of Non-Peptidic CRF1 Receptor Antagonists in Anxiety, Depression, and Stress-Related Disorders: Evidence from Animal Models. Pharmacology \&amp; Therapeutics. 128, 460-487. 10.1016/j.pharmthera.2010.08.011. 